\title{
DETECTION AND SEVERITY CLASSIFICATION OF ROTOR IMBALANCE FAULTS IN INDUCTION MACHINES
}

\author{
by \\ HIMANSHU JAIN \\ Presented to the Faculty of the Graduate School of \\ The University of Texas at Arlington in Partial Fulfillment \\ of the Requirements \\ for the Degree of
}

MASTER OF SCIENCE IN ELECTRICAL ENGINEERING

THE UNIVERSITY OF TEXAS AT ARLINGTON AUGUST 2010 
Copyright @ by HIMANSHU JAIN 2010

All Rights Reserved 


\section{ACKNOWLEDGEMENTS}

It is a pleasure to thank those who made this thesis possible. First of all, I would like to thank my thesis supervisor, Dr. Wei-Jen Lee, whose constant guidance and support from the initial to the final level was instrumental in developing an understanding of the subject. Thanks are due to Dr. William Dillon and Dr. Rasool Kenarangui as well, whose suggestions during various stages of the thesis proved very useful. I am also grateful to my colleague at ESRC, Korkua Suratsavadee; discussions with whom played an important role in developing the methodology presented in this thesis. I would also like to express my gratitude towards Mr. Sam Williams, without whose help in making hubs for test motors, none of the experiments in this thesis could have been performed.

However, I would be failing in my duty if I do not thank my parents, without whose blessings, not an iota of the thesis would have been possible.

Lastly, I offer my regards to all those who supported me in any respect during the development of this thesis.

April 28, 2010 


\section{ABSTRACT \\ DETECTION AND SEVERITY CLASSIFICATION OF ROTOR IMBALANCE FAULTS IN INDUCTION MACHINES}

HIMANSHU JAIN, M.S.

The University of Texas at Arlington, 2010

\section{Supervising Professor: Wei-Jen Lee}

As world economy continues to globalize, increased competition has lead to a reduction in profit margins. To remain profitable in such a competitive environment, an industry needs to reduce the downtime of critical components even for maintenance purposes. However, this should not jeopardize the genuine maintenance needs of the equipments. In other words, an optimized maintenance strategy is needed in which, maintenance is performed only when a need for it arises; unlike the traditional periodic maintenance. Condition based Maintenance $(\mathrm{CBM})$ is one such strategy.

Induction machines are work horse of an industry. Their criticality to industry may be gauged by the fact that they account for more than $60 \%$ percent of the energy consumed in USA's manufacturing sector. Hence, CBM for induction machines makes perfect economic sense. Although CBM is a three step process, first step i.e. fault diagnostics or identifying a fault and determining its severity, has been studied most widely for induction machines. It is for this reason that literature is abounds with techniques for detecting various fault conditions at an incipient stage in induction machines. Rotor imbalance is one such fault condition. Several researchers have studied rotor imbalance fault in induction machines. They have identified the 
signatures to look for in the stator current to detect it. However, an accurate explanation for appearance of these signatures is lacking. Moreover, in majority of the papers, only one phase of stator current has been used for detecting and classifying the severity of rotor imbalance. Since current sensors are available in all the three phases for protection and control purposes, combining fault information from all of them may yield more accurate results.

Therefore, this thesis focuses on providing an accurate explanation for the appearance of rotor imbalance signatures in stator current and developing a comprehensive rotor imbalance diagnostics scheme that incorporates sensor fusion. 


\section{TABLE OF CONTENTS}

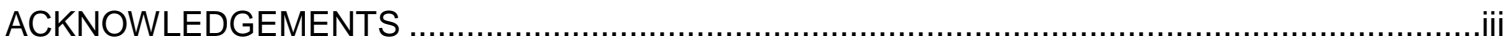

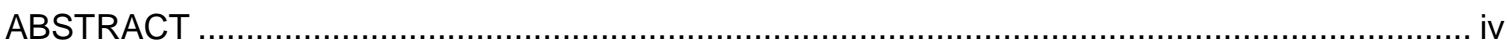

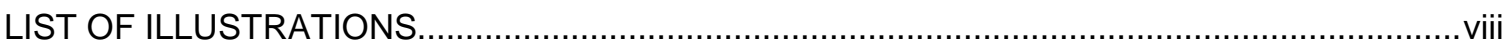

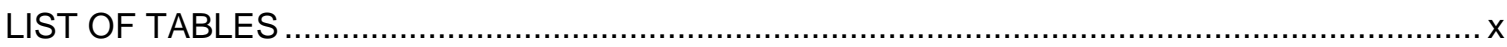

Chapter Page

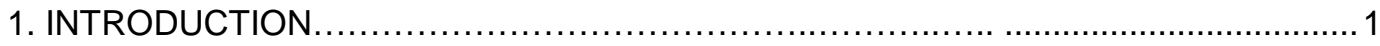

1.1 Introduction to Condition Based maintenance .......................................... 1

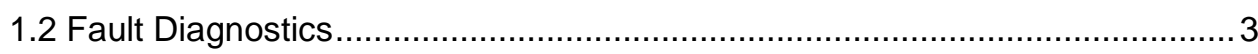

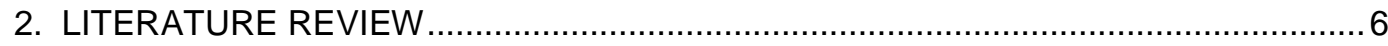

3. TECHNIQUES FOR ROTOR IMBALANCE MODELING AND SENSOR FUSION .......9

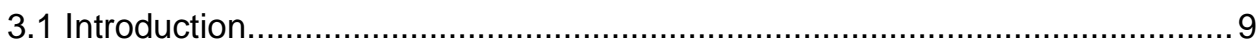

3.2 Mathematical modeling of Rotor Imbalance Fault........................................ 9

3.2.1 Application of Space Phasor Theory in Modeling Motor with Rotor Imbalance ............................................................... 9

3.2.2 Solving SQIM Modeling Equations using SIMULINK................... 18

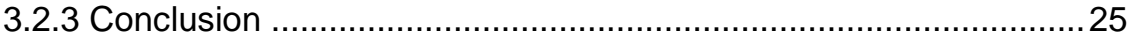

3.3 Methods for Rotor Imbalance Severity determination:

ANFIS and Dempster Shafer Theory ............................................26

3.3.1 Adaptive Network Based Fuzzy Inference System (ANFIS) .........26

3.3.2 Dempster Shafer (DS) Theory .............................................29

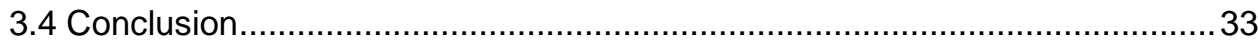

4. TEST BED BASED APPROACH FOR ROTOR IMBALANCE DIAGNOSTICS............34

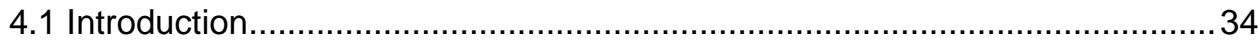

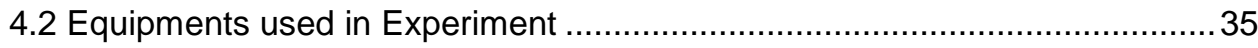


4.2.1 Test Motor 35

4.2.2 Current Transducers (Hall Effect Sensors) ................................ 35

4.2.3 Vibration Transducers (Accelerometers) ...................................36

4.2.4 Data Acquisition Devices and Computer Interface ........................37

4.3 Experiment Set-up and Test Cases …..................................................... 40

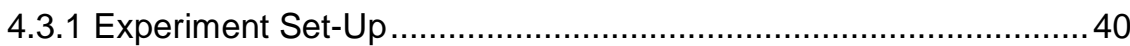

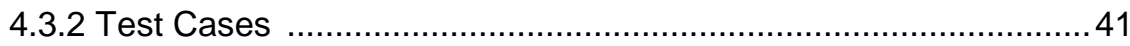

4.3.3 Fault Feature Extraction from Experiment Sets ........................ 41

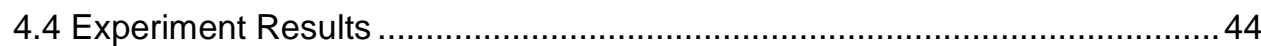

4.5 Sensor Fusion and Rotor Imbalance Severity Classification ........................47

4.5.1 ANFIS: Methodology and Results ............................................ 47

4.5.2 Fault Severity Classification using Dempster Shafer Theory ........53

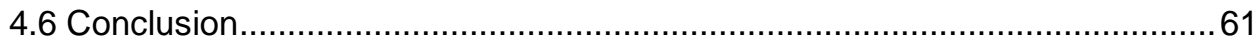

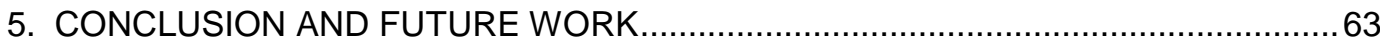

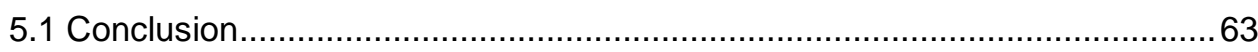

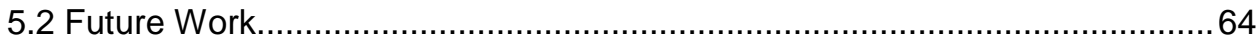

APPENDIX

A. MATLAB CODES FOR ROTOR IMBALANCE FEATURE EXTRACTION AND SEVERITY CLASSIFICATION USING DEMPSTER SHAFER THEORY ...................66

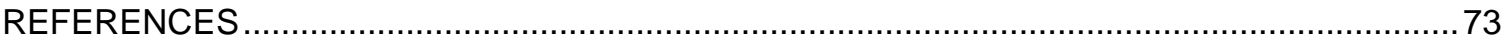

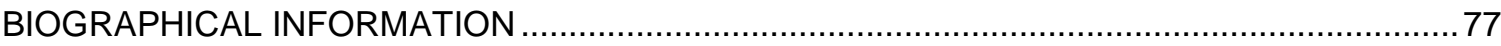




\section{LIST OF ILLUSTRATIONS}

Figure

Page

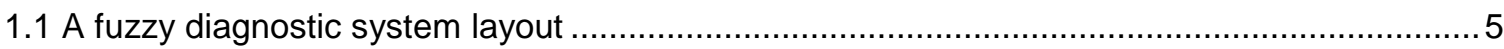

3.1 Cross-section of an elementary symmetrical three-phase machine ................................... 11

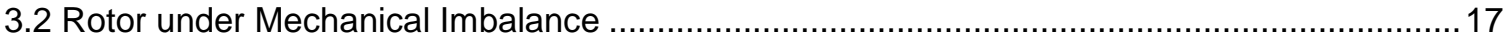

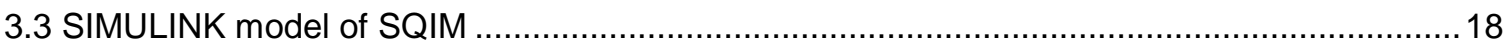

3.4 Rotor speed at steady state ( $\mathrm{rad} / \mathrm{sec})$ vs time $(\mathrm{sec})$

(a) Load torque $=0 \mathrm{~N}-\mathrm{m}$. b). Load torque $=2 \mathrm{~N}-\mathrm{m}$.

3.5 Electromagnetic torque at steady state $(\mathrm{N}-\mathrm{m})$ vs time (sec)

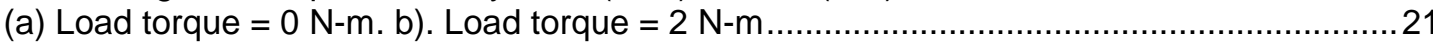

3.6 Stator current spectrum under different degrees of imbalance .............................................22

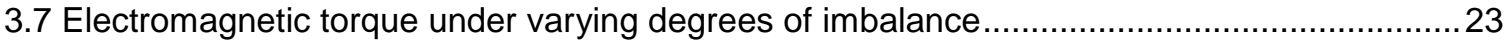

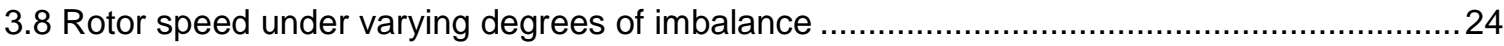

3.9 Rotor current spectrum (referred to rotor side)

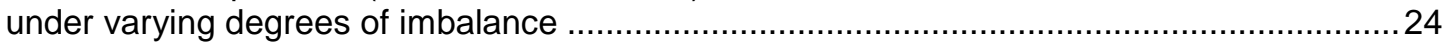

3.10 Rotor current spectrum (referred to stator side)

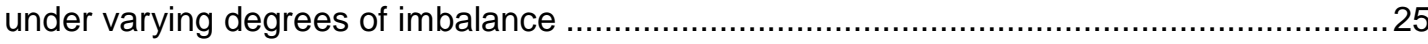

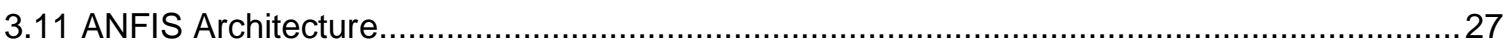

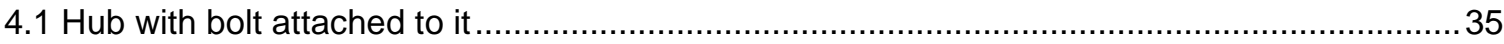

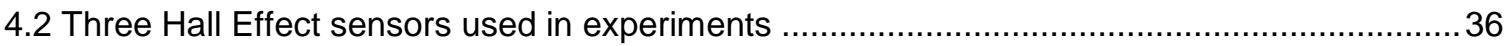

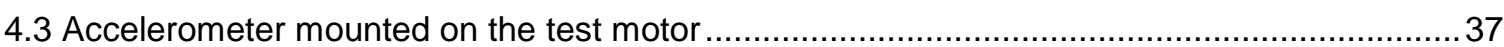

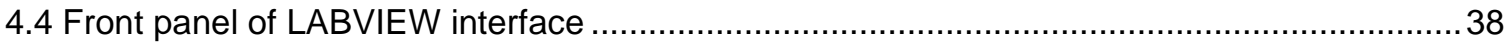

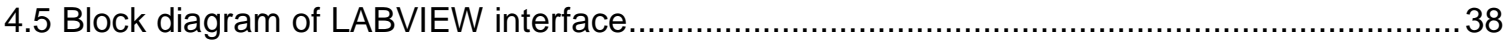

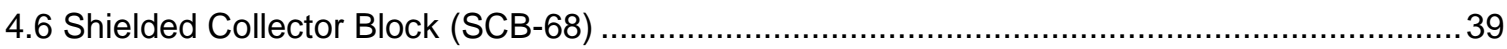

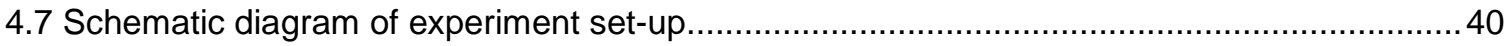

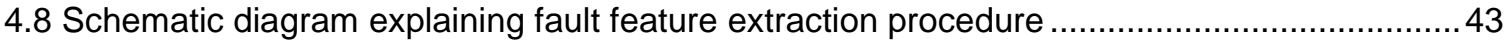

viii 
4.9 Fourier coefficients for ' $f s+f r$ ' frequency component

in phase A current spectrum under different degrees

of imbalance; 4 different days

4.10 Fourier coefficients for 'fs+fr' frequency component in phase B current spectrum under different degrees

of imbalance; 4 different days

4.11 Fourier coefficients for ' $\mathrm{f} s+\mathrm{fr}$ ' frequency component in phase $C$ current spectrum under different degrees

of imbalance; 4 different days 45

4.12 Fourier coefficients for 'fr' frequency component in $\mathrm{X}$ axis vibration spectrum under different degrees of imbalance; 4 different days 46

4.13 ANFIS editor GUI 47

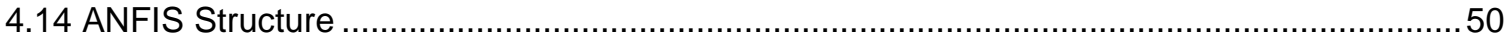

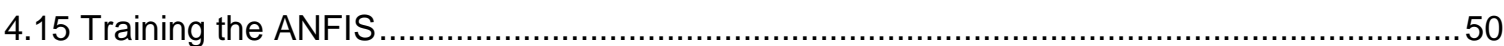

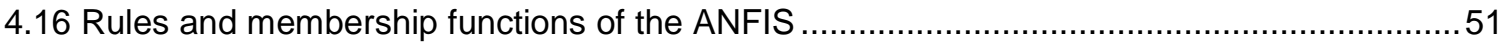

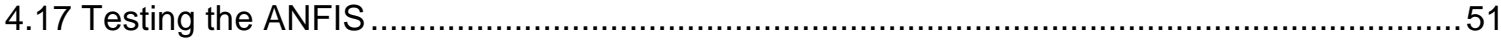

4.18 Trend of phase $A$ and phase $B$ imbalance features for the testing set. ' $X$ ' axis is 'Row numbers' as in Table 4.1 ..............................................52

4.19 Procedure for sensor fusion and imbalance classification using DS theory 55

4.20 Confidence in 'No-Fault' hypothesis before and after sensor fusion ..................................56

4.21 Confidence in 'Minor-Fault' hypothesis before and after sensor fusion ..............................57

4.22 Confidence in 'Major-Fault' hypothesis before and after sensor fusion ................................58 


\section{LIST OF TABLES}

Table

Page

3.1 Parameters of motor used for testing SQIM model in SIMULINK

3.2 Value of parameters in SQIM equations based on Table 3.1

4.1 Contents of 5 columns in each row of the training and testing arrays for ' $n$ ' experiment sets. ' $n$ ' $=16$ for training array and

' $n$ '= 3 for testing array

4.2 ANFIS Summary 52

4.3 Arrangement of rows in each column of array used for imbalance severity classification using DS theory

4.4 Mean percentage belongingness of each fault level to the three hypotheses after evidence combination

4.5 Mean percentage belongingness of each fault level to the three hypotheses based on phase ' $A$ ' fault feature set BPAs

4.6 Mean percentage belongingness of each fault level to the three hypotheses based on phase 'B' fault feature set BPAs

4.7 Mean percentage belongingness of each fault level to the three hypotheses based on phase ' $C$ ' fault feature set BPAs 60 


\section{CHAPTER 1}

\section{INTRODUCTION}

\subsection{Introduction to Condition Based Maintenance}

For any industry, a key to competitiveness is the reduction in production costs, of which equipment maintenance costs form a significant fraction. Thus, any reduction in maintenance costs can translate into significant savings in the production costs leading to an increased profit margin. However, it goes without saying that this reduction in cost should not in any way compromise with the genuine maintenance needs of the equipment. Thus, what is needed is an optimized maintenance strategy that can fulfill maintenance requirements with minimum expenditure.

Primarily, two maintenance strategies have been popular among industry- Reactive Maintenance and Time Based Maintenance. Reactive maintenance is basically a 'run till it fails' type of strategy where no maintenance is done till the equipment stops functioning. Majority of industries still follow this strategy [1]. At first glance, this choice may seem obvious since no maintenance cost is incurred till the equipment is replaced. However, it is important to realize that maintenance costs continue to accrue and total to the cost of equipment replacement, which may have been much lower had timely maintenance of equipment been done. It is this realization that lead to the formulation of Time Based Maintenance or Periodic Maintenance Strategy. In this strategy, a maintenance schedule is prepared based on past experience with equipment performance, and periodic maintenance of the equipment is done irrespective of the actual condition of the equipment. This philosophy is unduly expensive for two reasons [2]. First, maintenance may be performed on perfectly good machinery. Second, the very act of maintenance, even when performed correctly, often induces problems in previously functioning machinery (so-called iatropic maintenance problems). In view of the deficiencies associated 
with these two maintenance strategies, industry has started to look towards Condition Based Maintenance (CBM) as a cost effective maintenance strategy [3], [4], [5] and [6].

CBM has been defined in various ways in literature [2], [7]. However, the gist of every definition is: CBM is a strategy of doing maintenance only when there is an objective need for it. The importance of objectivity in CBM cannot be over-emphasized; since the overall aim of any CBM strategy is to make the maintenance decisions as objective, i.e. based on real maintenance needs, as possible. CBM tries to incorporate this objectivity in maintenance decisions by combining the best of data acquisition, signal processing and decision making techniques, to give the decision makers sufficiently accurate idea of the condition of equipments and their maintenance needs. Equipped with this information, he/she can decide when to do the maintenance based on criticality of equipments and or profit considerations.

From the above discussion on the definition and importance of CBM, it is clear that objectivity is central to CBM. This objectivity is attained by following three steps while implementing a CBM strategy. These steps are:

- Diagnostics

- Off Line- Background Studies, Fault Mode Analysis

- On Line- Real-time Fault Monitoring \& Diagnosis

- Prognostics

- Off Line-Background studies, Remaining Useful Life (RUL) analysis

$\circ \quad$ On Line-Real time prognostics and RUL estimation

- Maintenance Scheduling

Therefore, a complete CBM process starts with determining the 'symptoms' of an incipient fault (diagnostics) followed by an estimation of the time left for fault to develop into a failure (prognostics). Information about Mean Time to failure (MTTF) and RUL provided by prognostics, is then used to determine an optimal maintenance strategy, taking into account factors such as criticality of equipment, loss due to equipment downtime, etc (maintenance scheduling). In this thesis, however, only fault diagnostics for rotor imbalance in an induction machine has been performed. Two factors motivated the above choice: 
- Rotor imbalance is a common occurrence in wind turbines [8], [9] and [10]. Hence, developing a robust rotor imbalance detection and severity classification methodology may benefit this important industry.

- This thesis evolved from a Department of Energy sponsored Small Business Innovative Research (SBIR) project awarded to Signal Processing, Inc in which, the Energy Systems Research Center (ESRC) and Automation \& Robotics Research Institute (ARRI) at The University of Texas at Arlington were partners. This project primarily focused on rotor imbalance fault diagnostics. ESRC developed experiment test beds for this purpose. Availability of these test beds, therefore, provided an excellent platform to experimentally validate the rotor imbalance diagnostics scheme presented in this thesis.

Fault diagnostics being central to this thesis, is explained in detail in the next section.

\subsection{Fault Diagnostics}

Diagnostics, as the name suggests, refers to the identification of a fault before it becomes a failure. As is obvious, this identification is not possible unless there is prior information about the possible fault modes of equipment. Also required to be known a priori, are the system conditions that may be associated with the fault modes; since failure occurs at material level, but their effects are observed at system level in such forms as heat, vibration, noise, and/or debris in a lubricant, etc [2].

There are two ways by which the aforementioned information can be obtained [11]. First way is to use actual fault/failure legacy data from recorded machine histories, where information on the fault modes and associated system conditions are given. The second way is to develop test beds for inducing faults common to the equipment of interest. In this method, sensors are used to collect fault data which is analyzed to determine the effect of fault on system parameters such as vibration, current, voltage, etc. Second method has the obvious advantage of taking into account the behavior of the target machine and ambient conditions 
(power supply, mounting, etc) in determining the signatures for a particular fault mode. This approach, therefore, has been adopted in this thesis. Opinion of an expert who has a long experience in dealing with the equipment under consideration may prove very helpful in setting up experiments. Fault library preparation by this method may be accomplished in either of the following two ways, second being an extension of the first.

- Data collected by experiments may be organized as tables of frequency spectrum (FFTs), trends (using Kalman filtering), or moments about the mean (skew and kurtosis) of some system parameter(s) associated with each fault mode. This way a fault library becomes available with which actual data may be compared at any time to determine the fault type and its severity [12].

- The above step may be taken further and all the processed data as indicated above, may be fed into a neural network or a support vector machine or a neurofuzzy system [13] to store associations between fault data and the corresponding fault in a single network.

Once the fault libraries are prepared, equipments may be monitored in real time and data gathered from them compared with the fault libraries or fed into an intelligent classifier to indicate if any fault is developing and if it is, what the identity or severity of the fault is.

An additional step needs to be added to the aforementioned fault diagnostics procedure if multiple sensors are used to monitor the same system parameter. Hall et al, [2] have advocated the use of data fusion in CBM, since decision making using more than one sensor increases the accuracy of decision. In this scenario, Dempster-Shafer evidence combination [14] or neural nets or fuzzy logic decision making may be used to determine the identity of fault by combining identity declaration from individual sensors. An example of a diagnostic system developed by authors in [14] is shown in Fig. 1.1. 


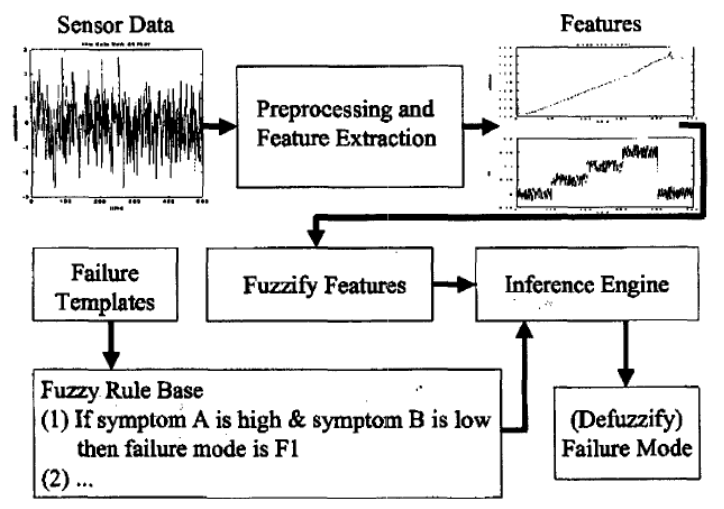

Fig. 1.1 A fuzzy diagnostic system layout [14]

This document is divided into 5 chapters. After this introductory chapter, Chapter 2 presents a review of literature on rotor imbalance fault diagnostics in induction machines. It highlights the areas in rotor imbalance diagnostics that need more attention, and how this thesis addresses them. Chapter 3 presents the theoretical background of techniques that were used in this thesis to address the issues highlighted in Chapter 2. Chapter 4 presents a comprehensive test bed based approach for rotor imbalance diagnostics using techniques introduced in Chapter 3. Chapter 5 is the concluding chapter, and it summarizes the contributions of this thesis. It also discusses the scope for future research on condition based maintenance of machines. 


\section{CHAPTER 2}

\section{LITERATURE REVIEW}

Condition based maintenance of a machine may be performed using either invasive or non-invasive sensors. Accelerometers, torque sensors, search coils, etc are invasive sensors as they need to be installed in close proximity to the motor and are rarely a part of normal motor installation. Traditionally, these sensors, especially vibration sensors, have been the primary source of information about motor condition. A lot of literature also exists on CBM using invasive sensors [3], [9], [15], [16], [17] and [18]. However, there are several drawbacks associated with these sensors [19], [20] such as the extra investment involved in their installation and maintenance. Hence, in recent years emphasis has been on developing CBM techniques for motors that are based on non-invasive sensors i.e. current and voltage sensors [19], [21-23], [24], [25-27], [28] and [29]. This is because these sensors are always installed with a machine for protection or control purposes [19], and if they could provide information about faults, extra sensors would not be required.

CBM using non-invasive sensors has been shown to provide very good results in detecting rotor imbalance. While Motor Current Signature Analysis (MCSA) has been used most extensively for this purpose, techniques using information other than current such as instantaneous power [29] have also been presented in the literature. Even within MCSA, several methods have been presented for determining rotor imbalance signatures from the stator current. These include determining rotor imbalance specific frequency component in stator current spectrum, instantaneous frequency of stator current [19], Pseudo Wigner Distribution (PWD) [19], and r.m.s value of stator current [27]. However, of all these the first method based on stator current spectrum has been the most popular [19], [25] and [27]. In this method the Discrete Fourier Transform (DFT) of stator current is taken. Magnitude of Fourier 
coefficients for fs $\pm f r$ frequency components, fault components arising out of rotor imbalance in the stator current, is then compared with no fault magnitude of these components to detect rotor imbalance. It must be noted here that even in a new motor fs \pm fr frequency components would exist due to unavoidable dynamic eccentricity or imbalance [21], [15]. Determining a baseline when the motor is new is, therefore, important to detect a rotor imbalance in future.

From the above review it was found that while several techniques have been explored to detect rotor imbalance using MCSA, very few papers exist where an explanation for the appearance of fs $\pm f r$ frequency components due to rotor imbalance has been given [24], [30]. Even in these papers, only a short theoretical reason was provided. Of the literature reviewed, only [19] attempted a mathematical modeling of rotor imbalance fault but with certain assumptions such as constancy of electromagnetic torque. Hence, there is a need for accurate mathematical modeling of rotor imbalance, so that a better understanding of the reasons that cause rotor imbalance fault signatures to appear in the stator current is obtained.

Another common feature in the literature has been an almost exclusive use of a single phase of stator current in performing MCSA for rotor imbalance diagnostics. While theoretically all phases should respond identically to rotor imbalance, real world noise, winding asymmetries, winding damage, etc, may cause a phase to behave differently over time. Moreover, accuracy of current sensor installed on the phase may deteriorate as well. If this phase happens to be the one being used for determining rotor imbalance signatures, false alarm may be raised about the degree of rotor imbalance in the machine. To solve this problem, sensor fusion seems to be a promising technique. Sensor fusion has the attractive property of 'graceful deterioration' of performance as it combines information from multiple sensors [2] to arrive at a decision. Therefore, it would not be out of place to combine fault information from the three phases of a machine to perform rotor imbalance diagnostics.

In view of the above discussion, this thesis attempts to provide an accurate modeling of rotor imbalance in induction machines so that the process behind appearance of rotor 
imbalance features in stator current is better understood, and also presents a comprehensive test bed based scheme for rotor imbalance diagnostics that incorporates sensor fusion. 


\section{CHAPTER 3}

\section{TECHNIQUES FOR ROTOR IMBALANCE MODELING AND SENSOR FUSION}

\section{$\underline{3.1 \text { Introduction }}$}

Chapter 2 pointed out the focus areas of this thesis. This chapter presents the techniques that were used to address these. Section 3.2 presents mathematical modeling of rotor imbalance fault using space phasor theory followed by simulation of the mathematical model in SIMULINK. Section 3.3 presents the theoretical background of two multi-input fault classification techniques that can be used for performing sensor fusion. These are Adaptive Network Based Fuzzy Inference System (ANFIS) and Dempster Shafer Theory in conjunction with Fuzzy c Means (FCM) clustering. Section 3.4 provides a summary of ideas developed in this chapter.

\subsection{Mathematical Modeling of Rotor Imbalance Fault}

Since the steady state torque is not constant under rotor imbalance fault, three phase circuit equations for a machine (in this case induction motor) need to be used for modeling rotor imbalance. Space Phasor Theory was chosen as the framework for this modeling. Section 3.2.1 details the application of this theory in modeling motor under rotor imbalance. Modeling equations framed in Section 3.2.1 were non-linear differential equations requiring a numerical method for their solution. Therefore, SIMULINK was used for solving these equations and details of this simulation are presented in section 3.2.2.

\subsubsection{Application of Space Phasor Theory in Modeling Motor with Rotor Imbalance}

\subsubsection{Introduction to Space Phasor Theory}

This section discusses in brief the Space Phasor Theory as detailed in [31]. Space Phasor Theory is very closely related to the two-axis theory of electric machines, but the simplicity and compactness of the space-phasor equations and the very clear pictures obtained 
by its application can yield further advantages. Before proceeding with the theory, a list of assumptions used in its development are given below:

- Air-gap is considered to be smooth with symmetrical three phase windings.

- Permeability of the iron parts is assumed to be infinite and the flux density is considered to be radial in the air gap.

- The effects of iron losses and end-effects are neglected.

Fig. 3.1 is the reference figure for the explanation that follows. The machine shown is a 2-pole machine. The stator and rotor windings are shown as single, multiple turn full pitch coils situated on the two sides of the air-gap; these, however, represent distributed windings, which at every instant produce sinusoidal m.m.f. waves centered on the magnetic axis of the respective phases. The phase windings are displaced by 120 electrical degrees from each other. In Fig. 3.1, $\theta_{r}$ is the rotor angle, the angle between the magnetic axes of the stator winding $s A$ and rotor winding $r a$. In general, the speed of the rotor is $\omega_{r}=d \theta_{r} / d t$, and its positive direction is also shown in Fig. 3.1. Primed quantities (such as $s A^{\prime}$ ) indicate current flowing 'out of the plane' of the paper while un-primed quantities (such as $s A$ ) indicate current flowing 'into the plane' of the paper. 


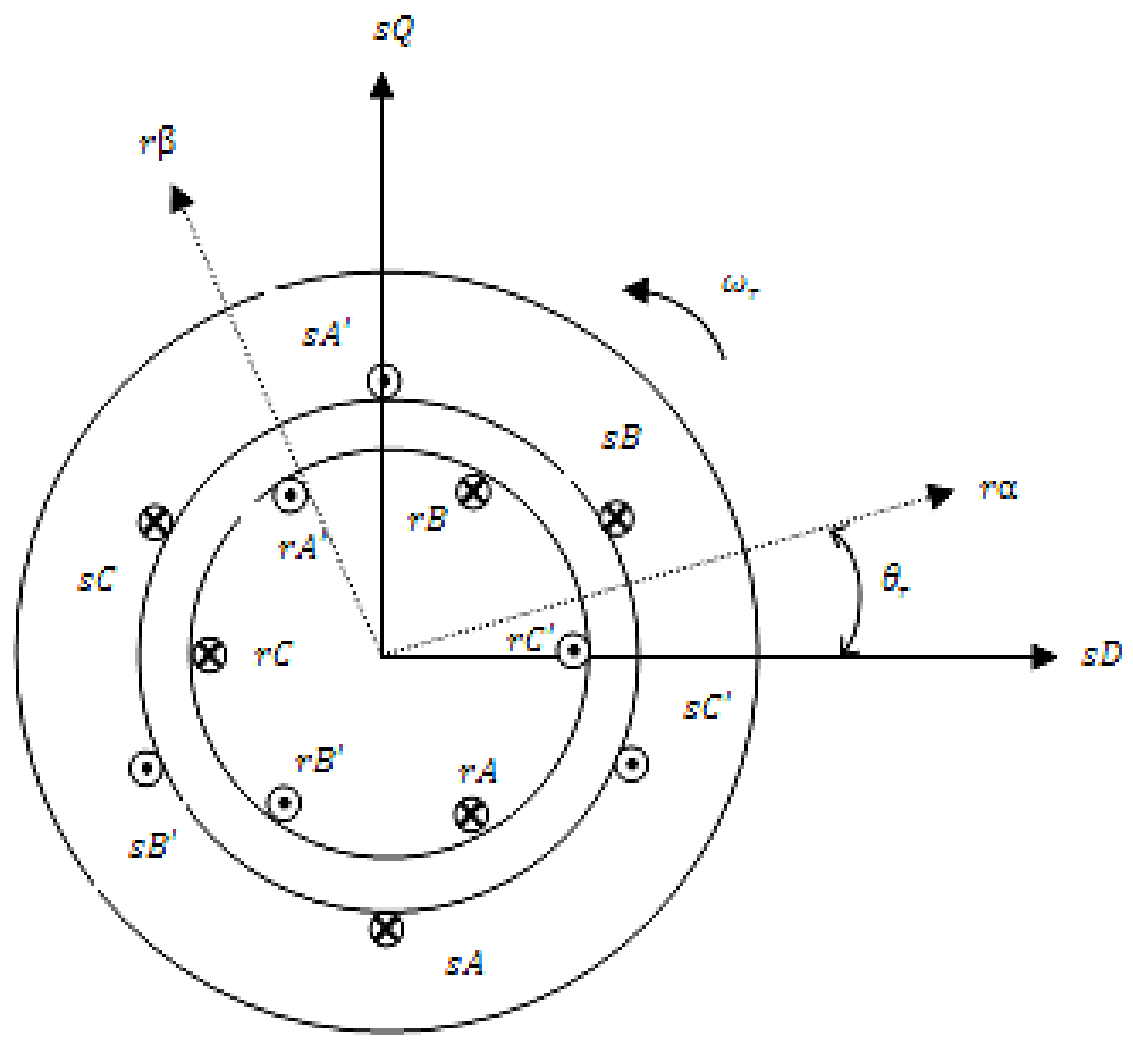

Fig. 3.1 Cross-section of an elementary symmetrical three-phase machine [31]

\subsubsection{Space Phasor representation of stator and rotor currents}

Let stator windings have an equal number of effective turns where and are the number of turns and the winding factor of a stator winding respectively. Now, if the stator windings are supplied by a system of three-phase currents , and , which can vary arbitrarily in time, the resultant m.m.f. distribution produced by the stator is as follows: if is the angle around the periphery with reference to the axis of stator winding , which coincides with the real axis of the stator denoted by in Fig. 3.1, then

By using complex notation, it is possible to put eqn 3.1 into the following form:

In eqn 3.2, is multiplied by the following quantity: 
$\overline{i_{s}}(t)=\frac{2}{3}\left[i_{S A}(t)+a i_{S B}(t)+a^{2} i_{s C}(t)\right]$

Where, $\overline{i_{s}}(t)$ is the complex space phasor of the three-phase stator currents in the complex plane in the stationary reference frame fixed to the stator. Furthermore, in eqn 3.2, $a$ and $a^{2}$ are spatial operators, $a=e^{j 2 \pi / 3}$ and $a^{2}=e^{j 4 \pi / 3}$. The stator current space phasor given by eqn 3.3 can be resolved into direct axis stator current $i_{S D}$ and quadrature axis stator current $i_{s Q}$ in the stationary reference frame fixed to the stator. Mathematically,

$\overline{i_{s}}(t)=i_{s D}(t)+j i_{s Q}(t)$

Rotor current space phasor in the stationary reference frame fixed to the stator $\overline{i_{r}^{\prime}}$ can also be obtained by following a similar procedure as above. Here, only the expression is listed and details may be found in [31]. The expression is:

$\overline{i_{r}^{\prime}}(t)=i_{r d}(t)+j i_{r q}(t)$

, where $i_{r d}$ and $i_{r q}$ are the direct and quadrature axes components of rotor current space phasor in a reference frame fixed to the stator.

\subsubsection{Space Phasor Representation of Stator and Rotor Flux linkages}

Similar to the definition of stator current space phasor, it is possible to define the space phasor of the stator flux linkages. Thus, in the stationary reference frame fixed to the stator, the total stator flux- linkage space phasor $\overline{\psi_{s}}$ can be expressed as follows:

$\overline{\psi_{s}}(t)=\frac{2}{3}\left[\psi_{S A}+a \psi_{s B}+a^{2} \psi_{s C}\right]$

, where the instantaneous value of the phase-variable flux-linkage components are

$$
\begin{aligned}
\psi_{s A}= & \overline{L_{s}} i_{s A}+\overline{M_{s}} i_{s B}+\overline{M_{s}} i_{s C}+\overline{M_{s r}} \cos \theta_{r} i_{r \alpha}+\overline{M_{s r}} \cos \left(\theta_{r}+2 \pi / 3\right) i_{r b}+\overline{M_{s r}} \cos \left(\theta_{r}+\right. \\
& 4 \pi / 3) i_{r c} \\
\psi_{s B}= & \overline{M_{s}} i_{s A}+\overline{L_{s}} i_{s B}+\overline{M_{s}} i_{s C}+\overline{M_{s r}} \cos \left(\theta_{r}+4 \pi / 3\right) i_{r \alpha}+\overline{M_{s r}} \cos \left(\theta_{r}\right) i_{r b}+\overline{M_{s r}} \cos \left(\theta_{r}+\right. \\
& 2 \pi / 3) i_{r c} \\
\psi_{s C}= & \overline{M_{s}} i_{s A}+\overline{M_{s}} i_{s B}+\overline{L_{s}} i_{s C}+\overline{M_{s r}} \cos \left(\theta_{r}+2 \pi / 3\right) i_{r \alpha}+\overline{M_{s r}} \cos \left(\theta_{r}+4 \pi / 3\right) i_{r b}
\end{aligned}
$$


$+\overline{M_{s r}} \cos \left(\theta_{r}\right) i_{r c}$

In eqns, 3.7, 3.8 and $3.9, i_{r \alpha}, i_{r b}$ and $i_{r c}$ are the rotor phase currents, $\overline{L_{s}}$ is the self inductance of a stator phase winding, $\overline{M_{s}}$ is the mutual inductance between the stator windings, and $\overline{M_{s r}}$ is the maximal value of the stator-rotor mutual inductance. Substituting eqns, 3.7, 3.8 and 3.9 into eqn 3.6, gives the following expression for $\overline{\psi_{\mathrm{s}}}$ :

$\overline{\psi_{s}}=\mathrm{L}_{\mathrm{s}} \overline{i_{s}}+\mathrm{L}_{\mathrm{m}} \overline{i_{r}^{\prime}}$

, where $\mathrm{L}_{\mathrm{s}}=\overline{L_{s}}-\overline{M_{s}}$ is the total three phase self inductance of the machine and $\mathrm{L}_{\mathrm{m}}=\frac{3}{2} \overline{M_{s r}}$ is the so called three phase magnetizing inductance.

Like stator and rotor current space phasors, stator flux space phasor may also be resolved into direct $\psi_{S D}$ and quadrature $\psi_{S Q}$ axes flux linkage components in the reference frame fixed to the stator. This conversion results in eqn 3.10 being divided into following two equations:

$\psi_{s D}=\mathrm{L}_{\mathrm{s}} i_{s D}+\mathrm{L}_{\mathrm{m}} i_{r d}$

$\psi_{s Q}=\mathrm{L}_{\mathrm{s}} i_{s Q}+\mathrm{L}_{\mathrm{m}} i_{r q}$

Rotor flux linkage space phasor in the stationary reference frame $\overline{\psi_{r}^{\prime}}$ may also be found by adopting the above procedure. Leaving the details, eqn 3.13 gives the expression for rotor flux linkage space phasor. Eqn 3.14 and eqn 3.15 give expressions for rotor flux linkage space phasor resolved into direct $\psi_{r d}$ and quadrature $\psi_{r q}$ axes components in the stationary reference frame fixed to the stator.

$\overline{\psi_{r}^{\prime}}=\mathrm{L}_{\mathrm{r}} \overline{i_{r}}+\mathrm{L}_{\mathrm{m}} \overline{i_{s}}$

$\psi_{r d}=\mathrm{L}_{\mathrm{r}} i_{r d}+\mathrm{L}_{\mathrm{m}} i_{s D}$

$\psi_{r q}=\mathrm{L}_{\mathrm{r}} i_{r q}+\mathrm{L}_{\mathrm{m}} i_{s Q}$

, where $\mathrm{L}_{\mathrm{r}}=\overline{L_{r}}-\overline{M_{S}}$ is the three phase self inductance of the rotor in the stationary reference frame fixed to the stator and $\overline{L_{r}}$ is the self inductance of the rotor. 


\subsubsection{Space Phasor Representation of Voltages}

Space phasors of the stator and rotor voltages can be defined similarly to the space-phasor quantities defined in the earlier sections. Thus, the stator-voltage space phasor in the stationary reference frame is:

$\overline{u_{s}}(t)=\frac{2}{3}\left[u_{s A}(t)+a u_{s B}(t)+a^{2} u_{s C}(t)\right]=u_{s D}+j u_{s Q}$

and the rotor voltage space phasor in the reference frame fixed to the stator is

$$
\overline{u_{r}^{\prime}}(t)=\frac{2}{3}\left[u_{r a}(t)+a u_{r b}(t)+a^{2} u_{r c}(t)\right] e^{j \theta_{r}}=u_{r d}+j u_{r q}
$$

In eqns 3.16 and $3.17, u_{s A}, u_{s B}, u_{s C}$ and $u_{r a}, u_{r b}, u_{r c}$ are the instantaneous values of the stator and rotor phase voltages respectively. $u_{S D}, u_{s Q}$ are the direct and quadrature axis components of $\overline{u_{s}}(t) . u_{r d}, u_{r q}$ are the direct and quadrature axis components of $\overline{u_{r}^{\prime}}(t)$.

Having determined the space-phasor representation of currents, fluxes and voltages, the next step in modeling a machine is to use standard circuit equations for an $R-L$ circuit that relate voltage, currents and flux linkages. However, before proceeding with this step it is important to note that in all the above expressions three phase variables were eventually converted into two variables - direct and quadrature axes components. There is a third variable as well that is termed as zero-sequence current, voltage or flux. Since in most cases this quantity is zero, direct and quadrature axes variables completely describe a three phase system. If, however, a zero sequence component is present, a third equation is also required. The expression for this equation is similar for all quantities. It is given for stator currents in eqn. 3.18

$u_{s 0}=\frac{1}{3}\left[u_{s A}(t)+u_{s B}(t)+u_{s C}(t)\right]$

3.2.1.4 Complete Electrical Equations for a Machine in Stationary Reference Frame Using eqns 3.3 and $3.4, i_{s D}$ and $i_{s Q}$ may be expressed in terms of stator current phase variables given by eqns 3.19 and 3.20 respectively .Similarly, eqn 3.16 may be used to express $u_{s D}$ and 
$u_{s Q}$ as a function of voltage phase variables. These expressions are given in eqn 3.21 and eqn 3.22. Similar expressions result for rotor space phasors as well.

$i_{S D}=\frac{2}{3}\left[i_{S A}-\frac{1}{2} i_{S B}-\frac{1}{2} i_{S C}\right]$

$i_{s Q}=\frac{1}{\sqrt{3}}\left[i_{s B}-i_{s C}\right]$

$u_{s D}=\frac{2}{3}\left[u_{s A}-\frac{1}{2} u_{s B}-\frac{1}{2} u_{s C}\right]$

$u_{s Q}=\frac{1}{\sqrt{3}}\left[u_{s B}-u_{s C}\right]$

In phase variable form and in respective reference frames, the stator and rotor voltage equations may be written as in eqns $3.23-3.25$ and $3.26-3.28$ respectively:

$u_{s A}(t)=R_{s} i_{s A}(t)+d \psi_{s A}(t) / d t$

$u_{s B}(t)=R_{s} i_{s B}(t)+d \psi_{s B}(t) / d t$

$u_{s C}(t)=R_{s} i_{s C}(t)+d \psi_{s C}(t) / d t$

$u_{r a}(t)=R_{r} i_{r a}(t)+d \psi_{r a}(t) / d t$

$u_{r b}(t)=R_{r} i_{r b}(t)+d \psi_{r b}(t) / d t$

$u_{r c}(t)=R_{r} i_{r c}(t)+d \psi_{r c}(t) / d t$

, where $i_{r a}, i_{r b}, i_{r c}$ and $\psi_{r a}, \psi_{r b}$ and $\psi_{r c}$ are rotor phase currents and flux linkages respectively in rotor reference frame and $R_{s}$ and $R_{r}$ are the stator and rotor resistances. If eqns 3.7, 3.8 and 3.9 are substituted in eqns $3.23,3.24$ and 3.25 respectively, and the resulting expression manipulated along with eqns 3.19 to 3.22 , eqn 3.29 results. Similar procedure when applied to eqns 3.26, 3.27 and 3.28 and the resulting equations transferred to stationary reference frame, eqn 3.30 results. Eqns 3.29 and 3.30 represent the complete electrical model of a machine in a reference frame fixed to the stator. In these equations $p$ is a symbol for differential operator $d / d t$. 


$$
\begin{aligned}
& {\left[\begin{array}{l}
u_{s D} \\
u_{s Q}
\end{array}\right]=\left[\begin{array}{cccc}
R_{s}+p \mathrm{~L}_{\mathrm{s}} & 0 & p \mathrm{~L}_{\mathrm{m}} & 0 \\
0 & R_{s}+p \mathrm{~L}_{\mathrm{s}} & 0 & p \mathrm{~L}_{\mathrm{m}}
\end{array}\right]\left[\begin{array}{l}
i_{s D} \\
i_{s Q} \\
i_{r d} \\
i_{r q}
\end{array}\right]} \\
& {\left[\begin{array}{l}
u_{r d} \\
u_{r q}
\end{array}\right]=\left[\begin{array}{cccc}
p \mathrm{~L}_{\mathrm{m}} & \omega_{r} \mathrm{~L}_{\mathrm{m}} & R_{r}+p \mathrm{~L}_{\mathrm{r}} & \omega_{r} \mathrm{~L}_{\mathrm{r}} \\
-\omega_{r} \mathrm{~L}_{\mathrm{m}} & p \mathrm{~L}_{\mathrm{m}} & -\omega_{r} \mathrm{~L}_{\mathrm{r}} & R_{r}+p \mathrm{~L}_{\mathrm{r}}
\end{array}\right]\left[\begin{array}{c}
i_{s D} \\
i_{s Q} \\
i_{r d} \\
i_{r q}
\end{array}\right]}
\end{aligned}
$$

3.2.1.5 Expression for Electromagnetic Torque in Terms of $i_{s D}, i_{s Q}, i_{r d}$ and $i_{r q}$.

By applying energy conservation in the machine, expression for electromagnetic torque can be obtained. Details of the derivation may be found in [31]. Eqn 3.31 lists the expression for electromagnetic torque of a machine with $P$ pole pairs in stationary reference frame fixed to the stator.

$t_{e}=-\frac{3}{2} P L_{m}\left(i_{s D} i_{r q}-i_{s Q} i_{r d}\right)$

\subsubsection{Complete Model of Machine when used under Rotor Imbalance}

As an electric machine involves motion, complete machine model includes mechanical equation of motion as well. This equation is given in eqn 3.32 .

$t_{e}-t_{l}=J \frac{d \omega_{m}}{d t}$

, where $t_{l}$ is the mechanical torque on the machine and $\omega_{m}$ is the mechanical speed of the machine related to electrical speed $\omega_{r}$ by the relation $\omega_{r}=P \omega_{m}$.

Eqns $3.29,3.30,3.31$ and 3.32 represent a complete model of an electric machine in stationary reference frame fixed to the stator. This model can therefore be applied to a Squirrel cage Induction Motor (SQIM) as well. However, an important point to note in modeling a SQIM is that there are no distributed three phase windings on the rotor. But, fortunately the cage rotor can still be modeled as an equivalent three phase distributed winding system [31], [32]. Hence, eqn 3.30 is a valid equation for SQIM as well. Since no external voltages are applied to the rotor in a SQIM, LHS of eqn 3.30 is zero. 
With a model in place for SQIM, next step is to model rotor imbalance. Fig. 3.2 illustrates the rotor under mechanical imbalance.

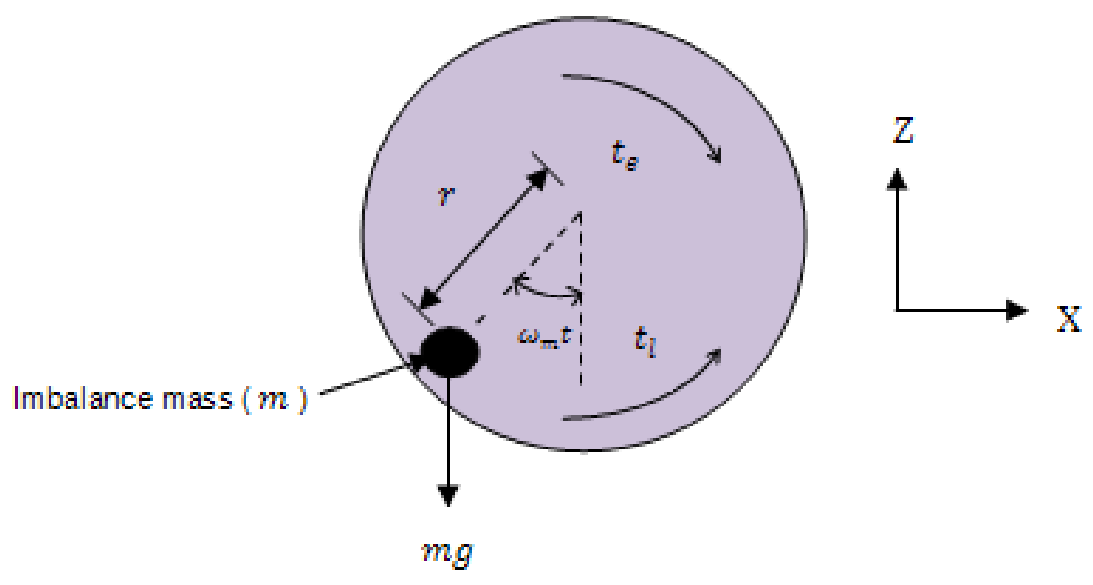

Fig. 3.2 Rotor under Mechanical Imbalance

From this figure it is clear that rotor imbalance manifests itself as an oscillating torque impressed on motor load torque. Therefore, expression for load toque on the motor becomes as given in eqn 3.33 .

$t_{l}=A+m g r \sin \left(\omega_{m} t\right)$

, where $A$ represents the constant component of load torque, $m$ is the imbalance mass, $g$ is the acceleration due to gravity and $r$ is the radial distance of imbalance mass from the center of rotation.

Thus, Eqns 3.29, 3.30 (with LHS equal to zero), 3.31, 3.32 and 3.33 represent a complete model of a SQIM with rotor imbalance. If these equations are solved, expressions for direct and quadrature axis stator currents will be obtained which can then be converted to phase variable format using eqns 3.19 and 3.20. However, in the above motor model equations, $\omega_{m}$ and hence $\omega_{r}$ cannot be assumed to be constant. This is because in an induction machine motor speed is dependent on the load and eqn 3.33 shows that load torque is not constant. This situation makes the motor model equations non-linear and hence numerical methods must 
be used to solve them. In this work, SIMULINK was used to solve the modeling equations. The process is explained in Section 3.2.2.

\subsubsection{Solving SQIM Modeling Equations using SIMULINK.}

\subsubsection{Testing SQIM model developed in SIMULINK}

SQIM equations were modeled in SIMULINK using its Simulink library. The model so developed was quite involved and is shown in Fig. 3.3. It was tested using motor parameters given in [33]. These parameters are reproduced in Table 3.1. The relationship of these parameters with variables used in space phasor equations in Section 3.2.1 is shown in Table 3.2.

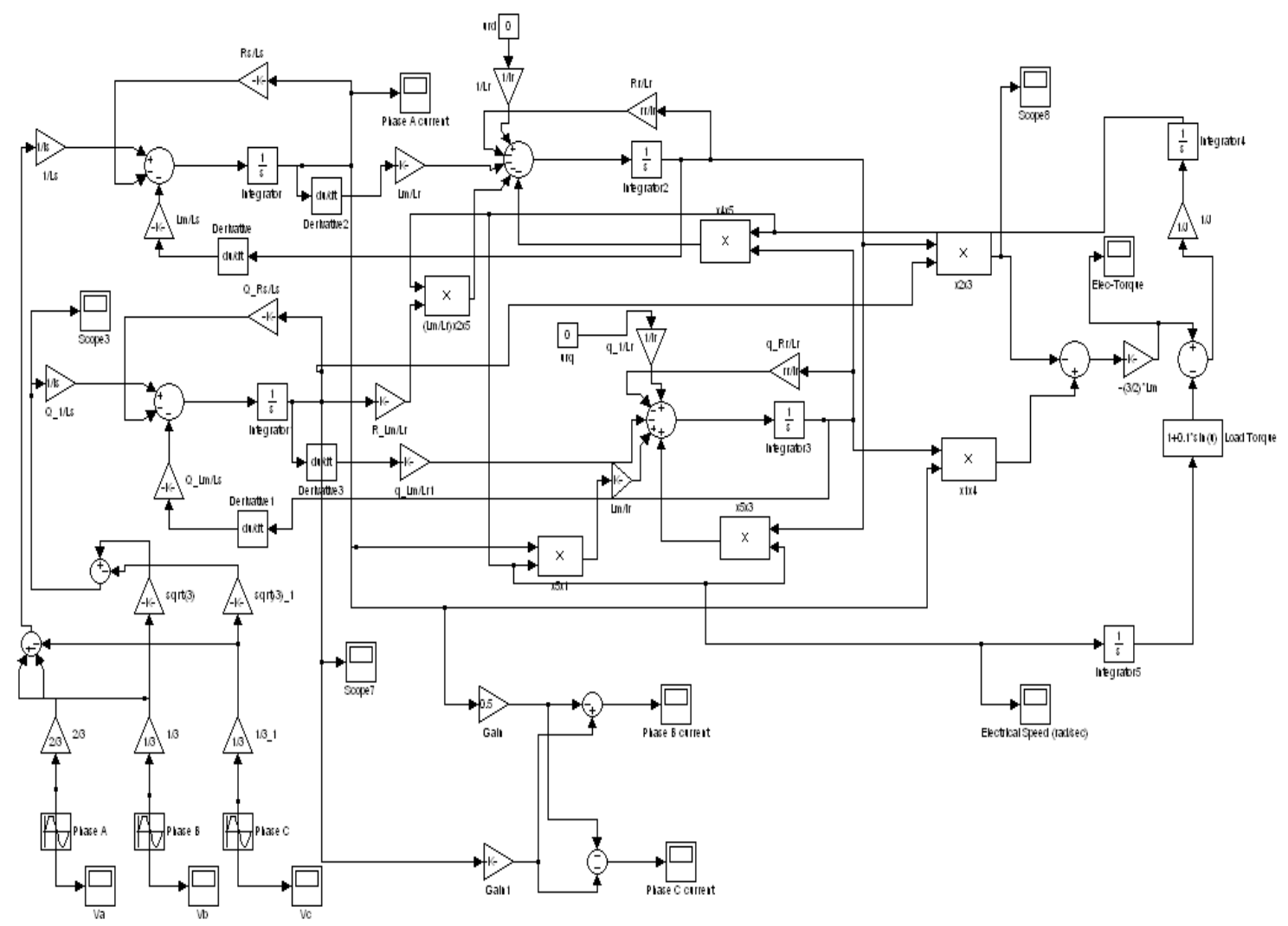

Fig. 3.3 SIMULINK model of SQIM 
Table 3.1 Parameters of motor used for testing SQIM model in SIMULINK

\begin{tabular}{|c|l|}
\hline Motor Parameter & Numerical Values \\
\hline Stator Resistance $\left(r_{s}\right)$ & $3 \mathrm{ohm}$ \\
\hline Rotor Resistance $\left(r_{r}\right)$ & $3 \mathrm{ohm}$ \\
\hline Magnetizing Inductance $\left(I_{\mathrm{m}}\right)$ & $0.1466 \mathrm{H}$ \\
\hline Stator Leakage Reactance $\left(\mathrm{I}_{\mathrm{s} 1}\right)$ & $0.0055 \mathrm{H}$ \\
\hline Rotor Leakage Reactance $\left(\mathrm{I}_{\mathrm{r} 1}\right)$ & $0.0055 \mathrm{H}$ \\
\hline Moment of Inertia $(\mathrm{J})$ & $0.01 \mathrm{~kg} \cdot \mathrm{m}^{2}$ \\
\hline
\end{tabular}

Table 3.2 Value of parameters in SQIM equations based on Table 3.1

\begin{tabular}{|c|l|}
\hline SQIM equation Parameters & Numerical Values \\
\hline$\overline{L_{s}}=\mathrm{I}_{\mathrm{s} 1}+\mathrm{I}_{\mathrm{m}}$ & $0.1521 \mathrm{H}$ \\
$\overline{L_{r}}=\mathrm{I}_{\mathrm{r} 1}+\mathrm{I}_{\mathrm{m}}$ & $0.1521 \mathrm{H}$ \\
\hline$\overline{M_{s}}=-\mathrm{I}_{\mathrm{m}} / 2=\overline{M_{r}}$ & $-0.0733 \mathrm{H}$ \\
\hline $\mathrm{L}_{\mathrm{m}}=3 / 2^{*} \mathrm{I}_{\mathrm{m}}$ & $0.2199 \mathrm{H}$ \\
\hline $\mathrm{L}_{\mathrm{s}}=\overline{L_{s}}-\overline{M_{s}}$ & $0.2254 \mathrm{H}$ \\
\hline $\mathrm{L}_{\mathrm{r}}=\overline{L_{r}}-\overline{M_{r}}$ & $0.2254 \mathrm{H}$ \\
\hline$R_{s}=r_{\mathrm{s}}$ & $3 \mathrm{ohm}$ \\
\hline$R_{r}=\mathrm{r}_{\mathrm{r}}$ & $3 \mathrm{ohm}$ \\
\hline Moment of Inertia $(\mathrm{J})$ & $0.01 \mathrm{~kg} \cdot \mathrm{m}^{2}$ \\
\hline No of Pole pairs & 2 \\
\hline
\end{tabular}

To test the machine model, two load torques- $0 \mathrm{~N}-\mathrm{m}$ and $2 \mathrm{~N}-\mathrm{m}$ were applied. If the machine were modeled correctly, electromagnetic torque would become equal to load torque in steady state in both cases. Further, rotor speed under $2 \mathrm{~N}-\mathrm{m}$ load torque must be lower than that under no-load. Rotor speed and electromagnetic torque for these cases is given in Fig. 3.4 and Fig. 3.5 respectively. 


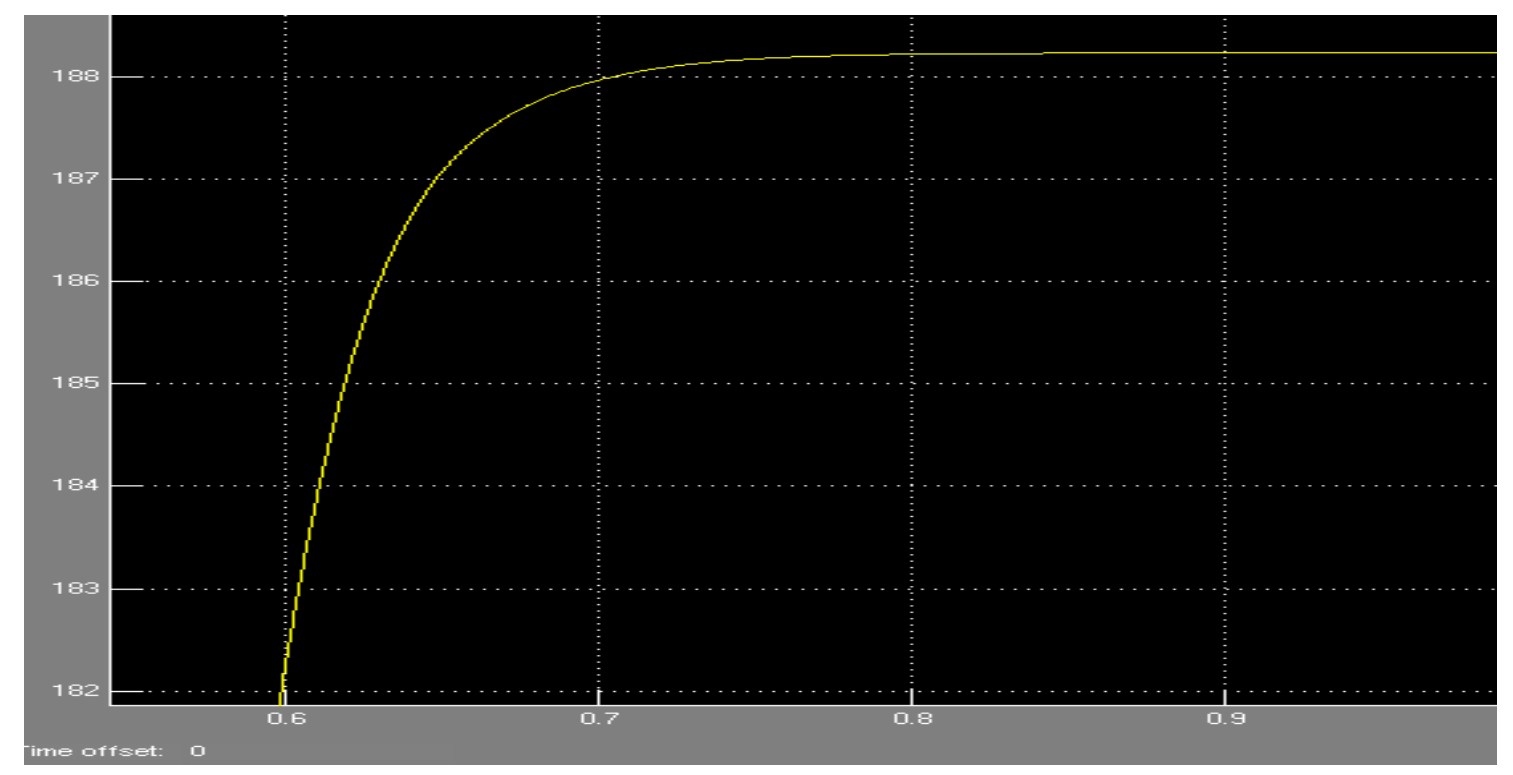

a).

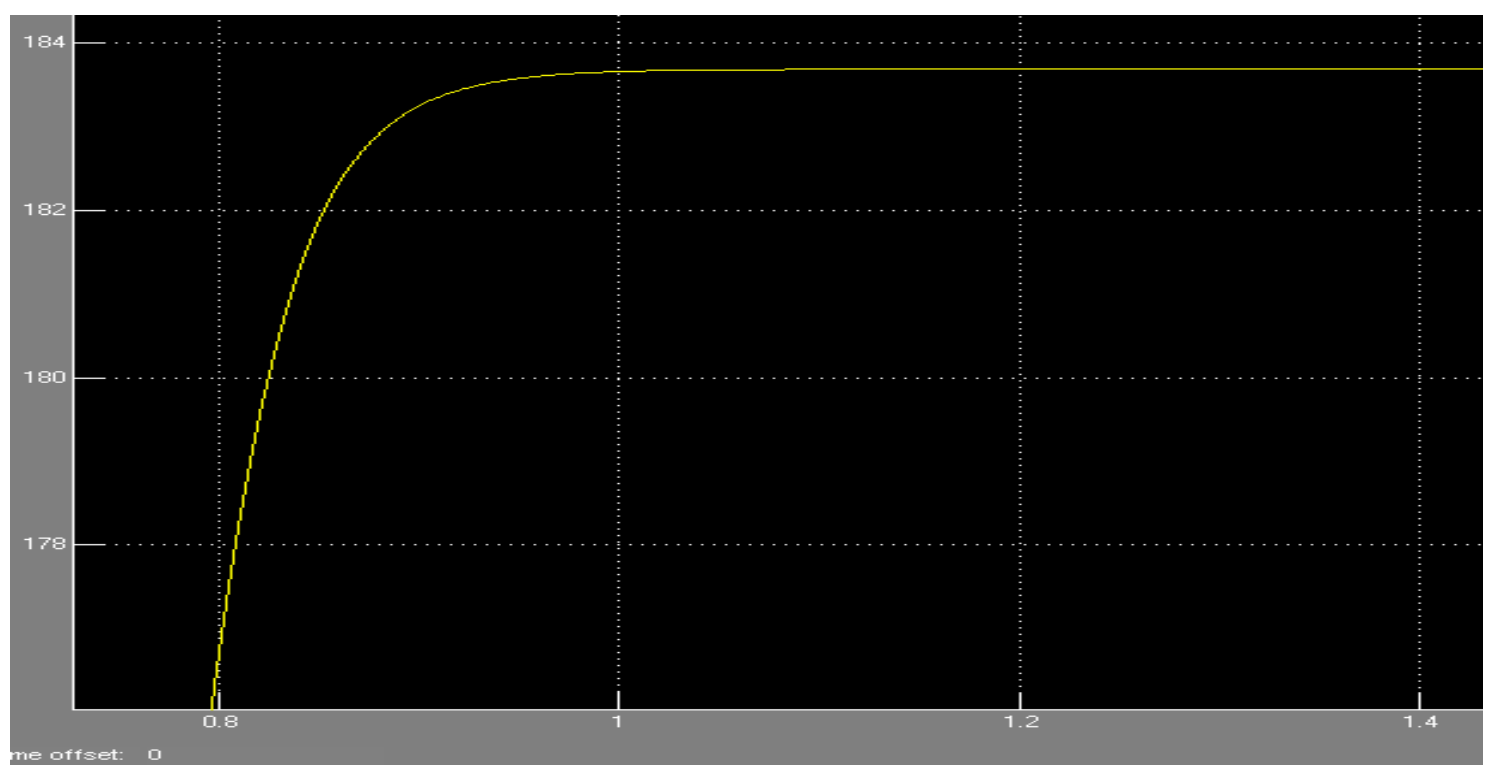

b).

Fig. 3.4 Rotor speed at steady state (rad/sec) vs. time (sec).

a). Load torque $=0 \mathrm{~N}-\mathrm{m}$. b). Load torque $=2 \mathrm{~N}-\mathrm{m}$ 


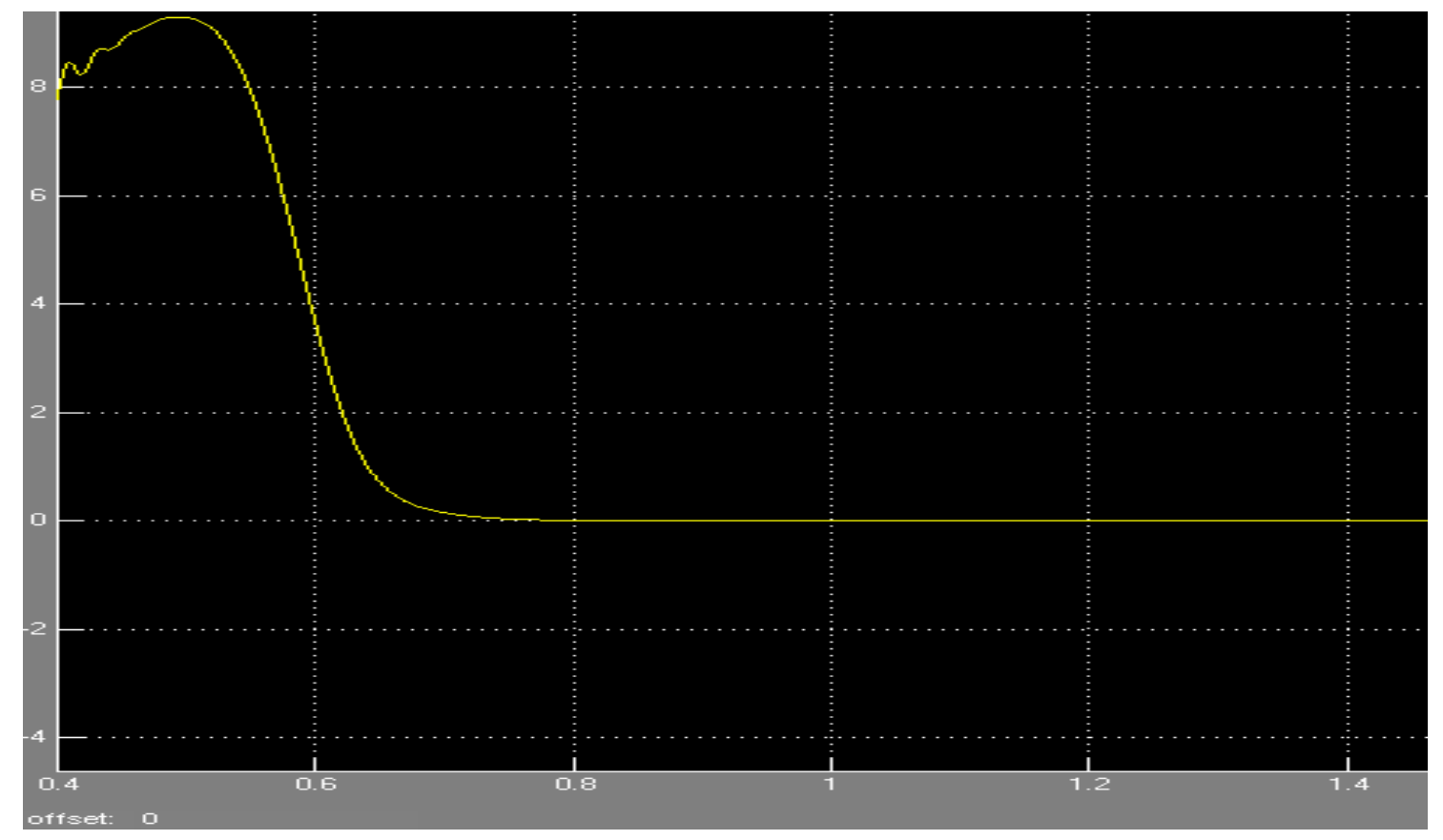

a).

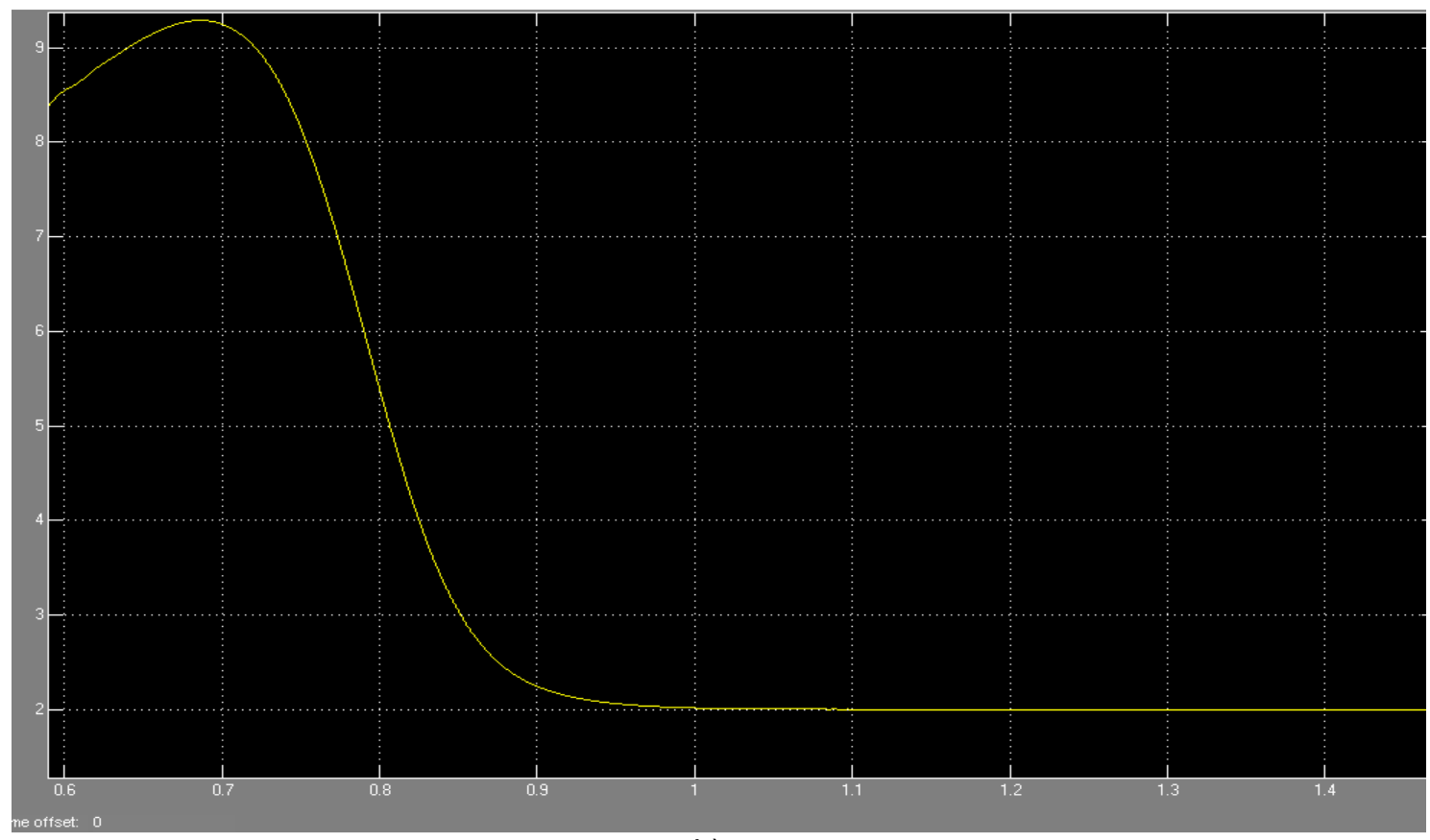

b).

Fig.3.5 Electromagnetic torque at steady state $(\mathrm{N}-\mathrm{m})$ vs. time (sec). a). Load torque $=0 \mathrm{~N}-\mathrm{m}$. b). Load torque $=2 \mathrm{~N}-\mathrm{m}$ 
Fig. 3.4 and Fig. 3.5 clearly show that at steady state, rotor speed decreased as load torque increased and electromagnetic torque became equal to load torque. Thus, it can be safely concluded that SQIM was modeled correctly in SIMULINK.

3.2.2.2 Studying Rotor Imbalance using SQIM model of Section 3.2.2.1

Having verified the SQIM model in Section 3.2.2.1, next step is to use it to find out whether rotor imbalance changes stator currents in the same manner as pointed out in literature. However, the more important objective is to find out the cause for such a change. To accomplish these objectives, imbalance torques of peak value $0 \mathrm{~N}-\mathrm{m}, 0.1 \mathrm{~N}-\mathrm{m}$ and $0.2 \mathrm{~N}-\mathrm{m}$ are impressed over a constant load torque of $1 \mathrm{~N}-\mathrm{m}$ (in accordance with the expression of load torque in Section 3.2.1.6). Spectrum of the resulting stator current is then analyzed to see if it changed from no imbalance situation. The spectrum is shown in Fig. 3.6. From this figure it can be seen that fs $\pm f r$ frequency components in the stator current spectrum changed as the rotor imbalance was introduced. Therefore, as reported in literature, these components can be used to detect rotor imbalance.

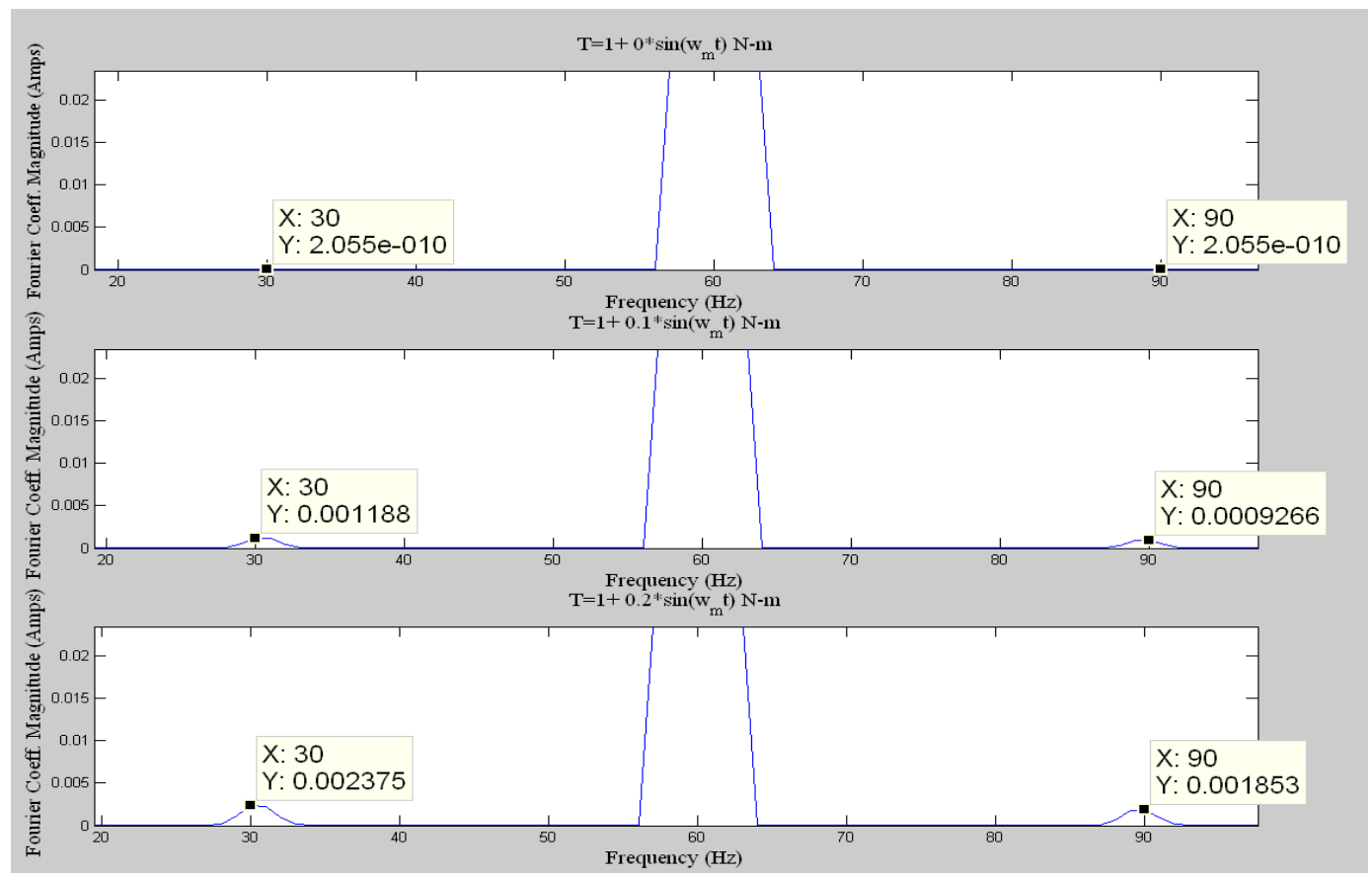

Fig. 3.6 Stator current spectrum under different degrees of imbalance 
While rotor imbalance signatures are now confirmed, it is still not clear as to what is going on inside the motor that causes these signatures to appear. To understand this, it is important to realize that in an induction machine electro-magnetic torque, rotor speed, rotor m.m.f and stator m.m.f are interrelated. Fig. 3.6-3.10 lend support to this assertion. Using these figures, an explanation is now given about the interactions that take place in a SQIM (or any other induction machine) to produce rotor imbalance signatures in stator current.

From Fig. 3.7 it is clear that, rotor imbalance induced oscillation in load torque causes 'fr' $\mathrm{Hz}$ oscillation to get superimposed on electromagnetic torque of the machine; magnitude of oscillation is proportional to the degree of imbalance. This causes ' $\mathrm{fr}$ ' $\mathrm{Hz}$ oscillation to appear in steady state rotor speed as well (Fig. 3.8). Since frequency of current induced in rotor depends on rotor speed, 'fr' $\mathrm{Hz}$ oscillation appears in the rotor current. This is demonstrated by Fig. 3.9 which shows spectrum of Phase A of rotor current referred to the rotor. Rotor currents when referred to the stator contain fs $\pm f r$ frequency components as shown in Fig. 3.10.

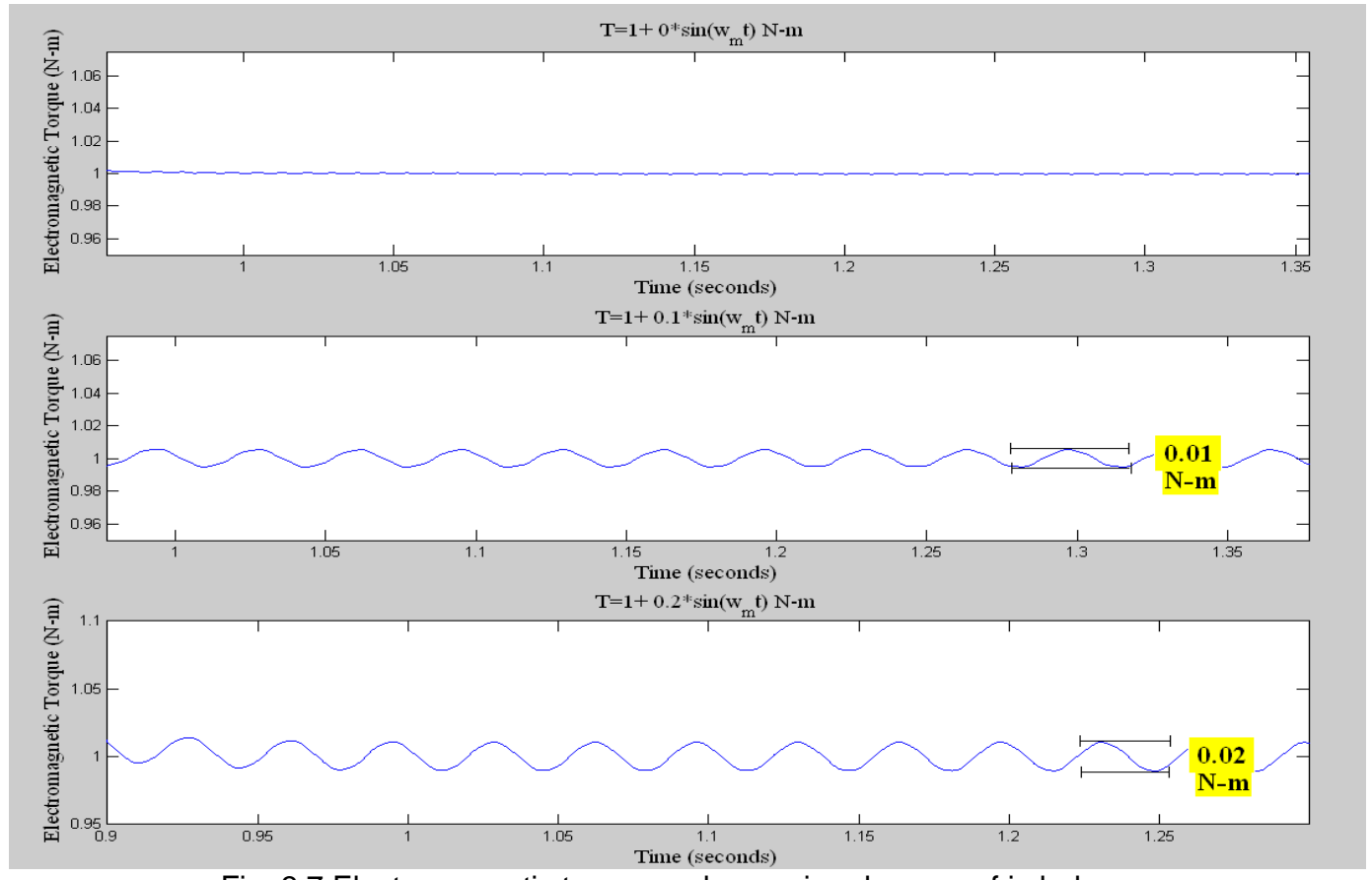

Fig. 3.7 Electromagnetic torque under varying degrees of imbalance 


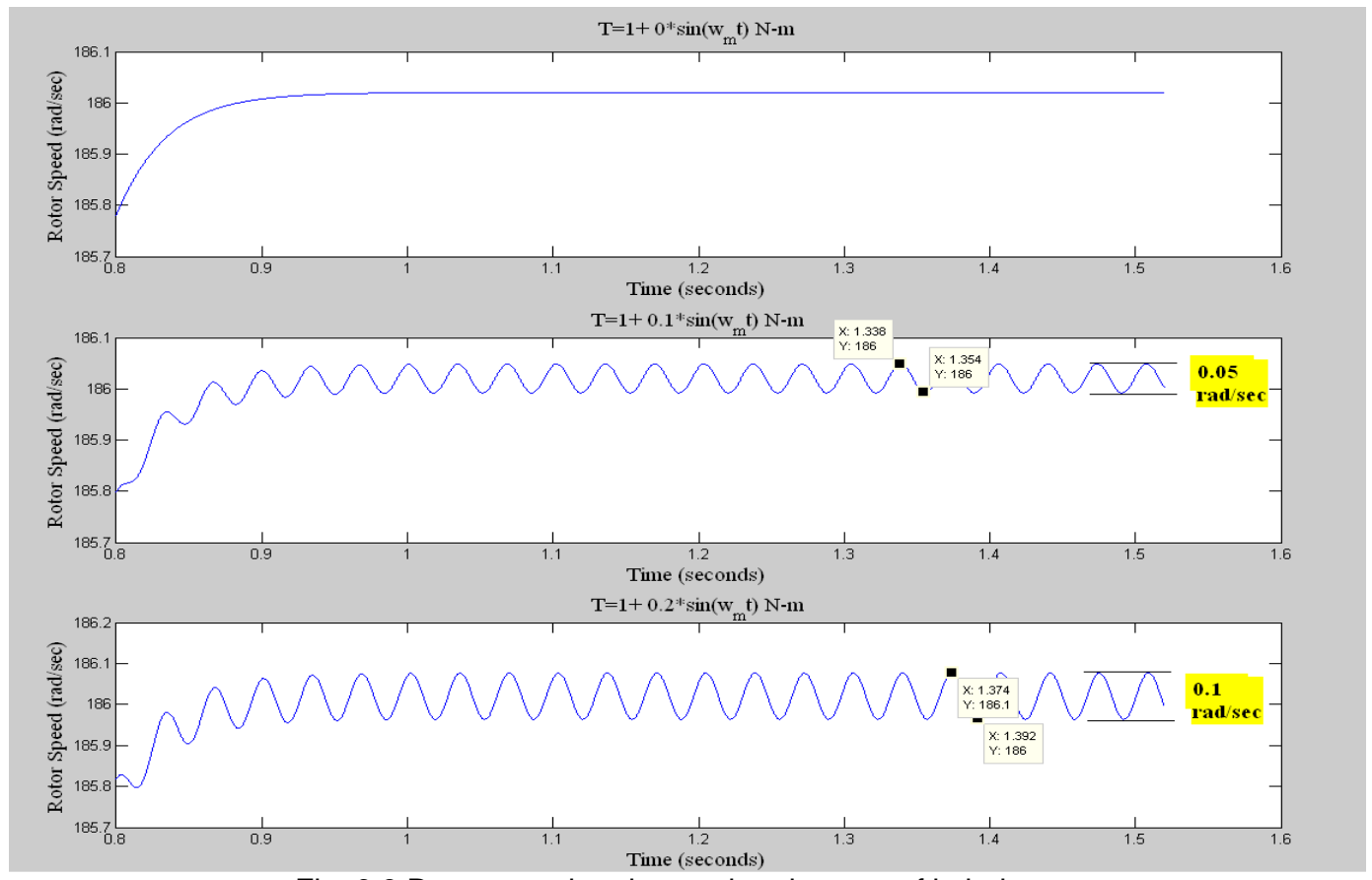

Fig. 3.8 Rotor speed under varying degrees of imbalance

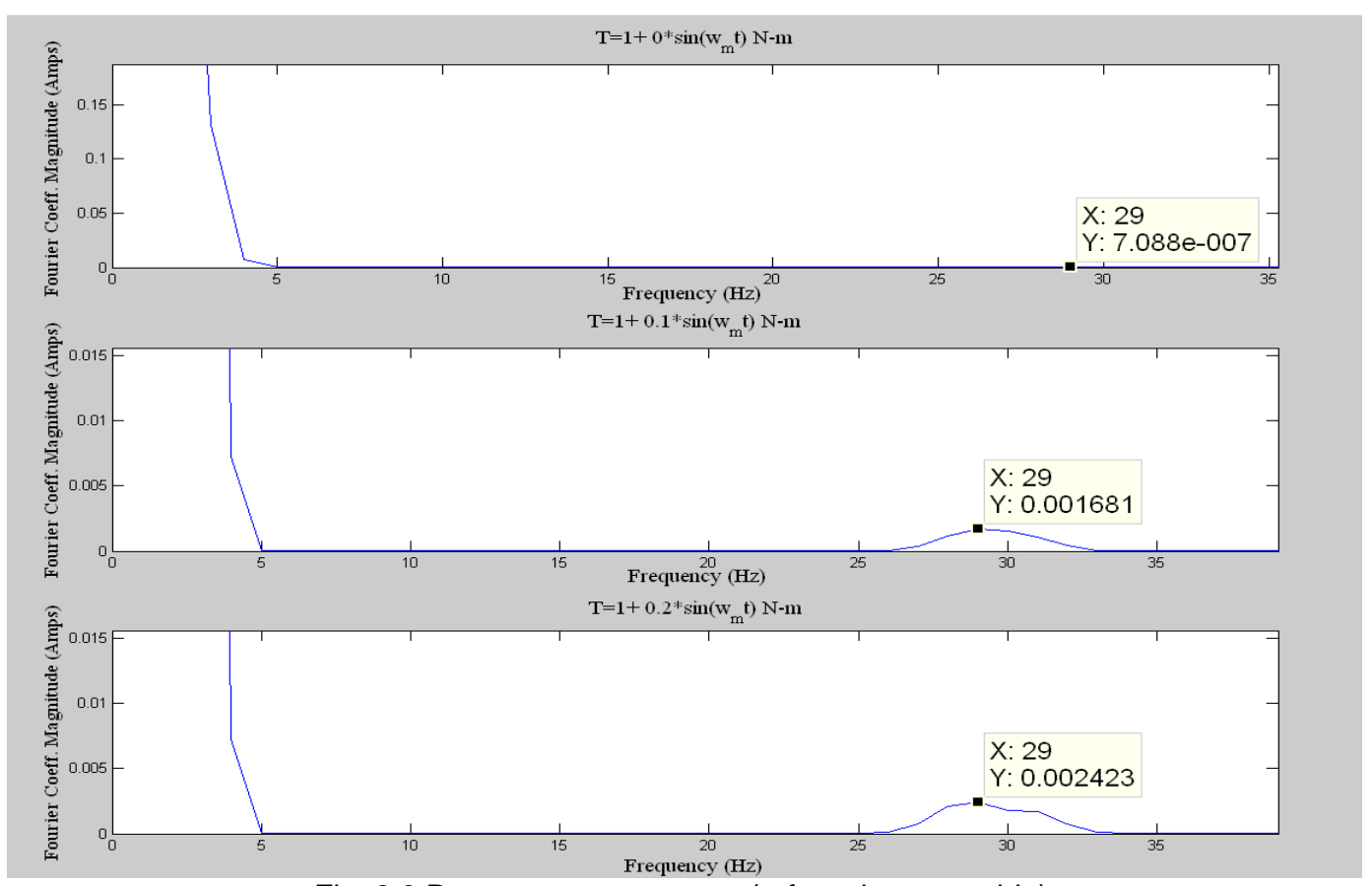

Fig. 3.9 Rotor current spectrum (referred to rotor side) under varying degrees of imbalance 


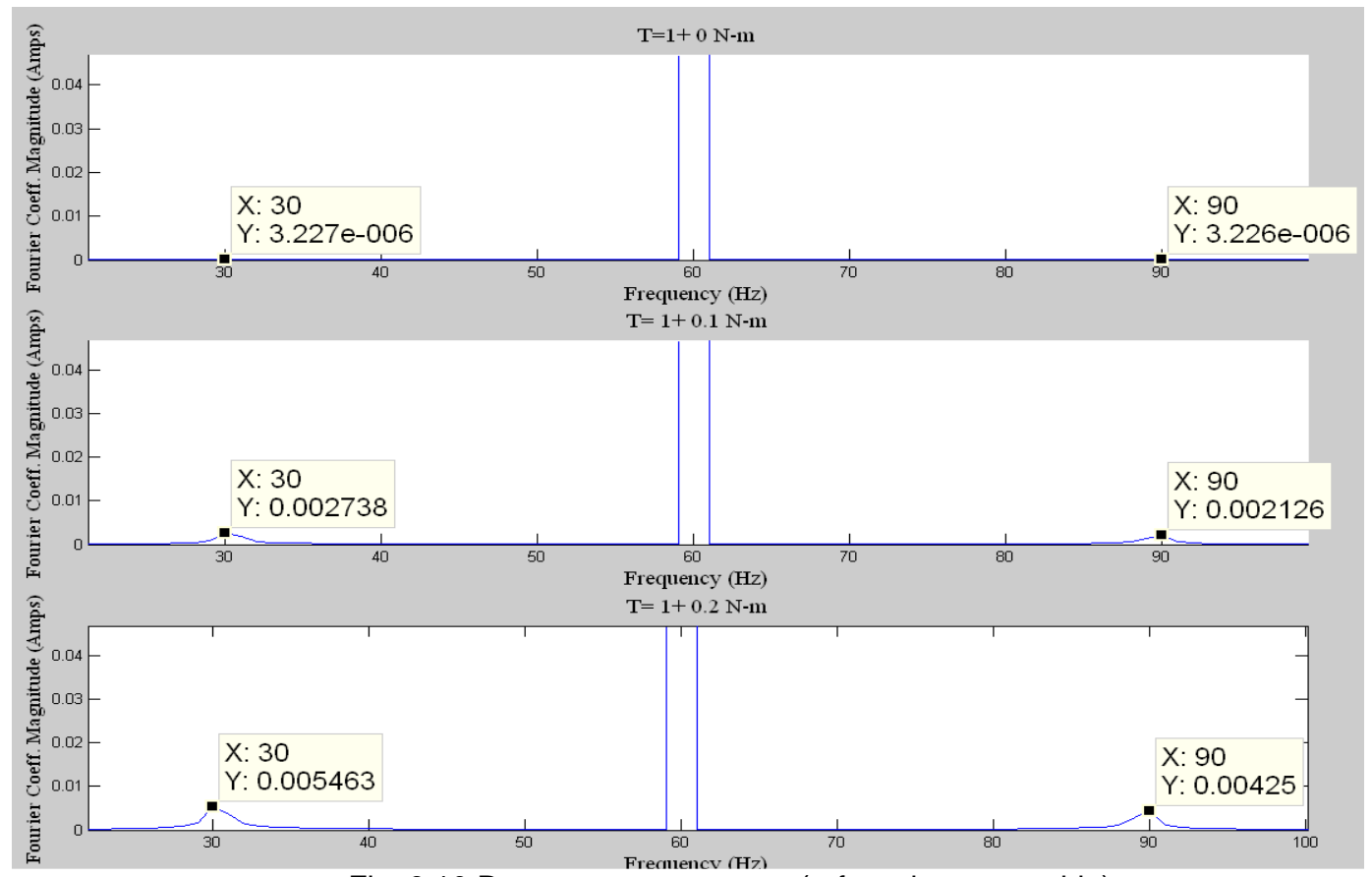

Fig. 3.10 Rotor current spectrum (referred to stator side) under varying degrees of imbalance

Since rotor flux contains the same frequency components as the rotor currents, it induces voltages in the stator that contain fs \pm fr frequency components (eqn $3.29 ; i_{r d}$ is equal to $i_{r a}$, rotor current referred to stator side, when zero sequence current is zero). These induced voltages cause fs \pm fr frequency components to appear in the stator current as well (Fig. 3.6).

\subsubsection{Conclusion}

In Sections 3.2.1 and 3.2.2, methods for modeling SQIM under rotor imbalance and solving the resulting equations were presented. These methods helped obtain a clear understanding of the effect of rotor imbalance on operation of SQIM. Using them it was conclusively proved that fs \pm fr frequency components are valid signatures of rotor imbalance. Further, the interactions in a SQIM that generate these signatures also became clear. In addition, Fig. 3.6 made it clear that a trend exists between magnitude of Fourier coefficients of fs $\pm f r$ frequency components and degree of rotor imbalance. Hence, these components may be used to determine rotor imbalance severity. This last statement is the motivation for Section 3.3, 
where methods of utilizing fs \pm fr frequency components in determining severity of rotor imbalance are discussed.

\subsection{Methods for Rotor Imbalance Severity Determination:}

ANFIS and Dempster Shafer Theory

In Section 3.2.2.2, it was shown (Fig. 3.6) that rotor imbalance fault signature in the stator current increased with imbalance. Due to the assumptions made in modeling SQIM, the trend in fault signatures was found to be linear (Fig. 3.6). Hence, based on simulation results, determining degree of imbalance appears to be a trivial task. In an actual motor, however, nonidealities are invariably present (winding asymmetries, unbalanced voltages in distribution system, inherent rotor imbalance, static eccentricity, etc). These non-idealities may cause the trend to deviate from linearity. Moreover, due to random factors such as supply variations, environmental noise, etc, sensors may report different values of signatures for same degree of imbalance. Therefore, techniques are needed that may determine the trend of rotor imbalance severity using such features. Further, as pointed out in Chapter 2, decision regarding rotor imbalance severity would be more reliable and accurate if imbalance information from the three phases is combined. Hence, to incorporate the above requirements in an imbalance severity determination scheme, two methods are presented here. These are Adaptive Network Based Fuzzy Inference System (ANFIS) and Dempster Shafer (DS) Theory. The motivation for using these methods and their main features are now briefly discussed in Sections 3.3.1 and 3.3.2.

\subsubsection{Adaptive Network Based Fuzzy Inference System (ANFIS).}

Fuzzy Inference Systems (FIS) have proved to be very useful in modeling imprecise systems. They allow qualitative aspects of human reasoning to be incorporated in modeling a system without employing precise quantitative analysis. However, these systems have come in for criticism [34] because no standard methods exist for transforming human knowledge or experience into the rule base and database of a fuzzy inference system. It is precisely this lacuna of FIS that ANFIS tends to address. 
ANFIS was first introduced in a seminal paper [34] by Jyh-Shing Roger Jang. Since then, this method has been used in several applications such as control, prediction, inference and modeling. The architecture of ANFIS is given in Fig. 3.11 for a simple two input single output system [34].

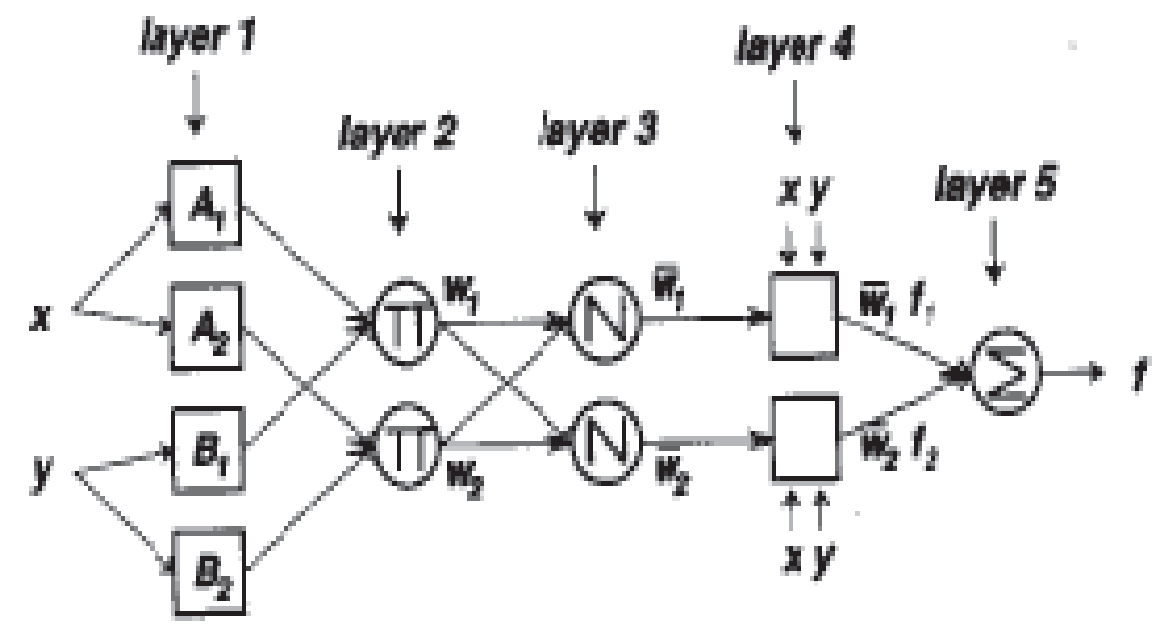

Fig. 3.11 ANFIS Architecture [34]

Layers in Fig. 3.11 perform the following functions:

Layer 1: It comprises of input membership functions that fuzzify the inputs. The shape of membership functions is described by set of parameters known as premise parameters.

Layer 2: This layer comprises of rule base. Fuzzified inputs are combined according to rules in this layer to determine the firing strength of each rule.

Layer 3: This is a normalization layer as indicated by symbol ' $N$ ' in Fig. 3.11. It normalizes the firing strength of each rule by dividing it with the sum of firing strengths of all rules.

Layer 4: The normalized firing strengths from Layer 3 are transformed in this layer by a node function whose parameters are called as consequent parameters.

Layer 5: This layer sums up all outputs from Layer 4 to generate a single crisp output. 
While above architecture is similar to that of any other FIS, what makes ANFIS different is the 'AN' part of its acronym. As mentioned above, ANFIS architecture contains a set of tunable premise and consequent parameters. In ANFIS, these parameters can be automatically updated using input-output data according to a hybrid learning rule. Hybrid learning rule transforms the given input-output relationship into another relationship such that the parameters defining the original relationship may be separated into linear and non-linear parameters. The motivation is to determine linear parameters by Least Squares Method in the forward pass and non-linear parameters by Gradient Descent method in the backward pass. The method is iterated over till some convergence criterion is met. This method is explained in great detail in [34].

From this discussion, it is clear that ANFIS solves the problem of FIS highlighted earlier. Input membership functions may initially be chosen according to human experience and then ANFIS may be used to fine tune these membership functions according to the hybrid rule. In case only input-output data is available, ANFIS input membership functions may be initialized using various techniques such as subtractive clustering or fuzzy-c-means clustering. After learning is complete, modified membership functions and rules are obtained that provide insight into the underlying relationship between inputs and outputs.

ANFIS, therefore, is a great tool to visualize how inputs interact to produce outputs; unlike neural networks where such visualization is hidden in a 'black box'. Moreover, system specific information may be incorporated in the general membership functions assigned by an expert using input-output data. Since ANFIS determines a relationship by error minimization over all the input-output pairs, it can deal with data that has been corrupted by noise. Further, as evident from its architecture, ANFIS can theoretically have any number of inputs. Thus, combining information from multiple sensors is easy in ANFIS. It was for these reasons that ANFIS was used in determining rotor imbalance severity in this work. While details of how ANFIS was adapted to this work are given in Chapter 4, it must be noted that since no a priori 
information was available on the type and number of input membership functions, subtractive clustering [42] was used for initializing them.

\subsubsection{Dempster Shafer (DS) Theory.}

\subsubsection{Primary features and Important Definitions}

DS Theory is a mathematical theory of evidence. It was developed by Arthur P. Dempster and generalized later by Glen Shafer [35]. The main features of this theory as discussed in [36] are:

- It allows for the allocation of a probability mass to sets or intervals.

- It does not require an assumption regarding the probability of the individual constituents of the set or interval.

- It allows for combination of evidence obtained from multiple sources and modeling of conflict among them.

It is the last feature of this theory that motivated its application in determining rotor imbalance severity; since a combination of fault information from multiple sensors was desired for making a decision about imbalance severity.

While details of this theory may be found in [35], [36] and [37], it is important to discuss three functions that form the basis of this theory. These are the Basic Probability Assignment (BPA) function denoted by $m$, the Belief function denoted by $\mathrm{Bel}$ and the Plausibility function denoted by $P l$.

The BPA [30] defines a mapping of the power set (each subset of the power set is a hypothesis to which evidence must be assigned) to the interval between 0 and 1 , where the BPA of the null set is 0 and the summation of the BPAs of all the subsets of the power set is 1 . The value of the BPA for a given set $A$ (represented by $m(A)$ ), expresses the proportion of all relevant and available evidence that supports the claim that a particular element of $X$ (the universal set) belongs to the set $A$. The value of $m(A)$ pertains only to set $A$ and makes no additional claims about any subsets of $A$. 
From the BPA, the upper and lower bounds of an interval can be defined. This interval contains the precise probability of a set of interest (in the classical sense) and is bounded by two non additive continuous measures called Belief $(\mathrm{Bel})$ and Plausibility $(\mathrm{Pl})$. The lower bound Belief for a set $A$ is defined as the sum of all the basic probability assignments of its proper subsets $(B)$ of the set of interest $(A)(B \subseteq A)$. The upper bound Plausibility is the sum of all the BPAs of the sets $(B)$ that intersect the set of interest $(A)(B \cap A \neq \emptyset)$. Formally, for all sets $A$ that are elements of the power set, $P(X)$

$$
\begin{aligned}
& \operatorname{Bel}(A)=\sum_{B \mid B \subseteq A} m(B) \\
& \operatorname{Pl}(A)=\sum_{B \mid B \cap A \neq \emptyset} m(B)
\end{aligned}
$$

The precise probability of an event lies within the lower and upper bounds of Belief and Plausibility, respectively. The probability is uniquely defined if $\mathrm{Bel}=\mathrm{Pl}$. This case corresponds to classical probability. Such a situation exists in this work and is explained further in Chapter 4.

\subsubsection{Dempster's Rule for Evidence Combination}

As highlighted in Section 3.3.2.1, evidence combination or sensor fusion is an important aspect of DS theory. Several techniques exist for this purpose [36], such as Dempster's Rule, Yager's rule, Inagaki's rule, Zhang's rule, Convolutive x- Average, etc. Depending upon the evidence, a particular rule may work better than others. Dempster's rule has been recommended for evidence combination whenever the evidence from different sources has small conflict. Since this was the case in this work (reason is given in Chapter 4), Dempster's rule was used here.

Dempster's rule combines multiple belief functions through their BPAs. These belief functions are defined on the same frame of discernment, but are based on independent sources of evidence. The Dempster rule is purely a conjunctive operation (AND). The combination results in a Belief function based on conjunctive pooled evidence [36]. Specifically, the 
combination (called the joint $m_{12}$ ) is calculated from the aggregation of two BPAs $m_{1}$ and $m_{2}$ in the following manner:

$$
\begin{aligned}
& m_{12}(A)=\frac{\sum_{B \cap C=A} m_{1}(B) m_{2}(C)}{1-K} \quad \text { when } A \neq \varnothing \\
& \text { where, } m_{12}(\varnothing)=0 \text { and } K=\sum_{B \cap C=\varnothing} m_{1}(B) m_{2}(C)
\end{aligned}
$$

'K 'Represents basic probability mass associated with conflict. This is determined by the summing of BPAs of all sets where the intersection is null. Dempster's rule is commutative, associative, but not idempotent or continuous. The denominator in Dempster's rule $(1-K)$ is a normalization factor. It has the effect of completely ignoring conflict and attributing any probability mass associated with conflict to the null set [36]. It is for this reason that this rule works best with low conflict evidence sets. Under high conflict, counterintuitive results are obtained as shown in [36].

From the above discussion, it is clear that before DS theory can be used to combine evidence, BPAs must be assigned to each hypothesis or interval for every source of evidence. This, however, is not an easy task, especially when no expert knowledge is available to determine BPAs for a hypothesis. Recently, Fuzzy C-means clustering has been proposed as an effective tool for assigning BPAs [35], [37]. Therefore, this technique is used in this thesis. What follows is a brief discussion on FCM clustering technique.

\subsubsection{Fuzzy C- Means (FCM) Clustering}

FCM clustering is an unsupervised clustering algorithm which can be applied successfully to several problems involving feature analysis, clustering and classifier design in fields such as astronomy, chemistry, geology, medical diagnosis, etc [35]. FCM algorithm partitions a data set $X=\left[x_{1}, x_{2}, \ldots ., x_{d}\right]^{T}$ into $c$ clusters by minimizing the objective function given by $J_{m}(u, v)=\sum_{i=1}^{c} \sum_{k=1}^{d} u_{i k}^{m}\left\|x_{k}-v_{i}\right\|^{2}$ subject to the constraint $\sum_{i=1}^{c} u_{i k}=1$. In this equation, $d$ is the number of samples in the vector $X, c$ is the number of clusters $(1 \leq c \leq d), u_{i k}$ is the element of the partition matrix $(c X d)$ containing the membership function, $v_{i}$ is the center of the 
$i^{\text {th }}$ cluster and $m$ is a weighting factor that controls the fuzziness of the membership function. The matrix $U$ is constrained to contain elements in the range $[0,1]$ such that $\sum_{i=1}^{c} u_{i k}=1$, for each $k \in[1, d] .\left\|x_{k}-v_{i}\right\|$ is the Euclidean 'distance' of a data point $x_{k}$ from cluster center $v_{i}$; in its place any other measure of 'distance' may also be used.

Minimization of the above expression of $J_{m}(u, v)$ is realized by an iterative procedure that involves the following steps [35]:

1. Choose the number of cluster centers $(c)$ and initialize each cluster center $\left(v_{i}\right)$.

At iteration number $l$,

2. Determine the membership value of each point in the data set $\left(u_{i k}(l)\right)$ using the following expression:

$$
u_{i k}(l)=\left(\sum_{j=1}^{c}\left(\frac{\left\|x_{k}-v_{i}(l)\right\|}{\left\|x_{k}-v_{j}(l)\right\|}\right)^{\frac{2}{m-1}}\right)^{-1}
$$

3. Calculate updated cluster center values vector $V^{t}(l)=\left[v_{1}(l), v_{2}(l), \ldots . v_{c}(l)\right]$ using:

$$
v_{i}(l)=\frac{\sum_{k=1}^{d} u_{i k}^{m} x_{k}}{\sum_{k=1}^{d} u_{i k}^{m}}
$$

4. If $\left\|V^{t}(l)-V^{t}(l-1)\right\|<\varepsilon$, then stop else repeat steps 2 to $4 . \varepsilon$ is a chosen positive threshold.

In this thesis, ' $f c m$ ' function of MATLAB was used for implementing the above algorithm. This function requires two inputs- data to be clustered and number of desired clusters. The syntax of this function is given below:

$$
\text { [Center, U, obj_fcn] = fcm (data, cluster_n) }
$$

, where 'Center' is a row vector of cluster centers, ' $U$ ' is an array contatining membership values for each cluster, 'obj_fcn' is the objective function to be minimized, 'data' is the data to be clustered and 'cluster_n' is the number of desired clusters.

Each column of the membership array $U$ contains degree of membership of a particular data element to a cluster. In context of DS theory, each cluster may be considered to 
be a hypotheses and membership corresponding to that cluster its BPA. Thus, the most important step in application of DS theory, i.e. initial BPA assignment, can be objectively accomplished using FCM clustering. It is for this reason that FCM clustering has been used in this thesis for initial BPA assignment. In the next chapter, FCM clustering based DS theory is applied to determine the degree of rotor imbalance.

\section{$\underline{3.4 \text { Conclusion }}$}

This chapter presented a method to model rotor imbalance in induction machines and also discussed two techniques that may be used to combine rotor imbalance information from three phase currents.

Section 3.2 developed a model of SQIM under rotor imbalance using space phasor theory. Using this model, three levels of rotor imbalance were simulated via SIMULINK. Simulation results helped verify the stator current fault features indicated in literature, and also gave a clear explanation of motor behavior that leads to the appearance of these fault signatures.

Similarly, section 3.3 gave the theory behind two intelligent classification techniques, ANFIS and FCM clustering based DS theory that may be used for performing sensor fusion. It became clear from the theory that these techniques could combine information from multiple inputs (sensors) and reach at decision (severity of rotor imbalance) using input information (fault features) that may be affected by noise.

Next chapter presents a test bed based approach to perform rotor imbalance diagnostics and simultaneously tests the performance of ANFIS and DS Theory in indicating severity of rotor imbalance via sensor fusion. 


\section{CHAPTER 4}

\section{TEST BED BASED APPROACH FOR ROTOR IMBALANCE DIAGNOSTICS}

\section{$\underline{4.1 \text { Introduction }}$}

As pointed out in chapter 1, any fault diagnostics scheme involves two steps. First step is to identify signatures of the fault being studied and the second is to use them to determine its severity. While the first step was accomplished in Chapter 3, where features for rotor imbalance fault were identified, the second step is yet to be accomplished. Moreover, it was shown in Chapter 1 that test bed approach in fault diagnostics holds an edge over legacy fault data based approach. This is especially true in case of rotor imbalance diagnostics as every machine has an inherent, but different level of rotor imbalance due to limitations of manufacturing process. Further, static eccentricity is also inherent in actual machines [15], [21] and it shows the same signatures in stator current spectrum as rotor imbalance. Therefore, a baseline must be determined for the target machine before any claim about the level of imbalance is made. Hence, a test bed based approach suits rotor imbalance diagnostics very well. This chapter presents a test based approach for rotor imbalance diagnostics, which determines the degree or severity of rotor imbalance by combining information from the three phases via ANFIS and DS Theory.

Section 4.2 gives a brief description of the test motor, current and vibration transducers, Data Acquisition apparatus and computer interfacing methodology used in the experiments. This section is followed by Section 4.3 that details the experimental set-up and tests performed for acquiring rotor imbalance signatures. In Section 4.4, utility of sensor fusion is brought out via a discussion on the trend observed in imbalance signatures obtained from the three phases. Section 4.5 demonstrates how imbalance signatures from the three phases may be combined by ANFIS and DS Theory to determine rotor imbalance severity. 


\subsection{Equipments used in Experiment}

\subsubsection{Test Motor}

The motor used in this work was a 1HP, Dayton-2Z007A 3-Ф, 2-pole, 3450rpm squirrel cage induction motor (SQIM). It had a 56HZ NEMA Frame, with Z implying an extended shaft. To create rotor imbalance in the motor, bolts of different weights were used. These bolts could be put on a balanced and detachable hub. Picture of hub with a bolt attached to it is shown in Fig. 4.1.

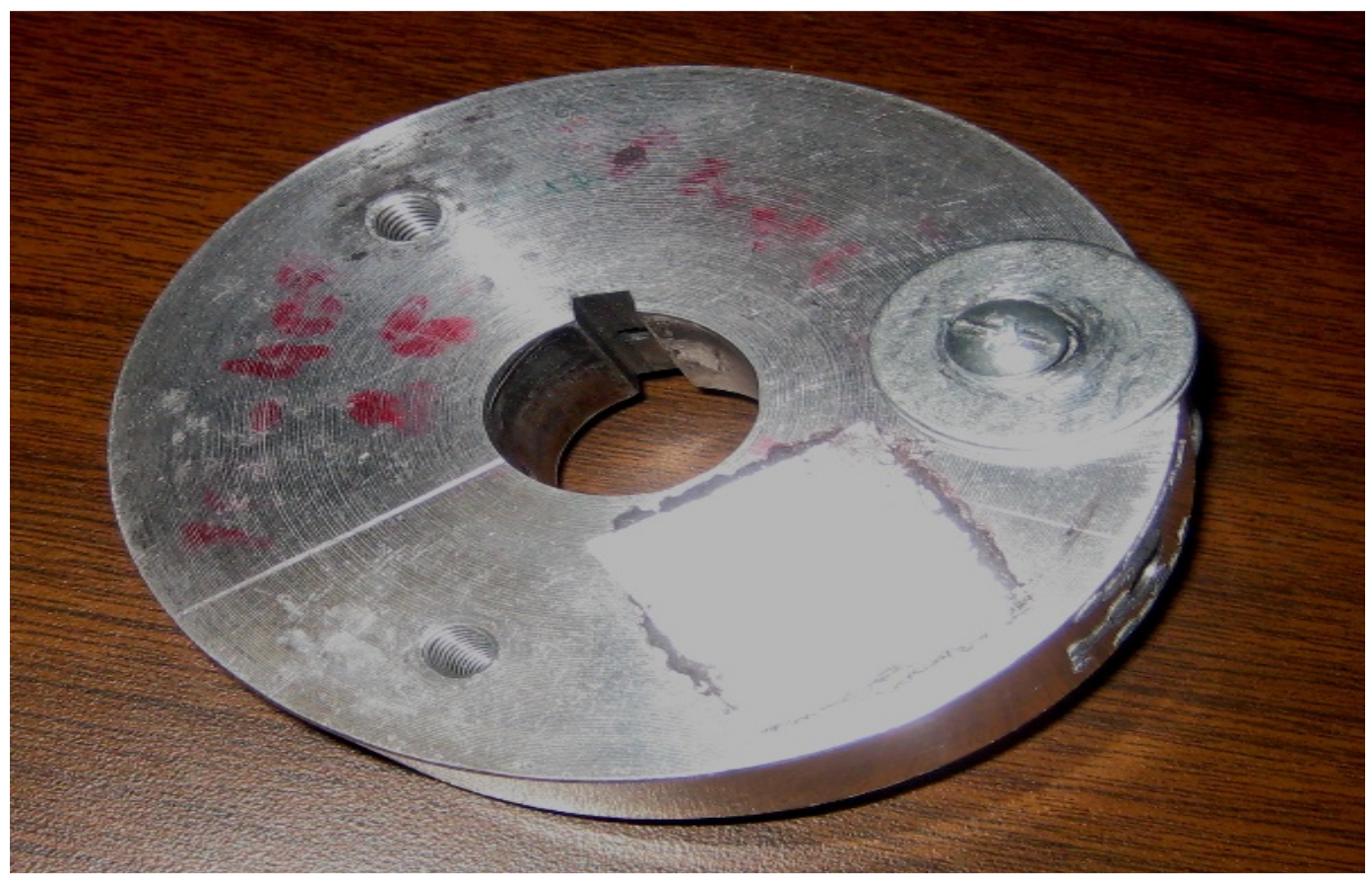

Fig. 4.1 Hub with bolt attached to it

\subsubsection{Current Transducers (Hall Effect Sensors)}

A Data Acquisition Card (DAQ) was used for acquiring current signals. Since the DAQ card accepts voltage input, a sensor was required to convert stator current into an equivalent voltage; Hall Effect Sensors were used for this purpose.

Tamura Corporation's L03S050D15 Hall Effect current transducers were used in this experiment. The primary reason for using these particular sensors was their high frequency response and rated output voltage of \pm 4 Volts that was well within the range of DAQ card used. 
Details of these sensors are given in the data sheet [38]. Picture of Hall Effect Sensors used is given in Fig. 4.2.

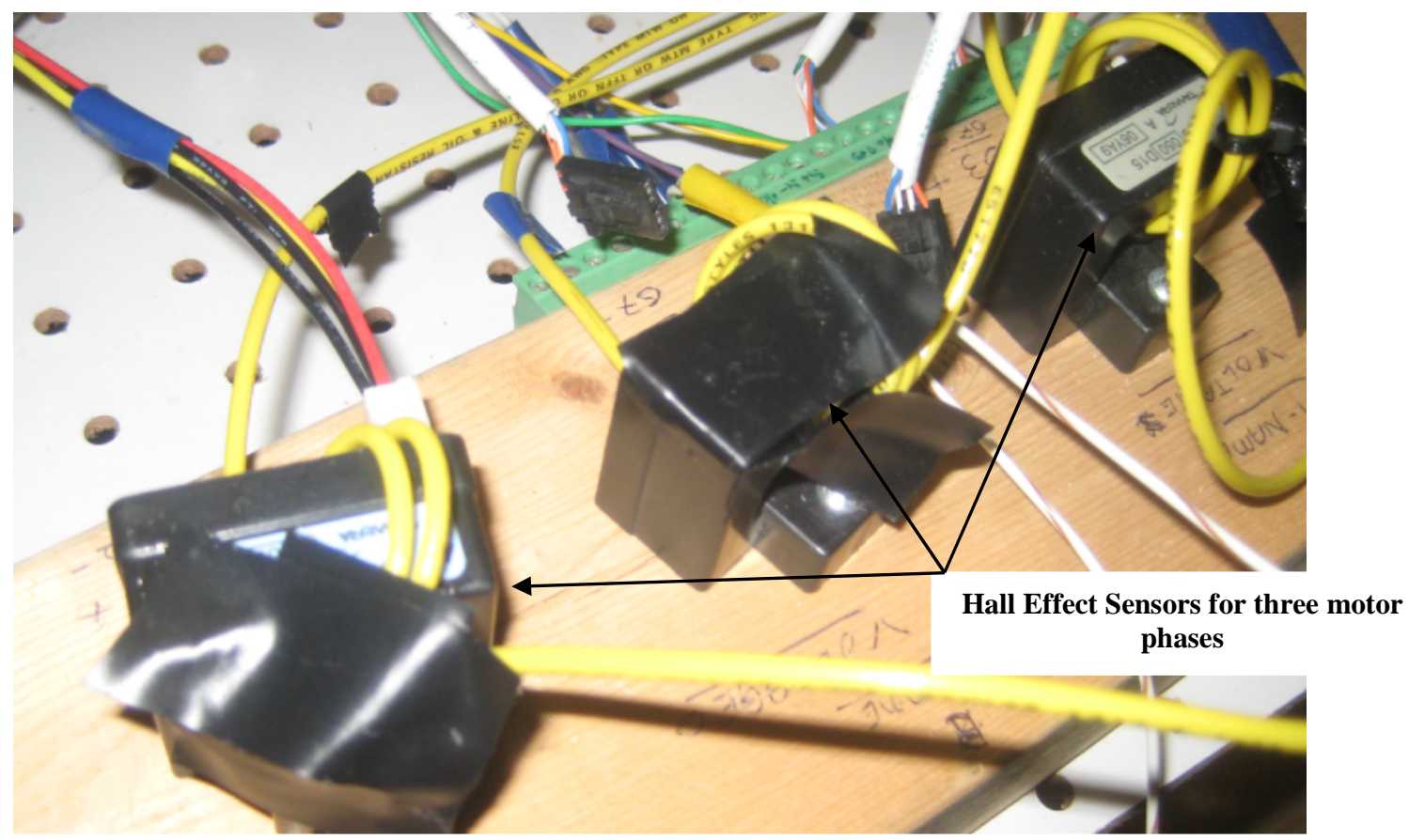

Fig. 4.2 Three Hall Effect sensors used in experiments

\subsubsection{Vibration Transducers (Accelerometers)}

It is natural to expect motor vibrations due to rotor imbalance. It is also obvious that vibrations will increase with an increase in rotor imbalance. Therefore, vibration fault features can be used to compare the performance of stator current fault features in rotor imbalance classification. It was with this intention that accelerometers were used to sense stator vibrations.

Analog Devices $\AA^{\prime}$ accelerometer-ADXL330 was used in this work. It is a MEMS tri-axial piezoelectric accelerometer. Vibration Force on the accelerometer produces a charge in the piezoelectric crystal which is converted into proportional output voltage by an internal circuitry. Though the frequency response of ADXL330 is limited to $1.6 \mathrm{KHz}$ along $\mathrm{X}$ and $\mathrm{Y}$ directions and $550 \mathrm{~Hz}$ along $\mathrm{Z}$ direction, this range is sufficient for all normal motor operations as they seldom 
operate at a supply exceeding $60 \mathrm{~Hz}$. Further details of ADXL330 can be found in the data sheet [39]. Fig. 4.3 shows the accelerometer mounted on the test motor.

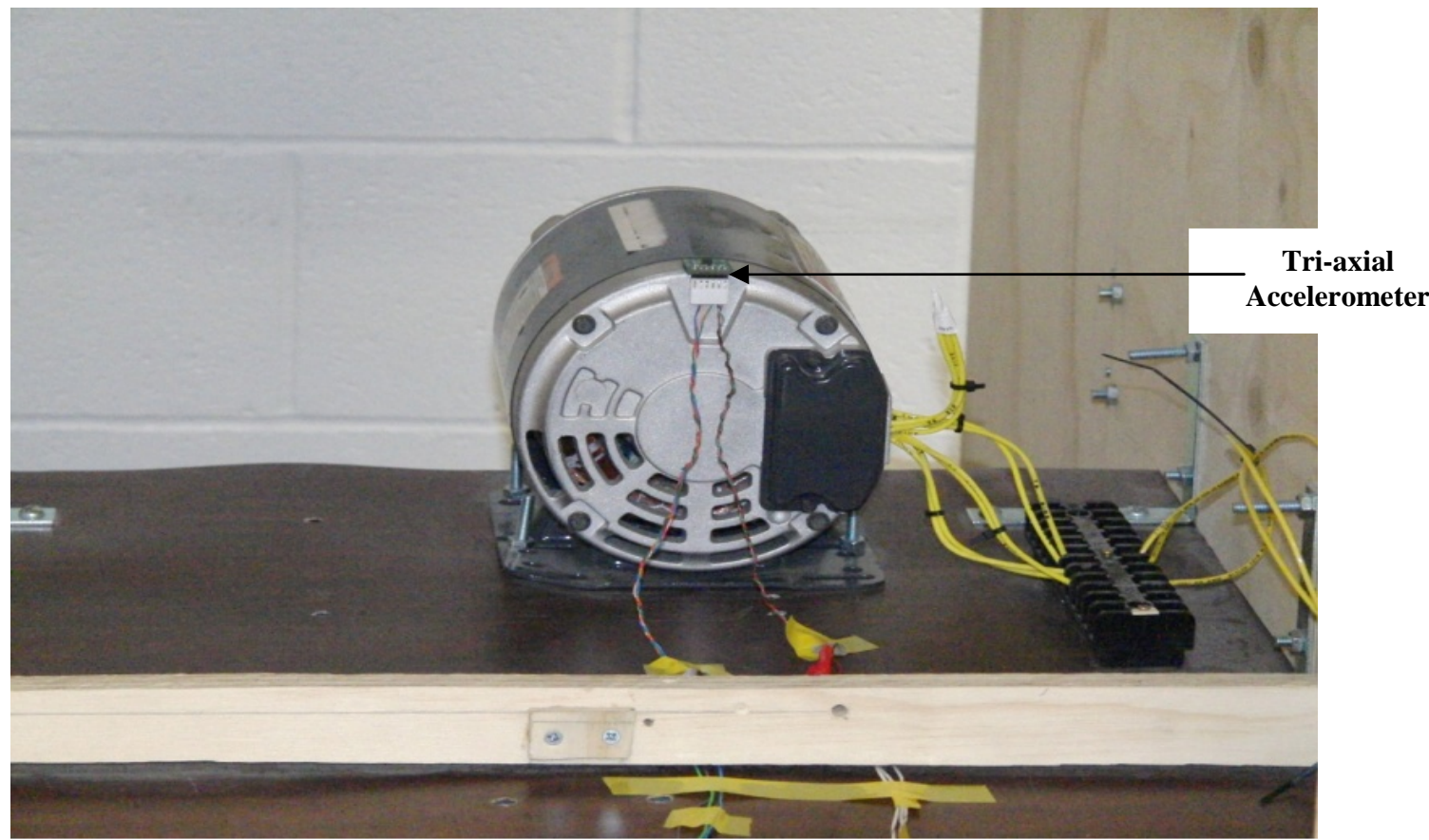

Fig. 4.3 Accelerometer mounted on the test motor

\subsubsection{Data Acquisition Devices and Computer Interface}

Before sensor data could be analyzed, it had to be acquired from the motor and saved in the computer. This was accomplished using National Instruments' SCB-68 Shielded Collector Block, PCI-MIO-16E4 (NI 6040E) DAQ card and LABVIEW 8.6.

\subsubsection{LABVIEW 8.6 Interface}

An interface was developed in LABVIEW 8.6 to acquire a user defined length of data. The data was then stored in a LABVIEW measurement file. This file was then converted into a text file using 'MATLAB script' Virtual Instrument (VI) block in LABVIEW. Name of the text file could be given by the user prior to starting the Data Acquisition process. The code in 'MATLAB script' VI was so written that it would search for the newest LABVIEW measurement file and convert it into a text file. This file could then be processed for determining fault features outside the LABVIEW environment. Instrument I/O, Programming and Mathematics functions of LABVIEW 
were used for creating the interface. The front panel of interface is shown in Fig. 4.4. Corresponding block diagram is shown in Fig. 4.5.

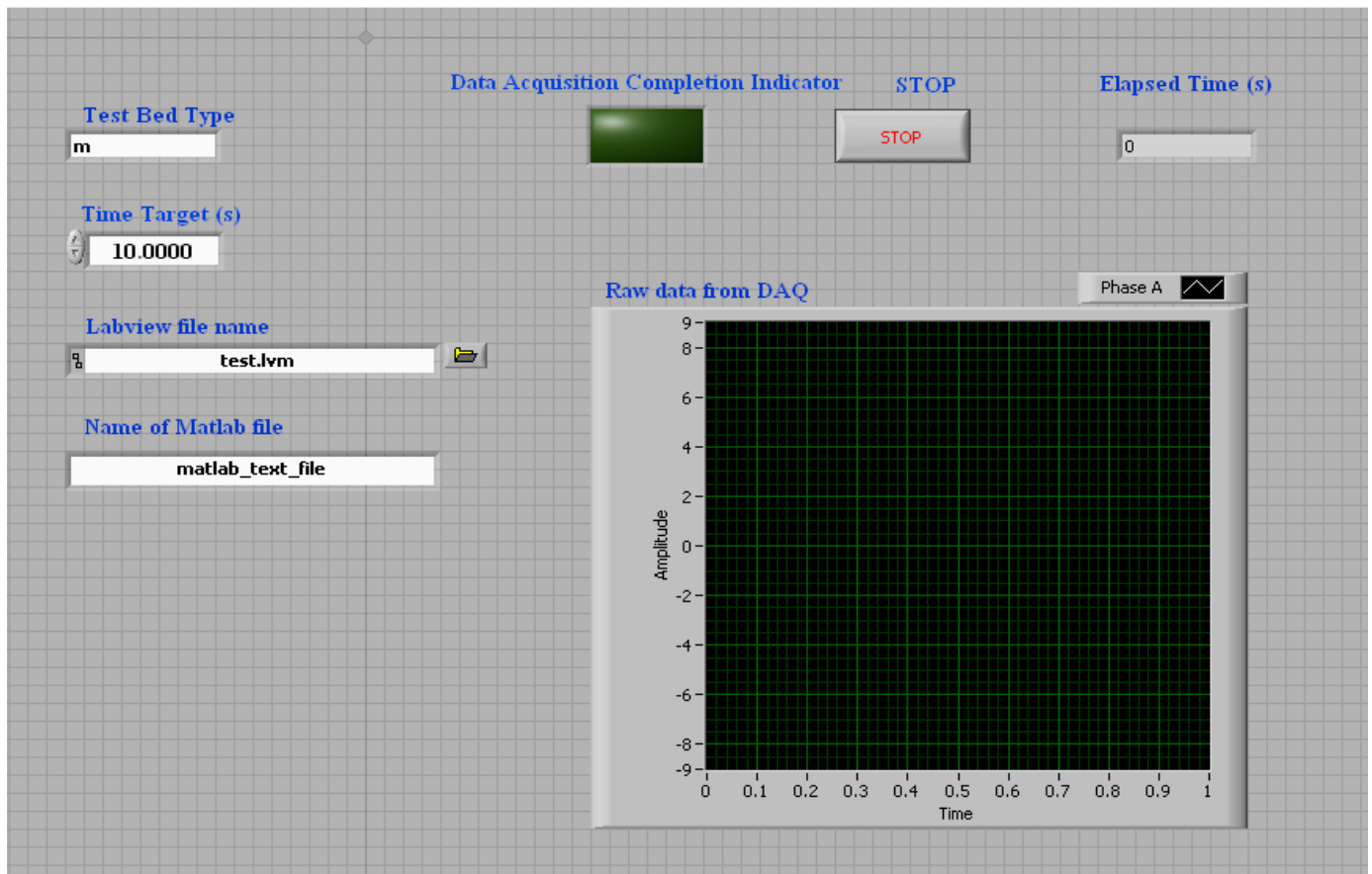

Fig. 4.4 Front panel of LABVIEW interface

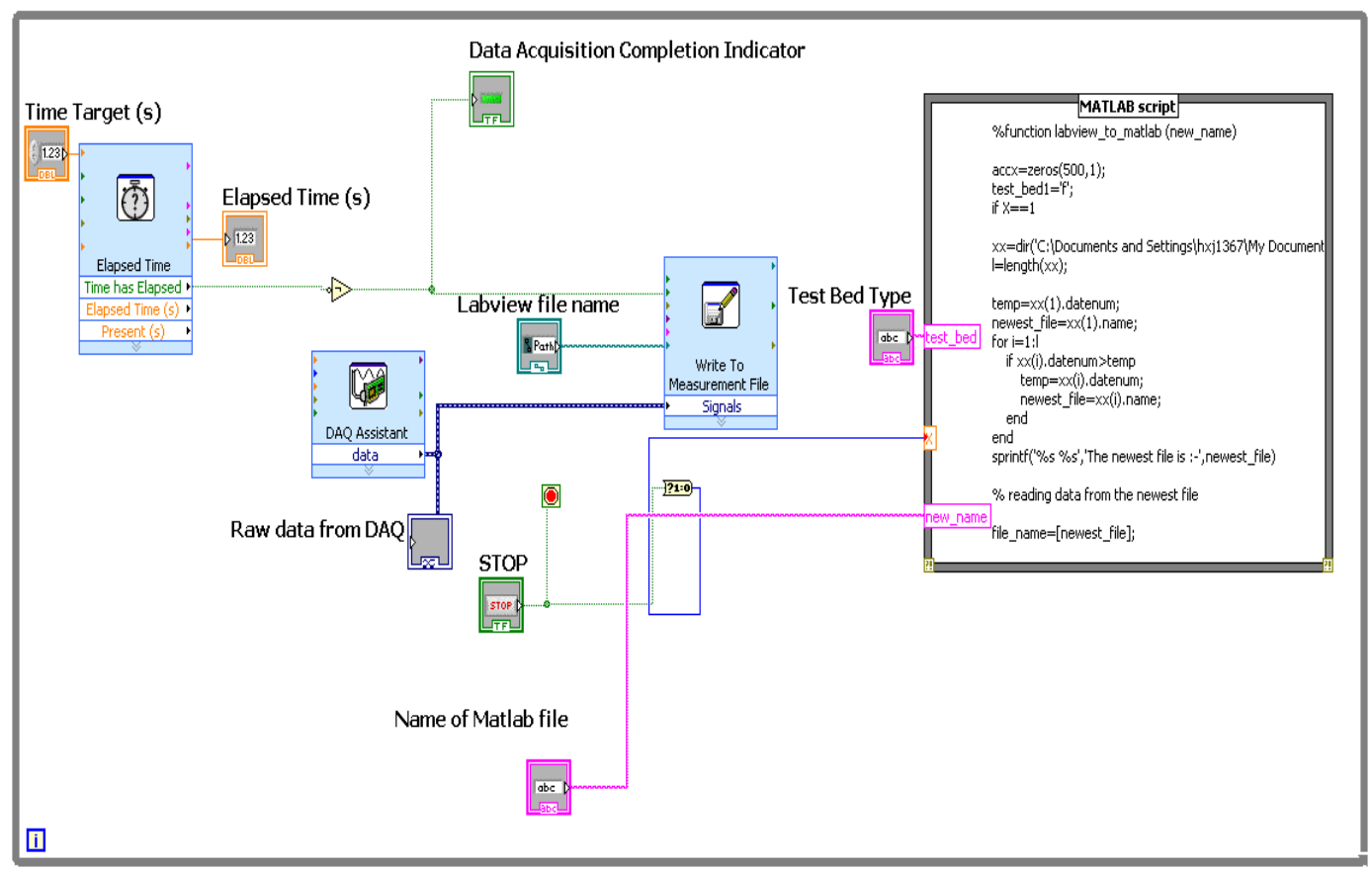

Fig. 4.5 Block diagram of LABVIEW interface 


\subsubsection{SCB-68 (Shielded Collector Block)}

SCB-68 is a shielded I/O connector block with 68 screw terminals for easy connection to a $\mathrm{NI}$ DAQ device. Depending on the Input signal type the location of connecting the signal on SCB68 changes. For example, in this work the output of Hall Effect Sensor was referenced to the power supply which in turn was connected to building ground. Hence the sensor output could either be connected as a Non Referenced Single Ended (NRSE) input or as a Differential input. However, the connection terminals would be different. SCB-68 as used in this work is shown in Fig. 4.6. Details of SCB-68 such as connection type recommendations for different inputs, location of channels for different supported DAQ cards, etc may be found in [40].

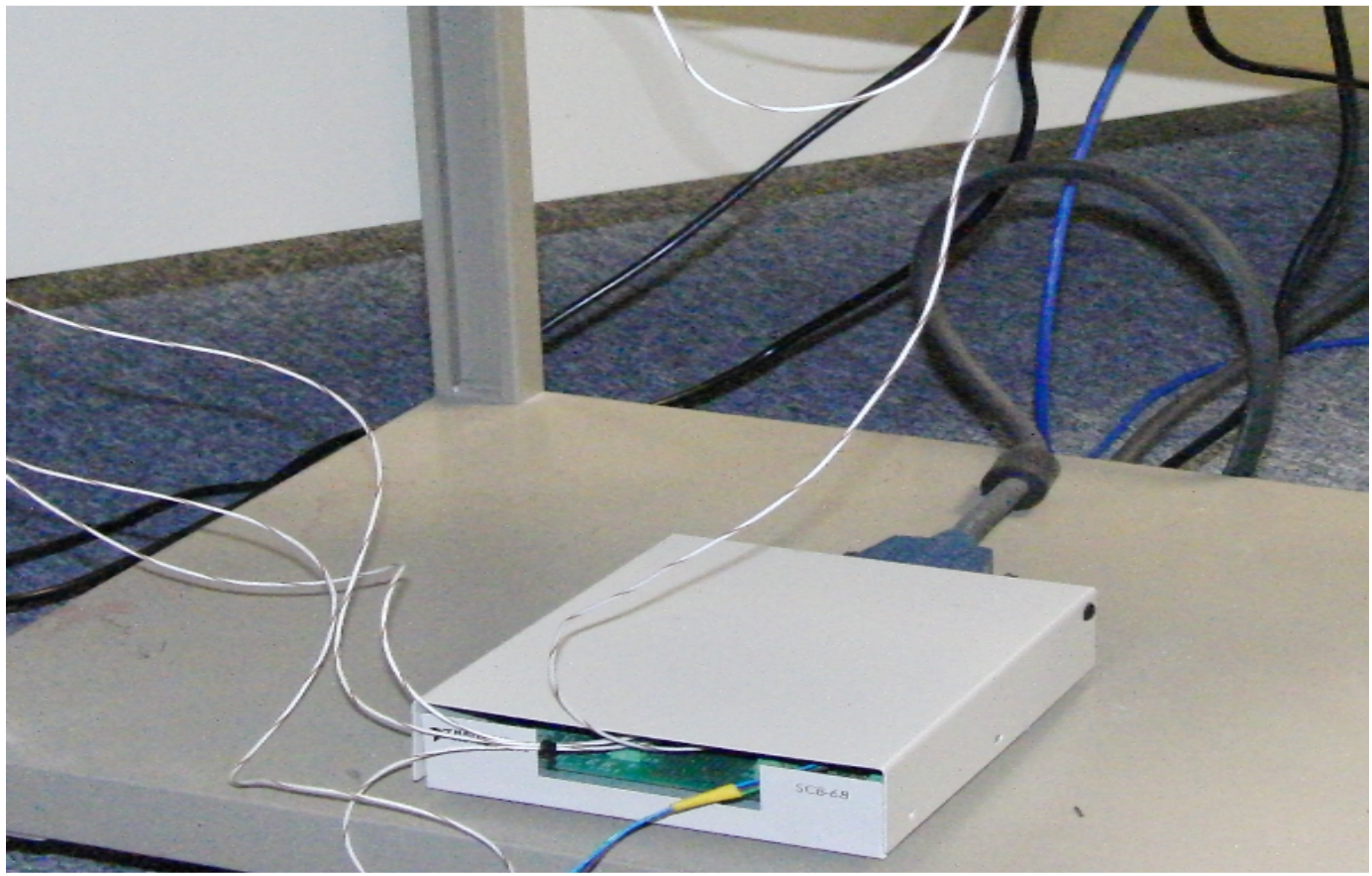

Fig. 4.6 Shielded Collector Block (SCB-68).

\subsubsection{NI PCI-MIO-16E4 (NI 6040E) DAQ Card}

This DAQ Card supports 16 Analog Channels (8 in differential mode as two channels make one differential channel) and has an input resolution of 12 bits. The maximum sampling rate is $500 \mathrm{~K}$ samples per second. The maximum value of input voltage that can be applied is $\pm 10 \mathrm{~V}$. Details of this card can be found in its manual [41]. 
In this work six analog channels of the DAQ card were used at a time. All the channels were configured for a sampling rate of $5 \mathrm{~K}$ samples per second. Three channels were configured as NRSE inputs for stator current measurement via Hall Effect Sensors while remaining three were configured in Referenced Single Ended (RSE) mode for measuring accelerometer output. The location of inputs on SCB-68 for the above channels was determined from the 'DAQ Assistant' VI block of LABVIEW.

\subsection{Experiment Set-up and Test Cases}

\subsubsection{Experiment Set-Up}

The schematic diagram of experiment set-up is shown in Fig. 4.7. Test motor could be fed directly from three phase mains supply or via a variable speed drive. A 15 amperes circuit breaker separated the motor from supply for protection purposes. Hall Effect sensors were placed on each phase of the motor to measure the stator current. In order to measure motor vibrations, the accelerometer was fixed to the motor frame with epoxy so that there was no relative motion between the accelerometer and the frame.

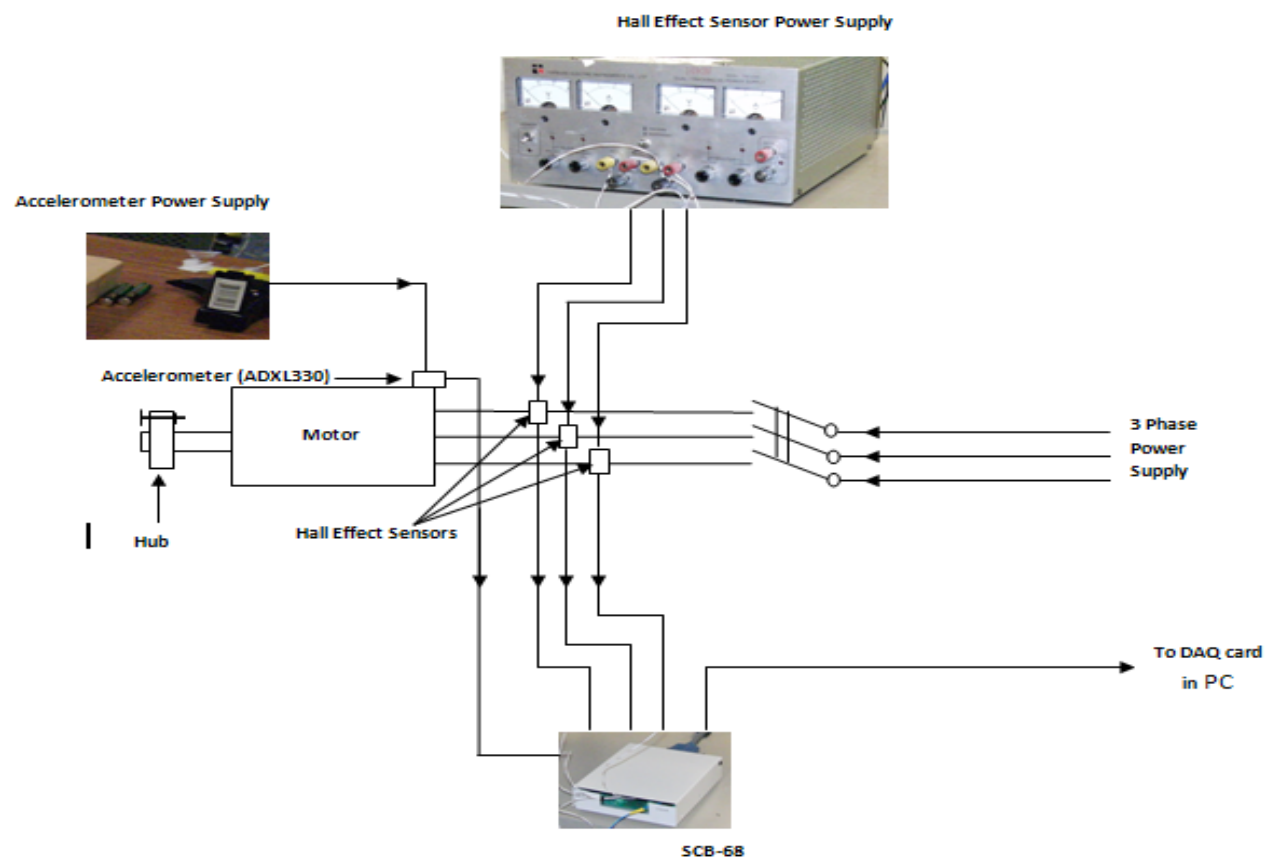

Fig. 4.7 Schematic diagram of experiment set-up. 
Hall Effect Sensors were fed from a bi-polar constant voltage power supply. A bi-polar supply was essential as Hall Effect Sensors used required an input of \pm 15 Volts. Similarly, the accelerometer also needed a power supply and $3 \mathrm{~V}$ batteries were used for this purpose. Outputs of all the sensors were brought into SCB-68 using as small a wire length as possible. This was done to reduce noise pickup. The output of SCB-68 was connected to DAQ card via a special shielded cable manufactured by National Instruments.

\subsubsection{Test Cases}

As mentioned in section 4.2, rotor imbalance was created using different weight bolts that were fixed to the hub. Four different levels of rotor imbalance were created using bolts of four different weights- $6 \mathrm{gm}, 11 \mathrm{gm}, 16 \mathrm{gm}$ and $21 \mathrm{gm}$. The idea here was to use the imbalance feature set so collected to determine the progression of rotor imbalance in the target machine by applying ANFIS and Dempster Shafer Theory.

One experiment set, therefore, comprised of five text files, one file for healthy motor (called 'Ogm' imbalance) and four files for rotor unbalanced with above mentioned weights. Each text file in turn was an array of 50000 rows and 6 columns. Three columns had stator current data while the other three columns had vibration data from the three axes of the accelerometer. Each column was 50000 data points in length as data was collected for a period of 10 seconds at a sampling rate of $5 \mathrm{~K}$ samples/second.

Twenty such experiment sets were prepared over a month. This was done to take into account random factors that are beyond control (mains supply variations, random noise in measurements, jitter in DAQ cards, etc). More confidence could therefore be placed on rotor imbalance severity classification based on these experiment sets.

\subsubsection{Fault Feature Extraction from Experiment Sets}

As demonstrated in the previous chapter, rotor imbalance manifests itself as ' $\mathrm{fs} \pm \mathrm{fr}$ ' frequency components in the stator current spectrum. In this work, however, only 'fs+fr' frequency component was used. This was done due to two reasons. Firstly, 'fs-fr' provides 
redundant information. Secondly, for a 2-pole motor 'fs-fr' lies very close to the dc value in frequency spectrum. Therefore, larger memory needs to be committed for increasing the resolution to extract this component.

As for vibration signals, while accelerometer provided vibration information for all the three axes, only $\mathrm{X}$ axis vibrations were processed as $\mathrm{Y}$ axis vibrations were not expected to increase with imbalance and $Z$ axis vibrations provided redundant information. Moreover, the role of vibrations here was only to verify the imbalance signature from stator currents for which $X$ axis vibrations were sufficient.

Therefore, four signals in each file of an experiment set were eventually processedthree phase currents and $\mathrm{X}$ axis vibration. Following procedure was adopted for extracting fault features from each of these four signals. Each signal in a file was divided into 10 bins of 1 second each (5000 elements) and the Fourier transform of each bin was taken. This step resulted in 10 columns of Fourier coefficients (5000 elements in length). In order to reduce the effect of random noise related frequencies, these 10 columns were averaged to give a single column of 5000 Fourier coefficients. Hence, each file in an experiment set was transformed into a $5000 \times 4$ array. Fig. 4.8 gives a schematic of the above procedure. 


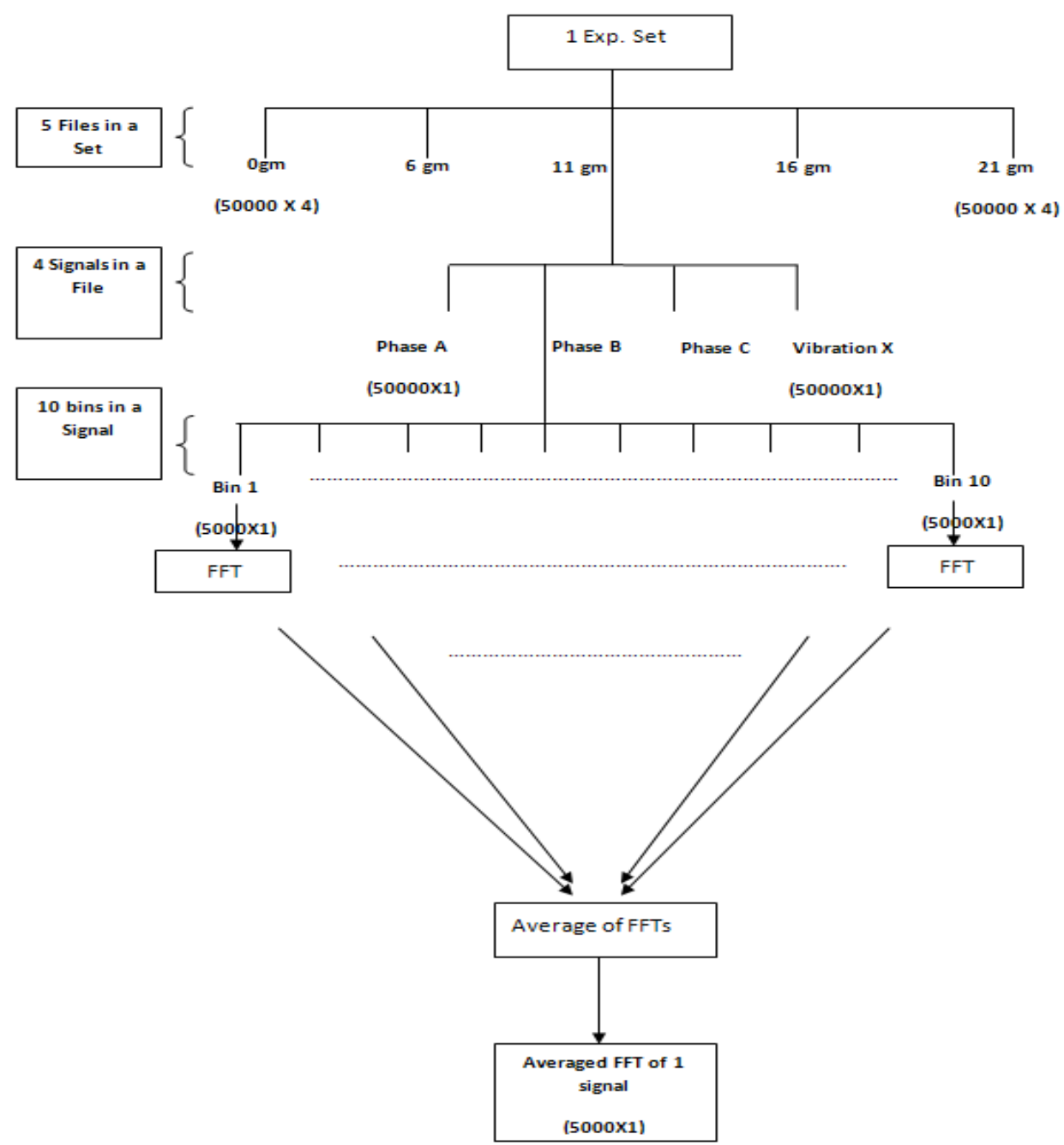

Fig. 4.8 Schematic diagram explaining fault feature extraction procedure

Since the frequency component of interest was 'fs+fr' for stator currents and ' $f r$ ' for $\mathrm{X}$ axis vibrations, maximum value of Fourier Transform magnitude in the range $2^{\star} \mathrm{fs}$ to $2^{\star} \mathrm{fs}-5 \mathrm{~Hz}$ was extracted from the stator current spectrum while maximum value in the range fs to fs- $5 \mathrm{~Hz}$ was extracted for $\mathrm{X}$ axis vibration spectrum. This was done due to two reasons. First, being a 2 pole motor 'fr' was nearly equal to 'fs' and second, rated slip of the motor was $2.5 \mathrm{~Hz}$ allowing $5 \mathrm{~Hz}$ bandwidth to cover the entire range of operation. In fact, $5 \mathrm{~Hz}$ bandwidth would suffice for most motors as the slip is seldom greater than $10 \%$. Thus, eventually each experiment set was 
converted into a $5 \mathrm{X} 4$ array of fault features; first three columns contained fault feature obtained from motor currents while the fourth column had $X$ axis vibration fault feature.

\subsection{Experiment Results}

Fig.4.9, 4.10 and 4.11 show the magnitude of Fourier coefficients for 'fs $+f r$ ' frequency component in stator current spectrum under different degrees of imbalance. Fig. 4.12 shows the trend in Fourier Coefficient magnitude for 'fr' frequency component in $\mathrm{X}$ axis vibration spectrum. This figure has been presented to compare the trend of vibrations with that of stator currents.
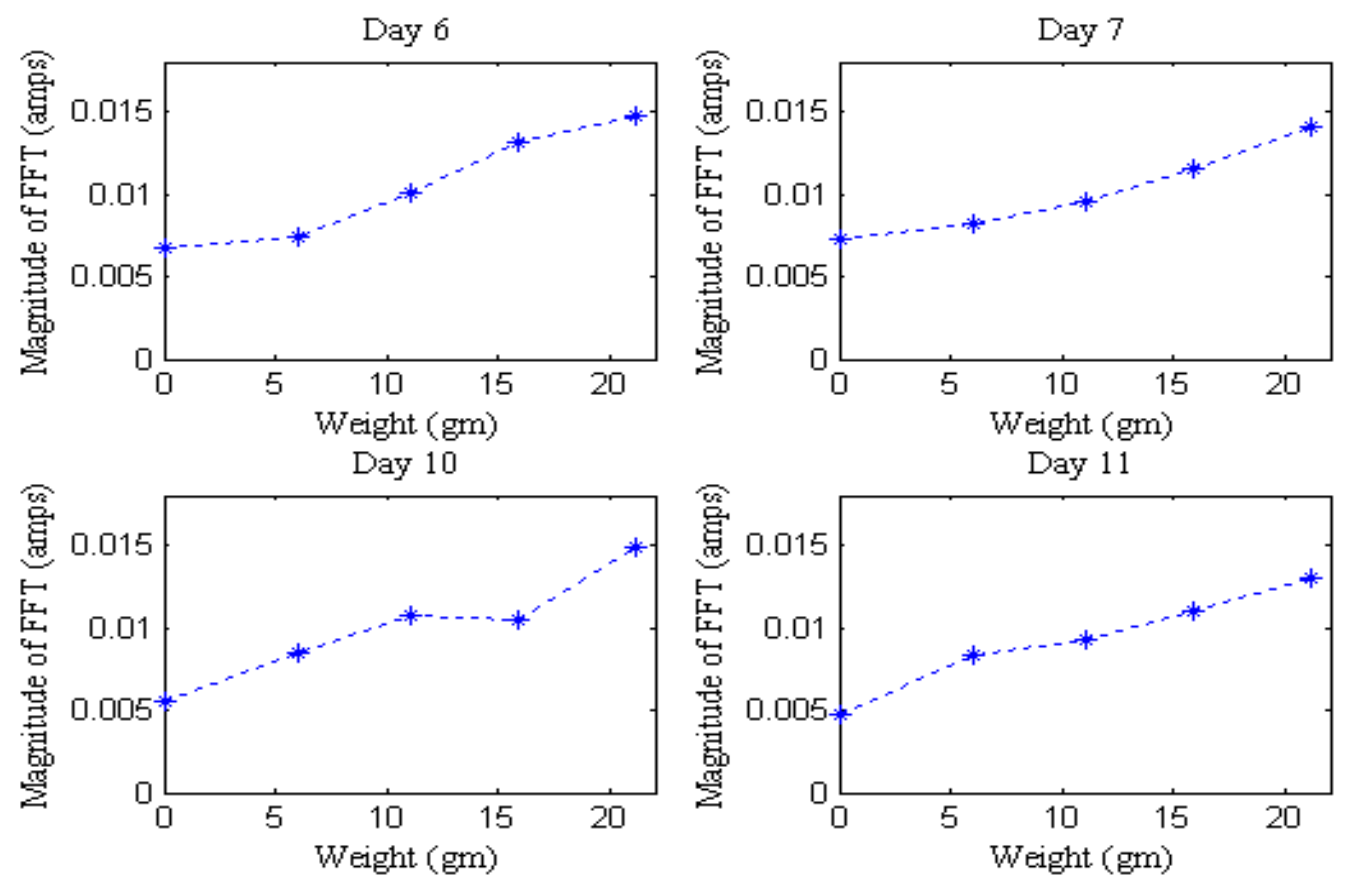

Fig. 4.9 Fourier coefficients for ' $f s+f$ ' frequency component in phase A current spectrum under different degrees of imbalance; 4 different days 

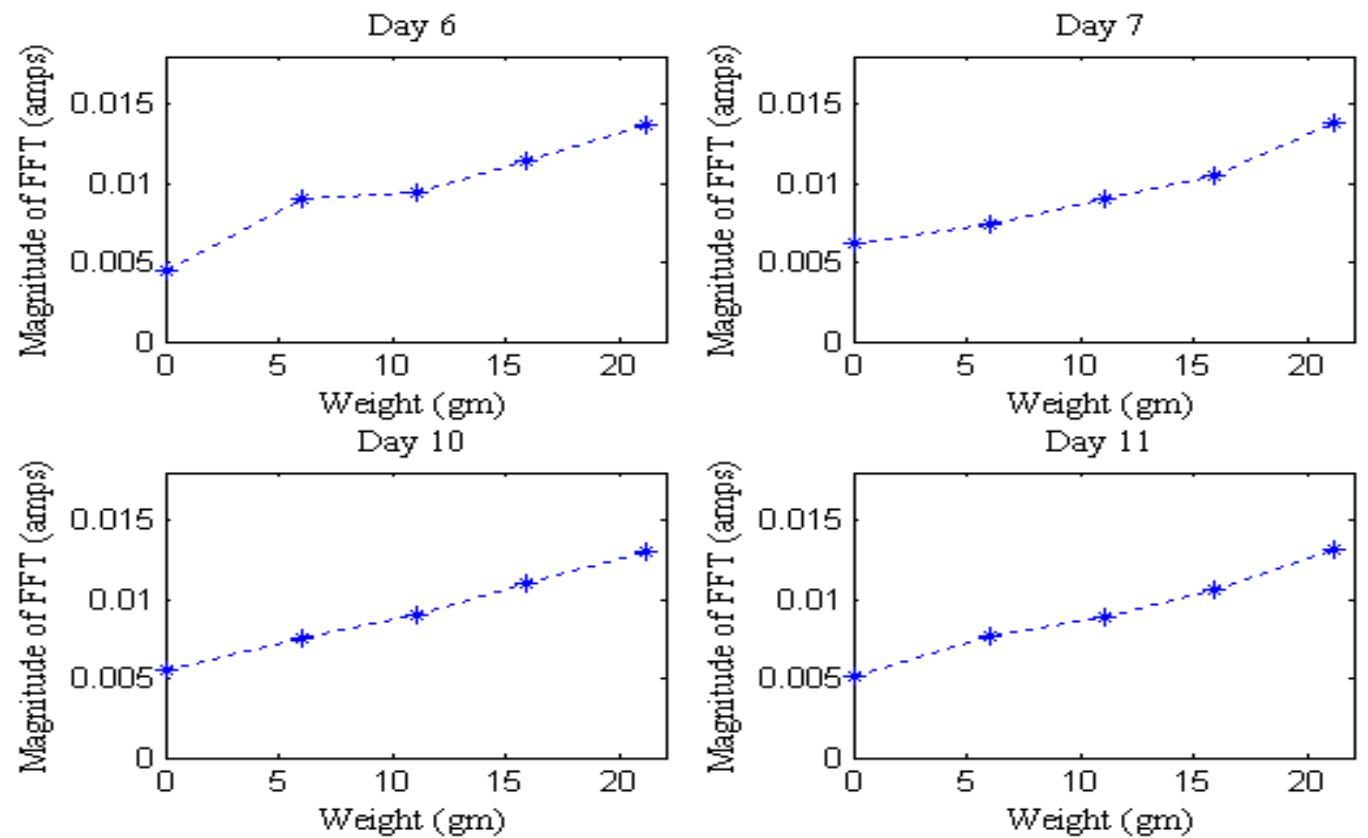

Fig. 4.10 Fourier coefficients for ' $f s+f r$ ' frequency component in phase B current spectrum under different degrees of imbalance; 4 different days
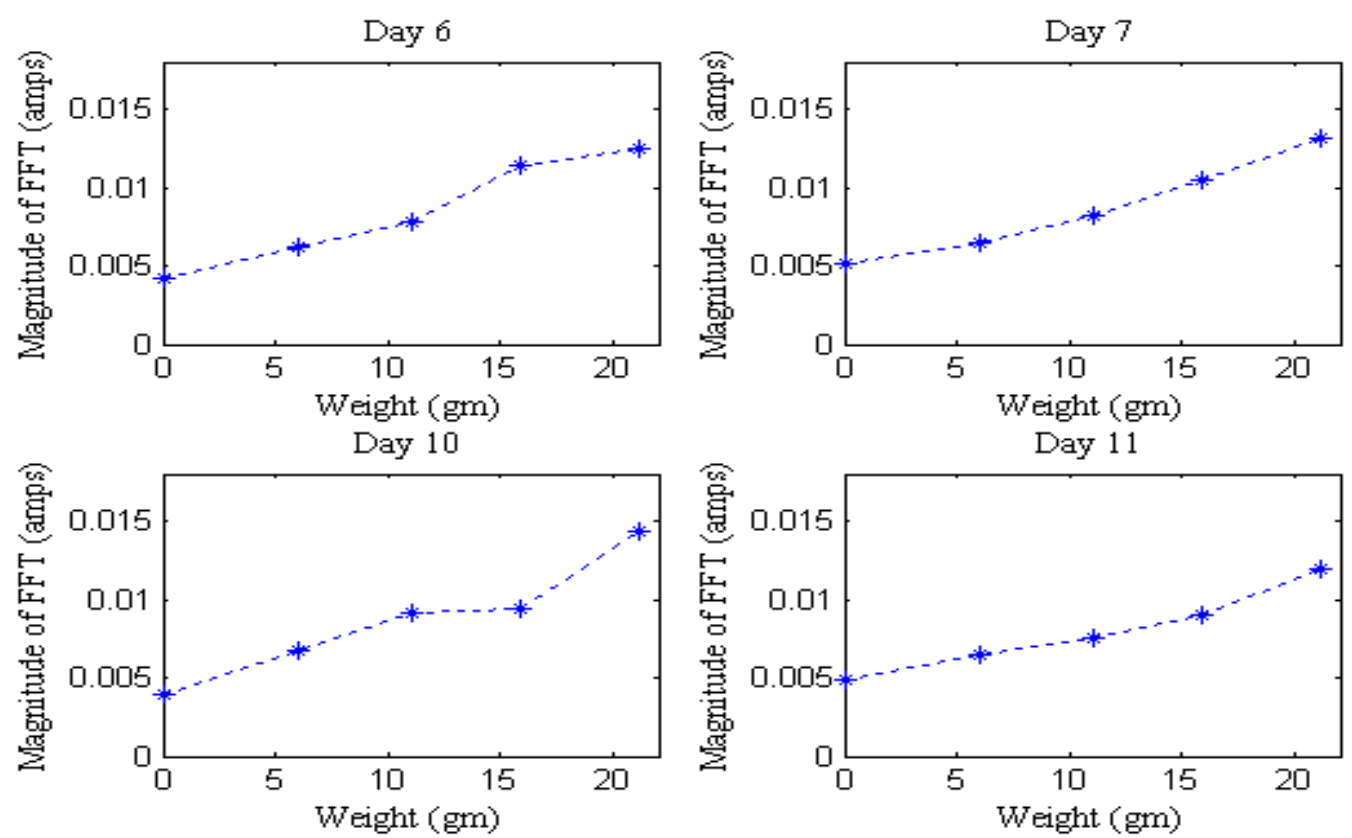

Fig. 4.11 Fourier coefficients for 'fs+fr' frequency component in phase $\mathrm{C}$ current spectrum under different degrees of imbalance; 4 different days 
Day 6

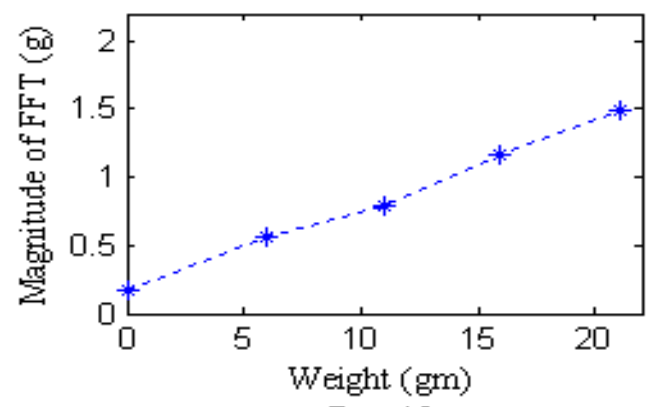

Day 10

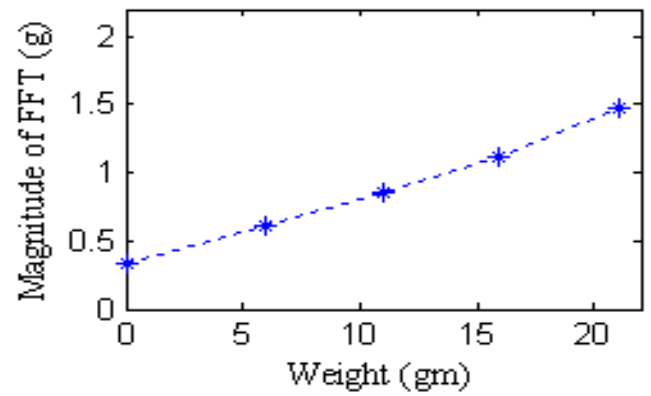

Day 7

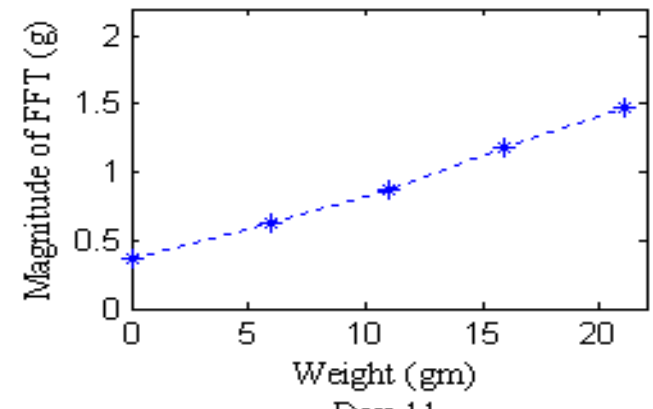

Day 11

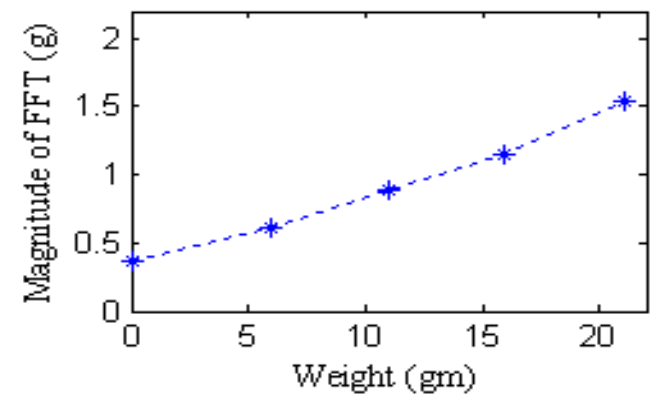

Fig. 4.12 Fourier coefficients for 'fr' frequency component in $X$ axis vibration spectrum under different degrees of imbalance; 4 different days

From Fig. 4.9 to Fig. 4.12, following observations may be made:

- Like the imbalance signature in vibration spectrum, signature in the current spectrum also increases in magnitude with an increase in the degree of imbalance. This validates the use of current signal for determining severity of imbalance.

- While fault signatures increase with an increase in imbalance for each phase, the trend is not same. Even for the same phase, trend is slightly different for different experiment sets.

The last observation makes a strong case for using intelligent classification techniques that may generalize the trend observed in Fig. 4.9 to Fig.4.11 by combining information from current sensors, and accurately determine the degree of rotor imbalance. The next section therefore, uses ANFIS and DS theory for determining the severity of rotor imbalance by combining fault information from current sensors. 


\subsection{Sensor Fusion and Rotor Imbalance Severity Classification}

\subsubsection{ANFIS: Methodology and Results}

\subsubsection{Methodology}

ANFIS was implemented in MATLAB using the built in ANFIS editor. Fig. 4.13 shows the ANFIS editor GUI. This GUI allows initialization of FIS using either 'grid partitioning' or 'subtractive clustering'. It further allows importing training, testing and validation data from either the disk or MATLAB workspace. The data, however, needs to be arranged as an array with number of columns being equal to the number of inputs plus one output. Since ANFIS implements only Sugeno type FIS, there can be only one output. Further, the inputs and outputs must be normalized such that they lie between 0 and 1 .

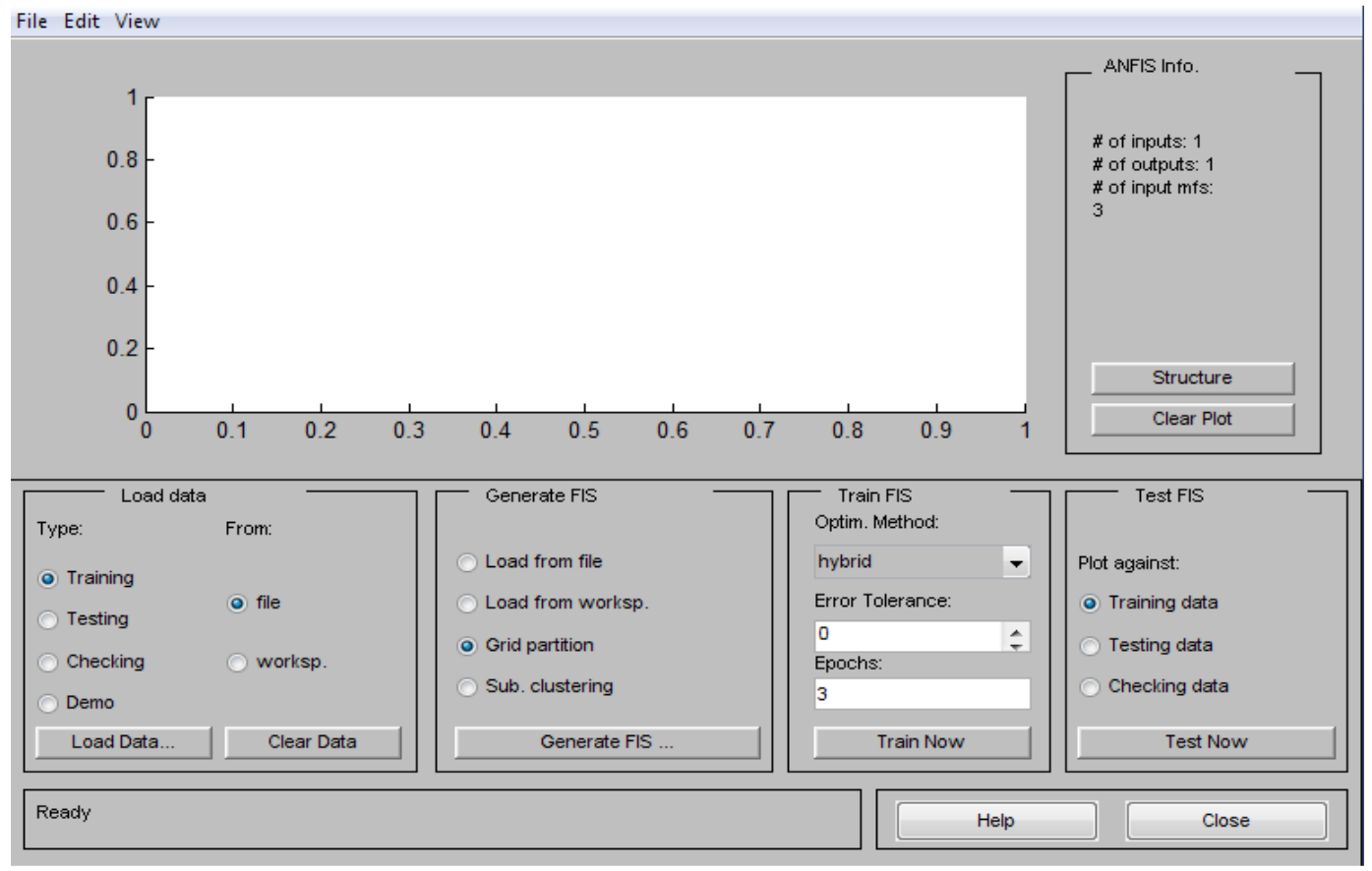

Fig. 4.13 ANFIS editor GUI

In view of the above requirements, the first step in implementing ANFIS was to prepare the training and testing data in appropriate format. As mentioned in section 4.3.3, each experiment set was finally processed into a $5 \times 4$ array of fault specific Fourier coefficients. Sixteen such arrays were combined together in a table to yield an $80 \times 4$ array for training the 
ANFIS. Three more sets were combined in a similar way to yield a $15 \mathrm{X} 4$ array for testing the ANFIS.

As ANFIS accepts data between 0 and 1 , both training and testing sets were normalized. Since there were four types of fault features ( 3 phase currents and $X$ axis vibration), 4 normalization factors were needed. For each feature type, normalization factor was taken as the median of respective $21 \mathrm{gm}$ fault features in the training set. Both training and testing set were normalized by dividing with these normalization factors. If after normalization a value came out to be greater than 1 , it was fixed at 1 . After training and testing sets were normalized, the column of 'desired' output was added to both of them; required format of inputoutput data to be used for implementing ANFIS via 'anfisedit' GUI of MATLAB. 21.1gm was assigned a fault level of 0.9 and other levels were assigned proportional values. No fault or $0 \mathrm{gm}$ level was given a value of 0.07 as the fault feature was not zero for this weight. Thus, training set eventually became an $80 \times 5$ array while testing set was converted to a $15 \times 5$ array. Table 4.1 lists the contents of 5 columns in each row of the training and testing arrays.

Table 4.1 Contents of 5 columns in each row of the training and testing arrays for ' $n$ ' experiment sets. ' $n$ ' $=16$ for training array and ' $n$ ' $=3$ for testing array.

\begin{tabular}{|l|l|c|}
\hline & Column 1-4; Fault features for: & Column 5 (Desired output) \\
\hline Row numbers : $1,6, \ldots 5 n-4$ & '0’ gm imbalance or 'No' Fault. & 0.07 \\
\hline Row numbers : $2,7, \ldots 5 n-3$ & '6’ gm imbalance & 0.26 \\
\hline Row numbers : 3,8,..5n-2 & '11' gm imbalance & 0.47 \\
\hline Row numbers : $4,9, \ldots 5 n-1$ & '16’ gm imbalance & 0.68 \\
\hline Row numbers : $5,10, \ldots 5 n$ & '21' gm imbalance & 0.90 \\
\hline
\end{tabular}

Although all 4 input columns could be used for training and testing the network, only two of the three currents were used as inputs to ANFIS. This was done because of the following reasons:

- The aim was to classify rotor imbalance severity using stator currents.

- Training data being limited, using three inputs increased the number of parameters to a large value increasing chances of over fitting and poor generalization. 
While any two phases could have been used as inputs to ANFIS; the results presented here are based on Phase A and Phase B being used as 2 inputs.

Having converted the training and testing sets into appropriate format and chosen the inputs, the next step was to initialize the FIS. Subtractive clustering [42] was used for this purpose as it allows an automatic selection of the number of membership functions for an input depending on the data. Once ANFIS was initialized, it was trained using hybrid algorithm (Section 3.3.1). The trained network was then tested with unseen data to check if the network had generalized the relationship between inputs and outputs. Section 4.5.1.2 presents and discusses the training and testing results of ANFIS.

\subsubsection{Results and Discussion}

ANFIS structure, training results, rules and testing results are shown in Fig. 4.14, 4.15, 4.16 and 4.17 respectively. Fig. 4.14 shows that subtractive clustering assigned two membership functions for each input. These membership functions were then modified during the training process to yield the final membership functions and rules illustrated in Fig. 4.16. When testing data was presented to the final trained ANFIS of Fig. 4.16, Fig. 4.17 resulted. This figure may be interpreted as follows:

$X$ coordinate axis of Fig. 4.17 represents the 'Row numbers' of Table 4.1 while the $Y$ coordinate axis represents two things- 'Desired output' or 'desired' rotor imbalance severity of Table 4.1 and estimated output or estimated rotor imbalance severity of ANFIS. Every point represented by a 'dot' on Fig. 4.17 has 'Row number' of Table 4.1 as its $X$ coordinate and 'Desired output' of Table 4.1 as $Y$ coordinate. On the other hand, every point represented by a 'star' in Fig. 4.17 has 'Row number' of Table 4.1 as its $X$ coordinate and ANFIS estimated output as $\mathrm{Y}$ coordinate. 


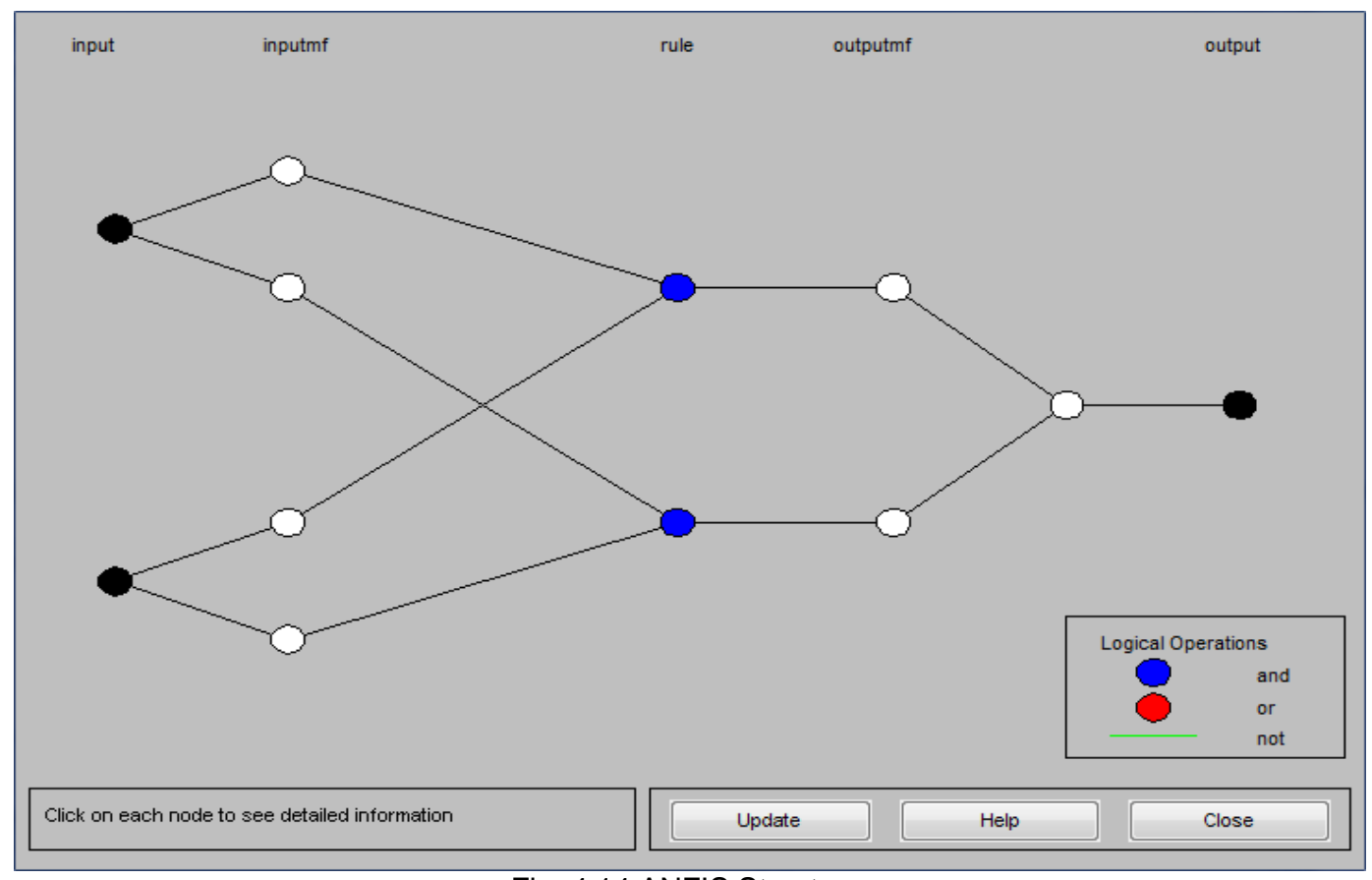

Fig. 4.14 ANFIS Structure

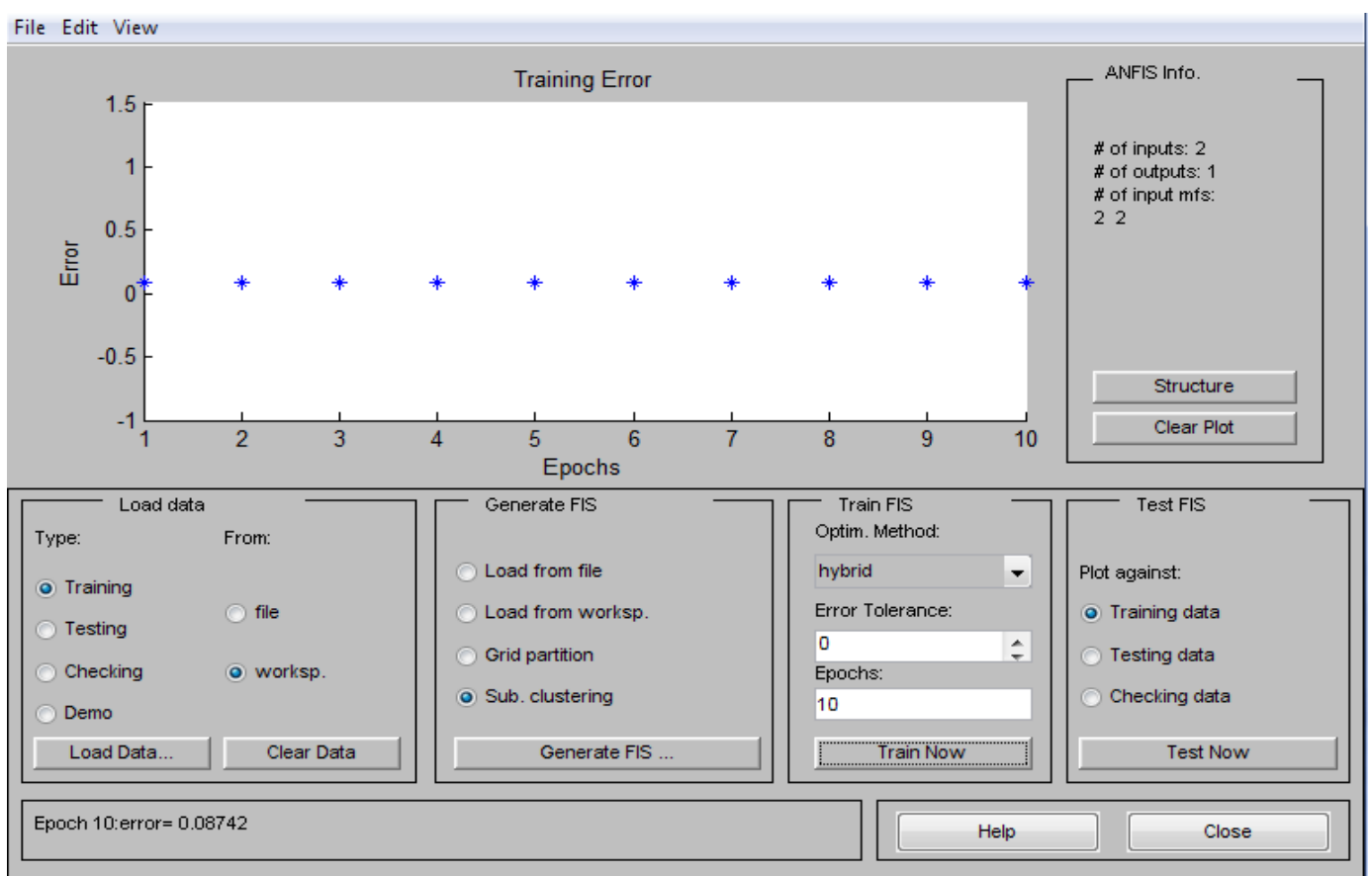

Fig. 4.15 Training the ANFIS 
File Edit View Options

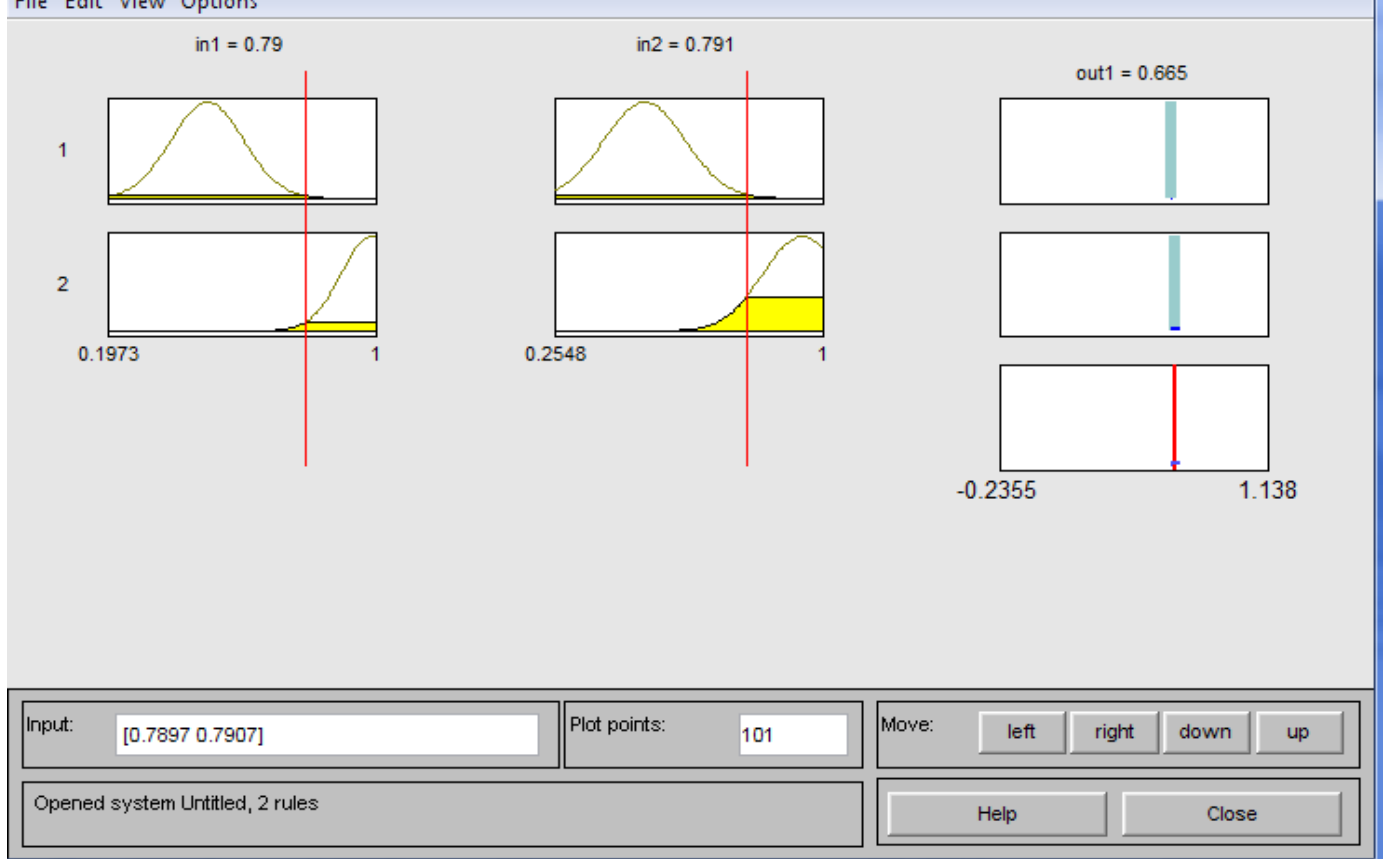

Fig. 4.16 Rules and Membership Functions of ANFIS

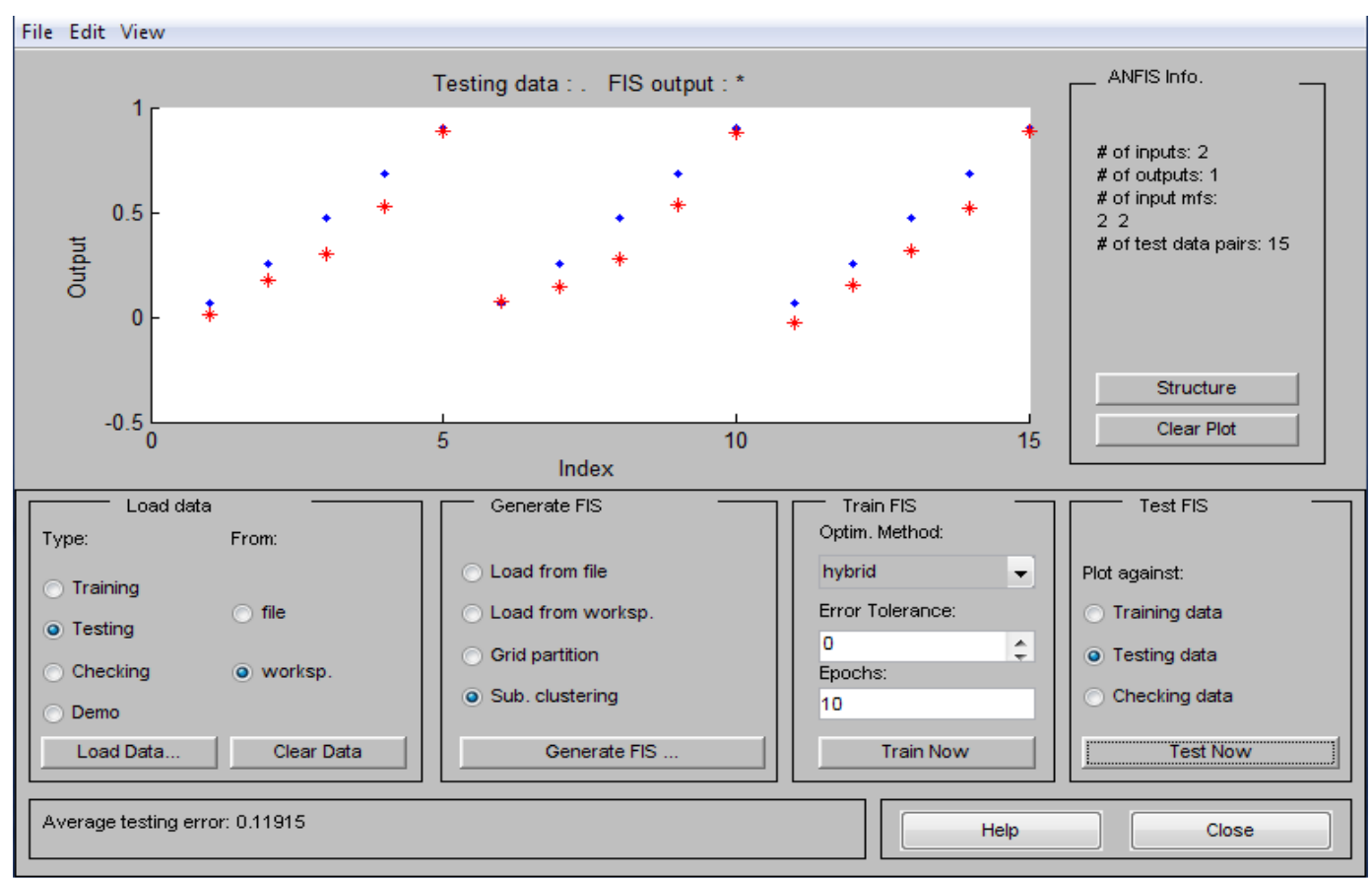

Fig. 4.17 Testing the ANFIS 


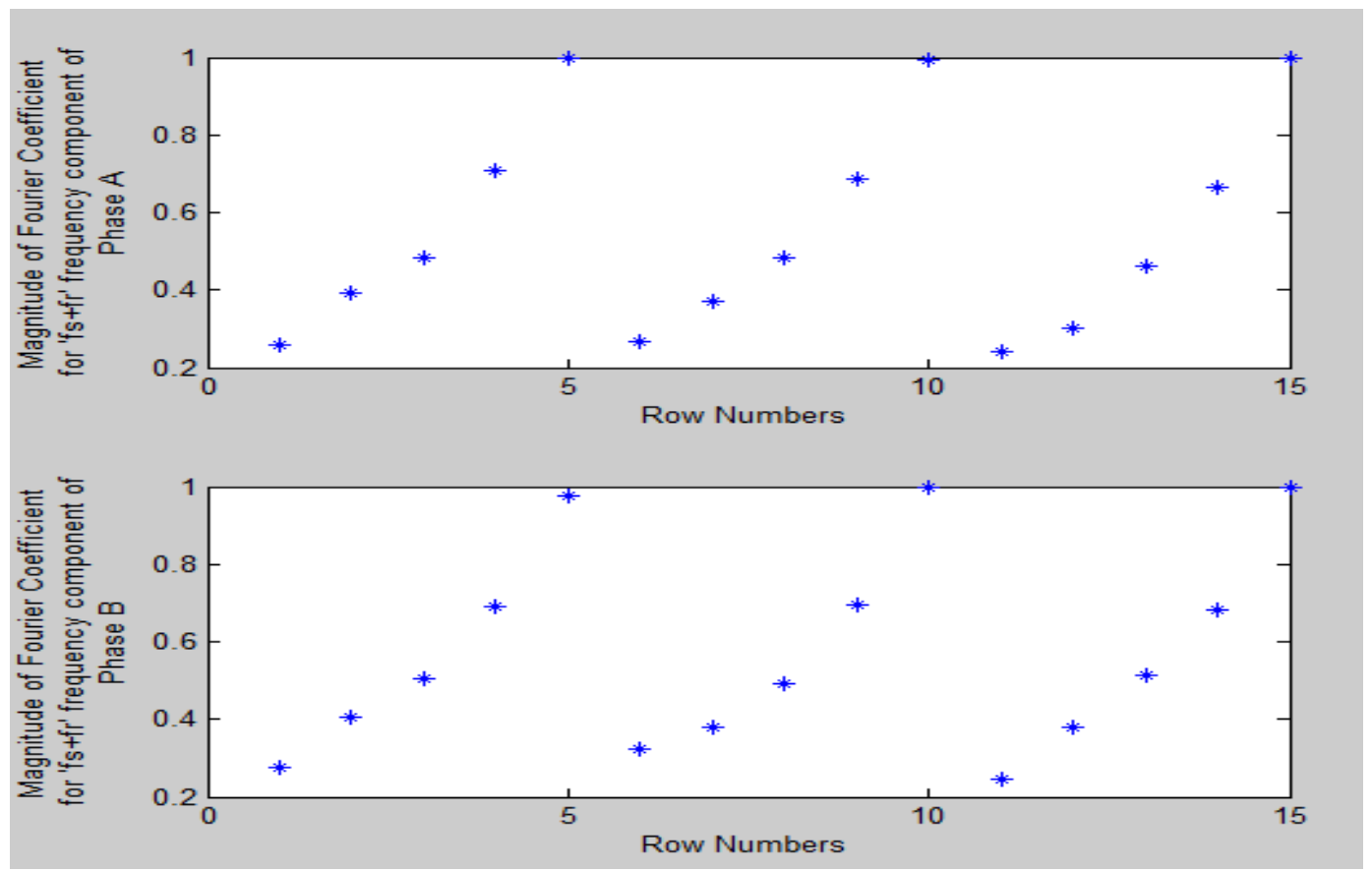

Fig. 4.18 Trend of phase A and phase B imbalance features for the testing set. ' $X$ ' axis is 'Row numbers' as in Table 4.1

Table 4.2 ANFIS Summary

\begin{tabular}{|c|l|l|}
\hline S. No & ANFIS Attributes & Values \\
\hline 1 & No of Inputs & 2 \\
\hline 2 & $\begin{array}{l}\text { Types of Inputs } \\
\text { No of membership } \\
\text { functions per input }\end{array}$ & 2 \\
\hline 3 & So of rules & 2 \\
\hline 4 & $\begin{array}{l}\text { FIS initialization } \\
\text { method }\end{array}$ & $\begin{array}{l}\text { Subtractive } \\
\text { Clustering }\end{array}$ \\
\hline 5 & $\begin{array}{l}\text { Training data points } \\
\text { /Average Error (\%) }\end{array}$ & $80 / 8.7$ \\
\hline 6 & $\begin{array}{l}\text { Testing data points } \\
\text { /Average Error (\%) }\end{array}$ & $15 / 11.9$ \\
\hline 7
\end{tabular}

Table 4.2 summarizes the ANFIS structure and also lists the training and testing errors.

From Table 4.2, Fig. 4.17 and Fig. 4.18, following observations may be made:

- While the average training error was $8.7 \%$, average testing error stood higher at $11.9 \%$.

- The 'stars' in Fig. 4.17 lay out the trend of rotor imbalance severity as estimated by ANFIS. This trend is similar to the trend of phase A and Phase B fault features (Fig. 
4.18) in the testing set. However, unlike the linear trend of 'desired' imbalance severity, the ANFIS estimated trend is not linear.

Above observations make it clear that although ANFIS was able to estimate the trend of rotor imbalance severity that matched closely with the trend in input fault features, there was a significant mismatch between the estimated trend and the assigned 'desired' trend. This mismatch might have been different had a different 'desired' trend been used while training the FIS. In the absence of an expert that may help in choosing a correct 'desired' fault severity trend, performance of imbalance classification is subject to the arbitrariness of choosing the 'desired' trend.

Therefore, discussion on ANFIS may be concluded by saying that, though it is an intuitive and effective technique of combining multiple sensors to determine the degree of rotor imbalance and determines rotor imbalance severity with reasonable accuracy, it suffers from the drawback of a need to assign numerical values to 'desired' level of severity that are seldom known.

Next section discusses severity classification of rotor imbalance using Dempster Shafer Theory and shows that it does not suffer from the above drawback of ANFIS.

\subsubsection{Fault Severity Classification using Dempster Shafer Theory \\ 4.5.2.1 DS Theory Classification Methodology}

As explained in the previous chapter, Dempster Shafer Theory is a frame work for combining evidence from different sources. It therefore fits very well with our present problem where we intend to combine the fault information from two or three separate Hall Effect sensors for determining rotor imbalance severity level.

Two steps, however, need to be completed before DS theory may be applied for evidence combination. These are:

- Determining the number and type of hypothesis.

- Assigning basic probabilities (BPAs) to each hypothesis for each sensor. 
In this work, three hypotheses were chosen- no fault, minor fault and major fault. These hypotheses were mutually exclusive and collectively exhaustive. This implied that each sensor would assign three basic probabilities to every data point in the fault feature space. These BPAs were assigned using FCM clustering since BPAs may be considered equivalent to membership values when the number of clusters are equal to the number of hypotheses (Chapter 3). Membership values corresponding to lowest value of cluster center were assigned as BPAs for no-fault hypothesis while those corresponding to highest value of cluster center were assigned as BPAs for major fault hypothesis. This procedure was adopted for each sensor.

As can be recalled from section 4.5.1.1, training data set for ANFIS was an $80 \mathrm{X} 5$ array. This array was used in DS based classification as well. However, two modifications were made in it:

1. As this method did not require any supervised training, column 5 of the array was not required. Similarly, column 4 containing vibration fault feature was also not used.

2. For better visualization and easier interpretation of results, data in the remaining three columns was arranged according to the format shown in Table 4.3.

Table 4.3 Arrangement of rows in each column of array used for imbalance severity classification using DS theory

\begin{tabular}{|l|l|}
\hline \multicolumn{2}{|c|}{ Column 1-3 (Fault features) } \\
\hline Row numbers : $1,2,3 \ldots .16$ & '0' gm imbalance or 'No' Fault. \\
\hline Row numbers : $17,18,19 \ldots . .32$ & '6' gm imbalance \\
\hline Row numbers : $33,34,35 \ldots . .48$ & '11' gm imbalance \\
\hline Row numbers : $49,50,51 \ldots \ldots 64$ & '16' gm imbalance \\
\hline Row numbers : $65,66,67 \ldots . .80$ & '21' gm imbalance \\
\hline
\end{tabular}

Once the array of fault feature was arranged as given in Table 4.3, FCM clustering was performed on each column of the array. This clustering gave an 80X9 array of BPAs, with three columns each for each phase current. These columns of 'evidence' were then combined by following Dempster's rule of evidence combination to give an $80 \times 3$ array of Belief or Plausibility 
or probability (all were same as hypotheses were mutually exclusive and exhaustive) of the hypotheses. It may be recalled from Chapter 3, that while several techniques exist for combining evidence under Dempster Shafer Theory, Dempster rule was used in this work as it has a good performance under low conflict evidence set. Since, Section 4.3.1 showed (Fig. 4.94.11) that conflict between each sensor was indeed low; use of Dempster's rule was justified. Fig. 4.19 illustrates the steps in imbalance classification using DS theory in conjunction with FCM clustering.

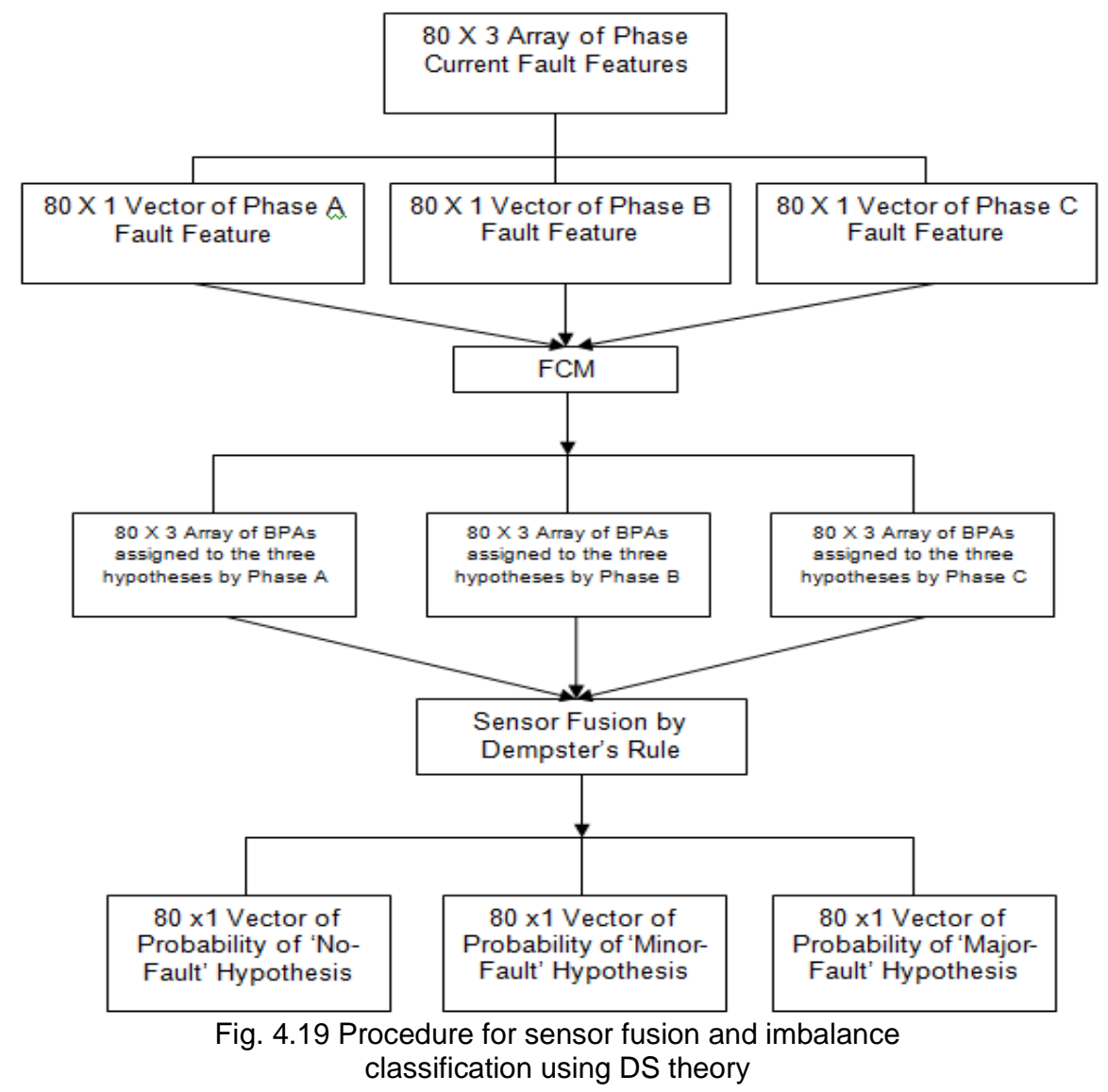

\subsubsection{DS Theory Classification results}

In all the figures that follow (Fig. 4.20 to Fig. 4.22), X coordinate axis represents 'Row numbers' as given in Table 4.3. Similarly, $\mathrm{Y}$ coordinate axis of first three plots in each of Fig. 4.20, 4.21 and 4.22, represents BPA assigned to a hypothesis by a phase, while the fourth plot in each of 
Fig. 4.20, 4.21 and 4.22 represents the Belief or Plausibility or probability of the hypothesis being true after sensor fusion.

Another point to keep in mind before interpreting the results is that, by nature of the normalization performed on the data used here (See Section 4.5.1.1) '21.1gm' imbalance is the highest fault level while 'Ogm' imbalance is the lowest fault level.

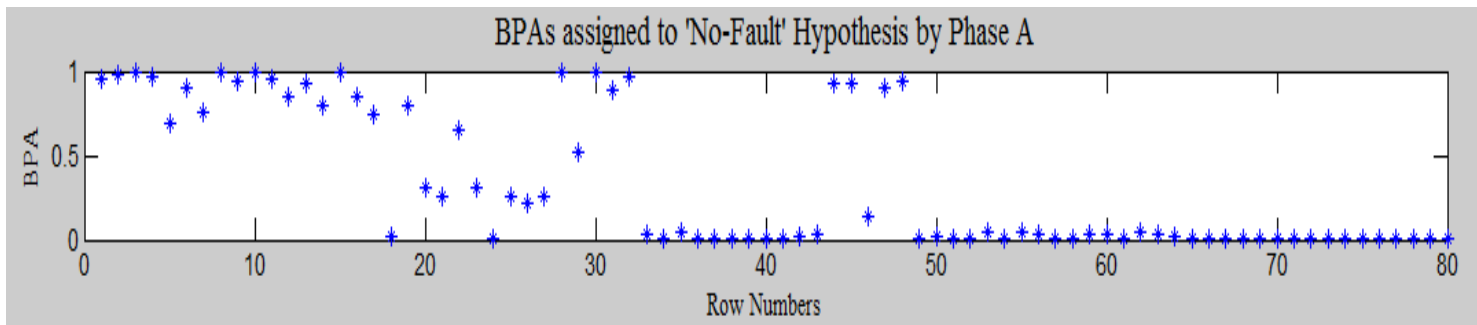

BPAs assigned to No Fault' Hypothesis by Phase B

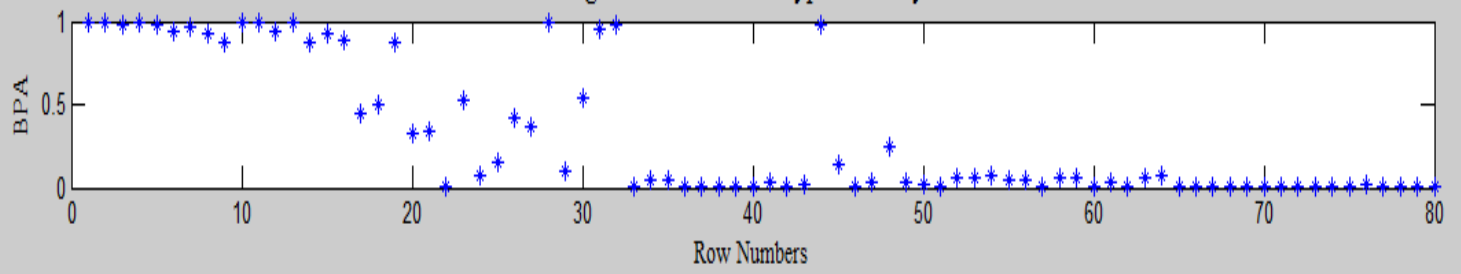

BPAs assigned to 'No Fault' Hypothesis by Phase C
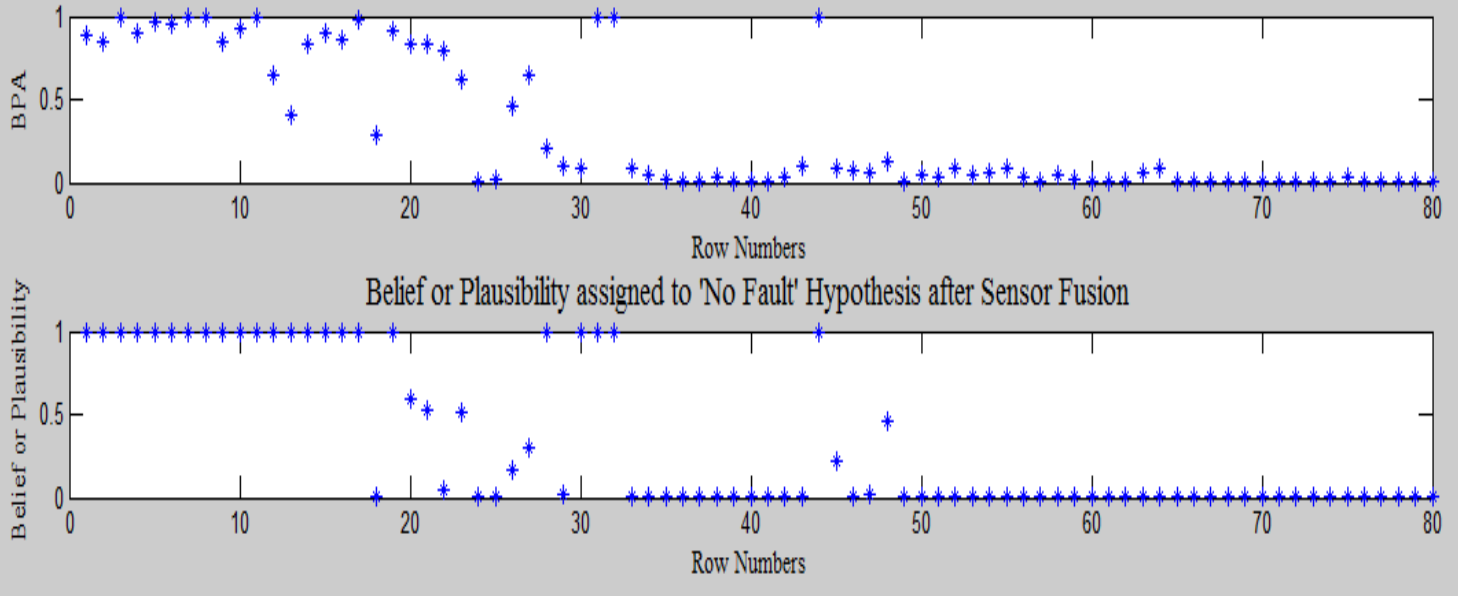

Fig. 4.20 Confidence in 'No-Fault' hypothesis before and after sensor fusion 


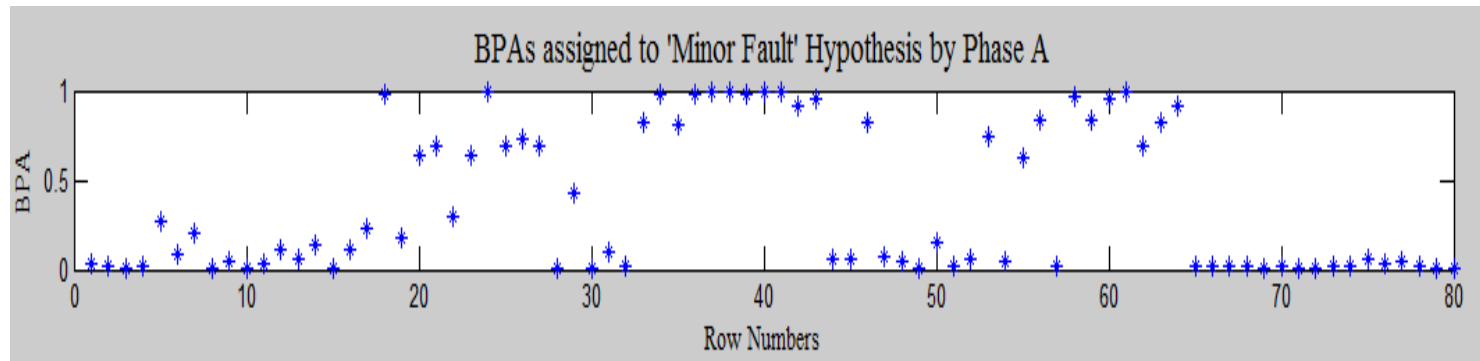

BPAs assigned to 'Minor Fault' Hypothesis by Phase B

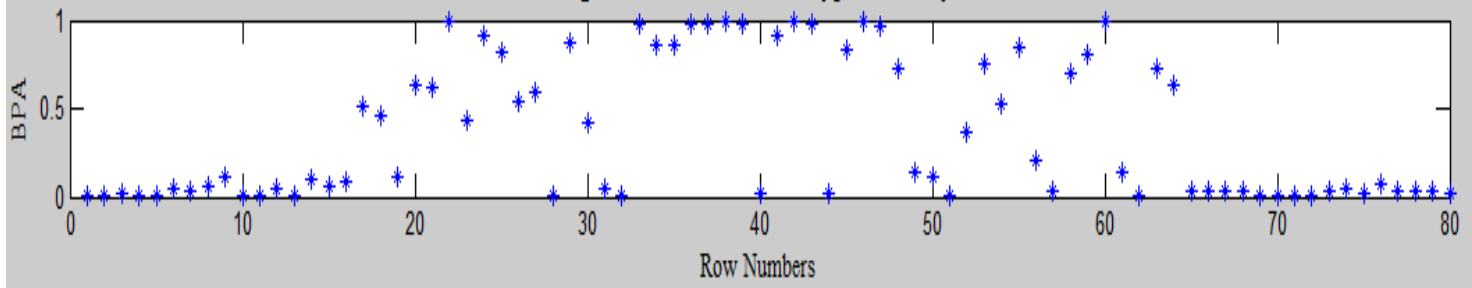

BPAs assigned to 'Minor Fault' Hypothesis by Phase C
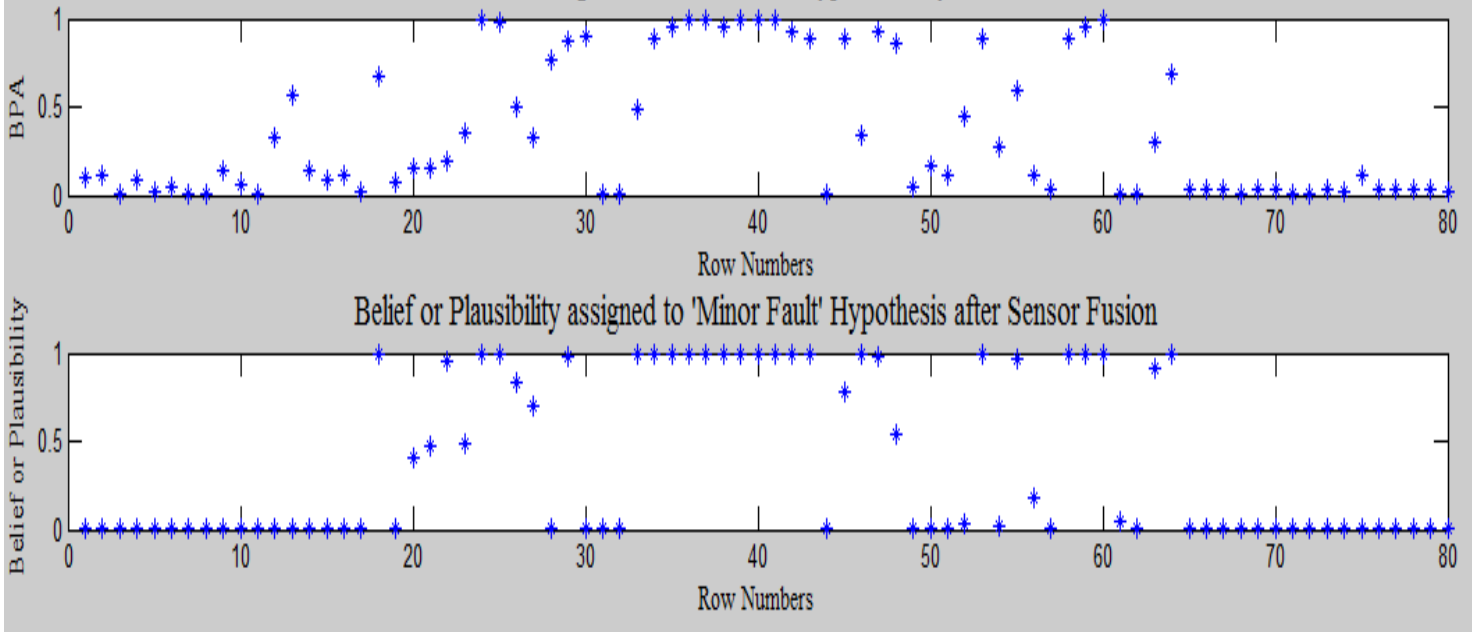

Fig. 4.21 Confidence in 'Minor-Fault' hypothesis before and after sensor fusion 


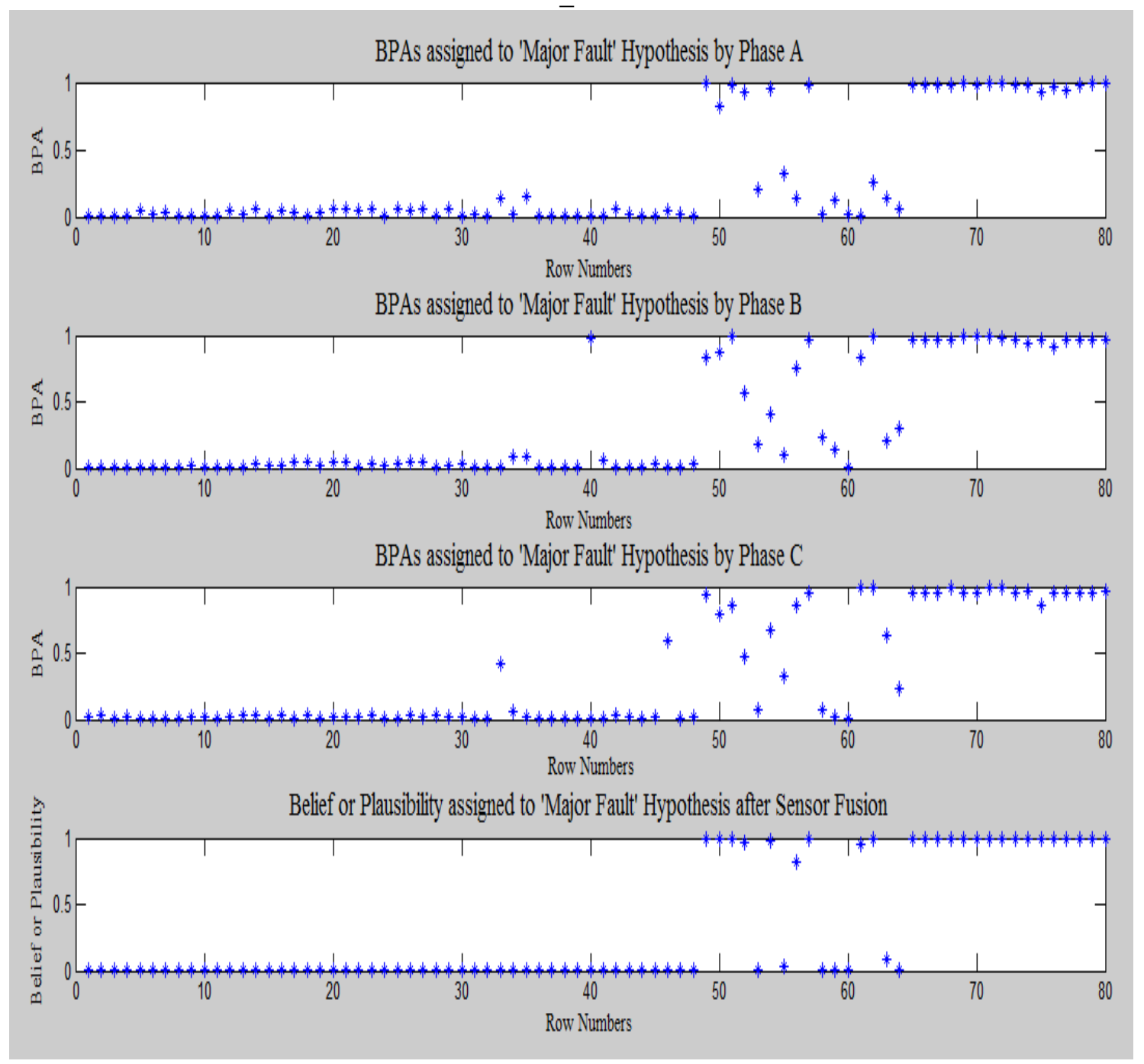

Fig. 4.22 Confidence in 'Major-Fault' hypothesis before and after sensor fusion

From Fig. 4.20 it is clear that sensor fusion asserts the belongingness of 'Ogm' imbalance (first 16 points) to 'No-Fault' hypothesis more strongly than any of the phases alone. Fig. 4.21 and Fig. 4.22 further show that sensor fusion is more assertive in rejecting '0gm imbalance' as belonging to 'Minor' and 'Major' fault hypothesis than any of the phases alone. Similar arguments may be made for '21gm' imbalance (points 64 to 80 ) as well. While any improvement for other imbalance weights is not clear from the figures, it is explicitly borne out by Tables 4.4, 4.5, 4.6 and 4.7. Table 4.4 gives the mean percentage belongingness of each 
fault level to the three hypotheses after evidence combination by DS theory. Table 4.5, 4.6 and 4.7 illustrate the same content as in Table 4.4 but based on BPAs assigned to individual phase current fault feature set. Next section discusses the observations made in Fig. 4.20 to Fig. 4.22 and Tables 4.4 to 4.7 .

Table 4.4 Mean percentage belongingness of each fault level to the three hypotheses after evidence combination

\begin{tabular}{|c|c|c|c|}
\hline & $\begin{array}{c}\text { No-Fault } \\
(\%)\end{array}$ & $\begin{array}{c}\text { Minor- } \\
\text { Fault (\%) }\end{array}$ & $\begin{array}{l}\text { Major- } \\
\text { Fault (\%) }\end{array}$ \\
\hline $0 \mathrm{gm}$ & $\mathbf{9 9 . 5 6}$ & $\mathbf{0 . 4 1}$ & $\mathbf{0 . 0 3}$ \\
\hline $6 \mathrm{gm}$ & 43.88 & 55.90 & 0.22 \\
\hline $11 \mathrm{gm}$ & 17.80 & 80.49 & 1.71 \\
\hline $16 \mathrm{gm}$ & 0.19 & 53.24 & 46.57 \\
\hline $21 \mathrm{gm}$ & $\mathbf{0 . 0 0}$ & $\mathbf{0 . 0 6}$ & $\mathbf{9 9 . 9 4}$ \\
\hline
\end{tabular}

Table 4.5 Mean percentage belongingness of each fault level to the three hypotheses based on phase 'A' fault feature set BPAs

\begin{tabular}{|c|c|c|c|}
\hline & $\begin{array}{c}\text { No-Fault } \\
(\%)\end{array}$ & $\begin{array}{l}\text { Minor- } \\
\text { Fault (\%) }\end{array}$ & $\begin{array}{l}\text { Major- } \\
\text { Fault (\%) }\end{array}$ \\
\hline 0gm & $\mathbf{9 0 . 7 9}$ & $\mathbf{7 . 3 0}$ & $\mathbf{1 . 9 1}$ \\
\hline $6 \mathrm{gm}$ & 51.08 & 45.58 & 3.34 \\
\hline $11 \mathrm{gm}$ & 25.11 & 71.75 & 3.14 \\
\hline $16 \mathrm{gm}$ & 2.41 & 54.30 & 43.29 \\
\hline $21 \mathrm{gm}$ & $\mathbf{0 . 3 9}$ & $\mathbf{1 . 7 0}$ & $\mathbf{9 7 . 9 1}$ \\
\hline
\end{tabular}

Table 4.6 Mean percentage belongingness of each fault level to the three hypotheses based on phase 'B' fault feature set BPAs

\begin{tabular}{|c|c|c|c|}
\hline & $\begin{array}{c}\text { No-Fault } \\
(\%)\end{array}$ & $\begin{array}{l}\text { Minor- } \\
\text { Fault (\%) }\end{array}$ & $\begin{array}{l}\text { Major- } \\
\text { Fault (\%) }\end{array}$ \\
\hline 0gm & $\mathbf{9 5 . 3 4}$ & $\mathbf{3 . 7 8}$ & $\mathbf{0 . 8 8}$ \\
\hline $6 \mathrm{gm}$ & 47.49 & 49.77 & 2.73 \\
\hline $11 \mathrm{gm}$ & 9.92 & 81.61 & 8.47 \\
\hline $16 \mathrm{gm}$ & 3.93 & 43.81 & 52.27 \\
\hline $21 \mathrm{gm}$ & $\mathbf{0 . 8 0}$ & $\mathbf{2 . 5 5}$ & $\mathbf{9 6 . 6 4}$ \\
\hline
\end{tabular}


Table 4.7 Mean percentage belongingness of each fault level to the three hypotheses based on phase 'C' fault feature set BPAs

\begin{tabular}{|c|c|c|c|}
\hline & $\begin{array}{c}\text { No-Fault } \\
(\%)\end{array}$ & $\begin{array}{c}\text { Minor- } \\
\text { Fault (\%) }\end{array}$ & $\begin{array}{l}\text { Major- } \\
\text { Fault (\%) }\end{array}$ \\
\hline $0 \mathrm{gm}$ & $\mathbf{8 7 . 2 1}$ & $\mathbf{1 1 . 2 0}$ & $\mathbf{1 . 5 8}$ \\
\hline $6 \mathrm{gm}$ & 54.73 & 43.72 & 1.55 \\
\hline $11 \mathrm{gm}$ & 10.43 & 81.95 & 7.62 \\
\hline $16 \mathrm{gm}$ & 3.98 & 40.39 & 55.63 \\
\hline $21 \mathrm{gm}$ & $\mathbf{1 . 0 9}$ & $\mathbf{3 . 0 2}$ & $\mathbf{9 5 . 8 7}$ \\
\hline
\end{tabular}

\subsubsection{Discussion}

From the above tables and figures following conclusions may be reached about Fault severity classification using Dempster Shafer Theory in conjunction with FCM:

- Fuzzy C-means clustering is an effective BPA assignment technique. This is clear from Tables 4.4 to 4.6 where BPAs (expressed as percentage) assigned to the hypotheses make logical sense. It can be seen that belongingness to 'No-Fault' hypothesis decreases as fault level increases while that to 'Major-Fault' hypotheses increases. Similarly, belongingness to 'Minor-Fault' hypothesis first increases and then decreases.

- As pointed out earlier, Sensor Fusion using Dempster-Shafer Theory gave more accurate results in determining low and high degrees of imbalance. This is indicated by $2-4 \%$ better performance of sensor fusion in detecting $21 \mathrm{gm}$ imbalance (compare last row of Tables 4.5, 4.6 and 4.7 with Table 4.4) and 5-13\% better performance in declaring no fault or 'Ogm imbalance' (compare $1^{\text {st }}$ row of Tables 4.5, 4.6 and 4.7 with Table 4.4).

- Sensor fusion performed better in case of classifying ' $6 \mathrm{gm}$ ' imbalance as well. This is clear from Tables 4.4 to 4.7 where ' $6 \mathrm{gm}$ ' imbalance being 'Major Fault' is probable to an extent of only $0.22 \%$ according to sensor fusion but it is probable to 
an extent of $3.34 \%$ as per Phase A, $2.73 \%$ as per Phase B and $1.57 \%$ as per Phase C.

- Performance of sensor fusion was better for ' $16 \mathrm{gm}$ ' imbalance as well. It was flagged to be 'No-Fault' with a probability of only $0.19 \%$ by sensor fusion. The probabilities assigned by individual phases were, however, considerably higher; $2.41 \%$ by Phase A, 3.93\% by Phase B and $3.98 \%$ by Phase C.

Therefore, it can be seen that accurate assertions on degree of rotor imbalance may be made by using FCM clustering to determine BPAs and then combining them by Dempster's rule. Hence, Dempster Shafer theory in conjunction with FCM clustering is an effective technique to determine degree of rotor imbalance.

\section{$\underline{4.6 \text { Conclusion }}$}

This chapter presented a test bed based approach for rotor imbalance diagnostics. Fault features in the three stator currents were obtained by conducting experiments on a SQIM motor over a period of 30 days. Using these features it was shown that the trend in fault features was not identical for the three phases and varied over time even for the same phase. This made a strong case for using intelligent sensor fusion techniques, ANFIS and Dempster Shafer Theory in conjunction with FCM clustering, to 'learn' the actual trend and accurately determine imbalance severity. Both techniques were used to determine the degree of imbalance from fault feature set. From the classification results it was found that while both methods allowed for sensor fusion and performed very accurate severity classification, DS theory in conjunction with fuzzy C-means clustering was more convenient and intuitive than ANFIS. This was due to the requirement of a numerical 'desired severity' assignment in ANFIS while DS theory didn't require any such assignment. Although the reason for this requirement being a problem was discussed in Section 4.5.1.2, it is explained more clearly by means of an example in the next and concluding paragraph of this chapter. 
Suppose a motor technician knows that for a particular machine up to $10 \mathrm{gm}$ imbalance is low severity, $10 \mathrm{gm}$ to $20 \mathrm{gm}$ is medium severity and severity is high thereafter. Tests may then be conducted as explained in this chapter with a number of weights lying in the ranges given above. Using DS theory in conjunction with FCM one may easily divide the fault feature set into three clusters as told by the technician. ANFIS however, will pose a problem of severity assignment to test weights of say $13 \mathrm{gm}$ and $19 \mathrm{gm}$ as they lay in the same severity level and so the expert (technician) has no knowledge about differentiating between these two cases. DS theory with FCM being used for BPA assignment to each hypothesis is, therefore, a better technique to determine degree of rotor imbalance. 


\section{CHAPTER 5}

\section{CONCLUSION AND FUTURE WORK}

\section{$\underline{5.1 \text { Conclusion }}$}

It was stated in Chapter 2 that this thesis had two objectives. First objective was to accurately model rotor imbalance fault in induction machines and explain the process that generates rotor imbalance signatures in stator current. The second objective was to develop a test bed based approach for rotor imbalance diagnostics that incorporated sensor fusion. While Chapter 3 presented the techniques for achieving the objectives, Chapter 4 presented a comprehensive test bed based rotor imbalance diagnostics scheme that could combine fault information from the three phases.

In Chapter 3, a SQIM with rotor imbalance was modeled using space phasor theory. Resulting equations were then solved using SIMULINK and rotor imbalance fault signatures in stator current were determined. They were found out to be the same as reported in literature and were further verified in Chapter 4 by experiments performed on an actual Squirrel Cage Induction Motor. However, the most important outcome of motor modeling was a clear picture of why these signatures appear. It was demonstrated that rotor imbalance superimposes $\mathrm{fr} \mathrm{Hz}$ oscillation on an otherwise constant steady state electromagnetic torque. As a result, rotor speed and rotor m.m.f also get modulated by $\mathrm{fr} \mathrm{Hz}$ oscillation. This rotor m.m.f induces voltages

with 'fs $\pm f r$ ' frequency components in the stator windings. Voltages with 'fs $\pm f r$ ' frequency components cause such frequency currents to flow in the stator as well.

Chapter 3 also presented two methods for performing sensor fusion. The first method was ANFIS. In this method, fault features and a corresponding desired severity level from two current sensors were used to train premise and consequent parameters of a rule base. This training enabled ANFIS to capture the relationship between fault features and severity level. 
ANFIS was shown to provide a good estimate of rotor imbalance severity besides providing a set of handy linguistic rules that related fault features from two sensors with degree of rotor imbalance. The only drawback of ANFIS was the need to assign a numerical value to an imbalance level. This requirement was, however, absent in rotor imbalance severity classification under Dempster Shafer Theory framework. It was shown that a piece of evidence could be assigned Basic Probability Assignment for each hypothesis using Fuzzy C-Means clustering (hypotheses here were synonymous with fault severity levels and could be expressed in linguistic terms). BPAs for each sensor when combined using Dempster's rule of evidence combination were shown to give more accurate results about fault severity than individual sensors.

In gist, this thesis provided a much clearer understanding of rotor imbalance fault addressed along with developing a new and holistic approach to reliably determine the severity of rotor imbalance by combining evidence from different phases of stator current. Since wind turbines are most prone to rotor imbalance fault, using the rotor imbalance detection and classification techniques developed here, rotor imbalance may be detected at an early stage and an optimal maintenance decision may be taken. This will not only benefit the owners of wind farms but also help increase the share of wind electricity by keeping wind turbines on-line for longer durations.

\section{$\underline{5.2 \text { Future Work }}$}

While this thesis focused on rotor imbalance fault due to its wide spread prevalence in wind farms, other faults related to bearings, broken rotor bars and stator windings are also major fault modes in machines. Of these, bearing fault is the most common accounting for the failure of more than $40 \%$ industrial motors. Ironically, however, this is the least investigated fault mode. Although some authors have attempted to determine bearing fault signatures, they have created bearing faults that are too drastic to occur in the initial stages. Since the aim of an effective CBM technique is to detect faults at an incipient stage, such an approach is not useful. 
Hence, simulating early stages of bearing fault and determining corresponding signatures is an important research area.

Another area that hasn't been explored much is the effect of Variable Frequency Drives (VFDs) on fault diagnosis. Since VFDs contain a lot of noise and harmonics, they may obscure the fault signatures determined for a mains fed machine. Hence, evaluating the effect of VFDs on established fault signatures is also a good research area.

Still another area of research in Condition based Maintenance of machines appears to be the implementation of fault diagnosis schemes on a Digital Signal Processor (DSP). This is important since most drives come equipped with a DSP and if fault diagnosis could be done on board then there would not be any need to periodically send data to a central control center. Only the status of fault may be relayed to the control room via SCADA or any other communication protocol such as Zigbee.

Hence, it can be said that CBM of electric machines is an important research area with immense potential for application in industry. To realize its full potential, cheap, comprehensive and robust fault diagnosis techniques must be developed, that may be incorporated in decision making software to make maintenance decisions based on actual machine condition than on some pre-determined rules of thumb. 


\section{APPENDIX A}

MATLAB CODES FOR ROTOR IMBALANCE FEATURE EXTRACTION AND SEVERITY CLASSIFICATION USING DEMPSTER SHAFER THEORY 


\section{A.1 MATLAB Code for Rotor Imbalance Feature Extraction}

\% This code extracts the fault features from current and $\mathrm{X}$-axis

vibration data according to the procedure presented in

Section 4.3.3. Signals were \% "windowed" using a 'Blackman'

window, to reduce leakage while taking the fourier transform

of the data. Primary variables used in this code are

explained below:

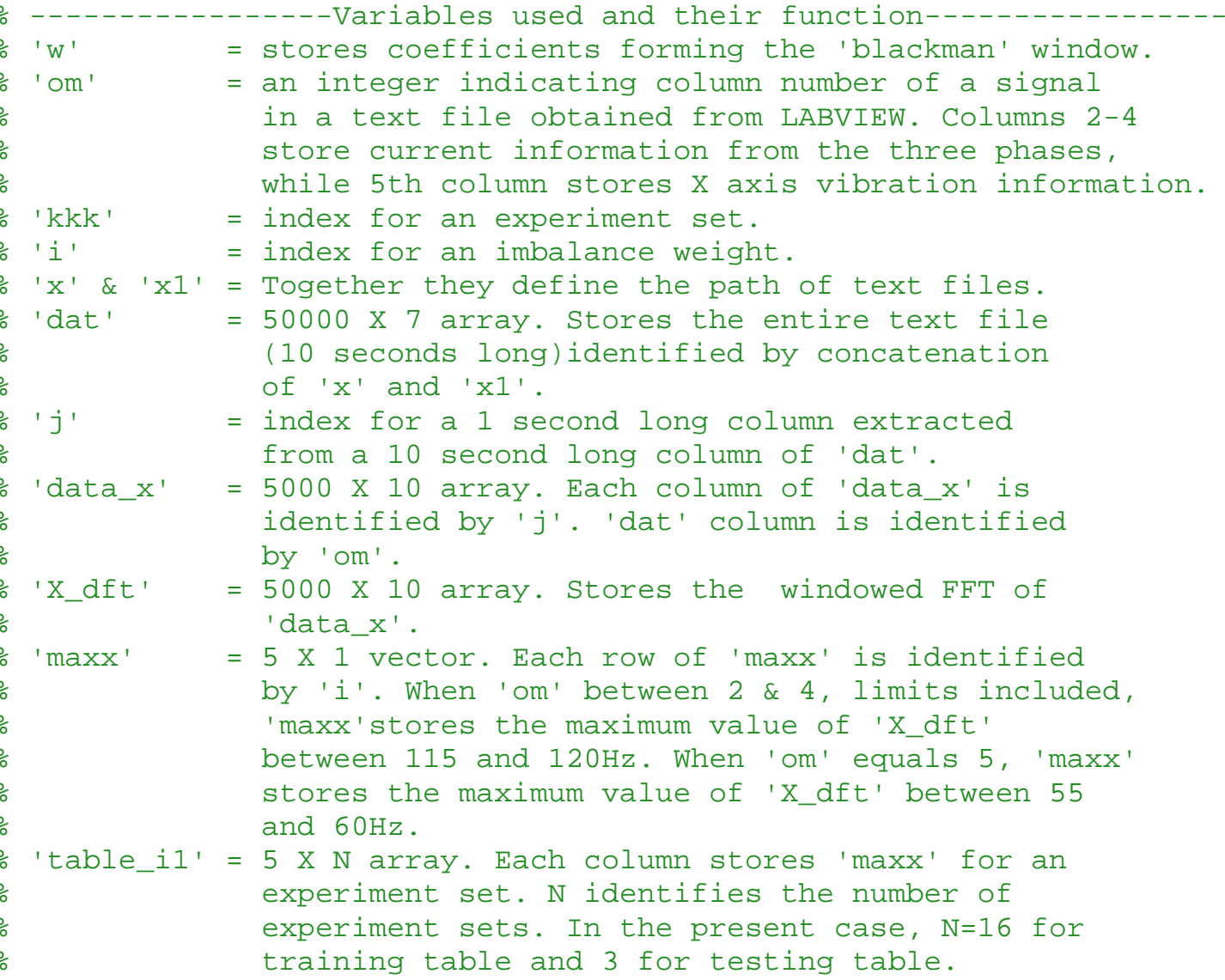




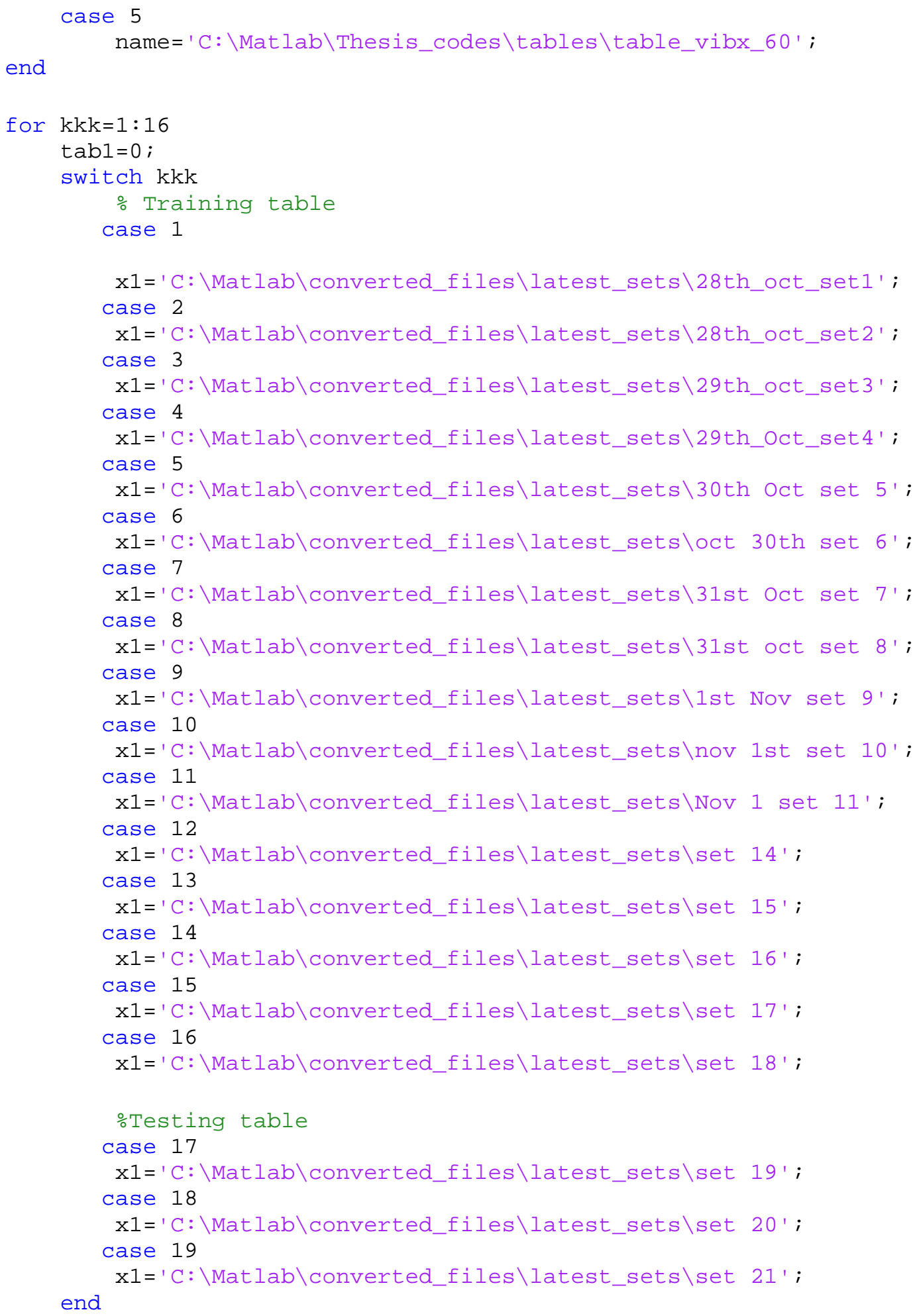




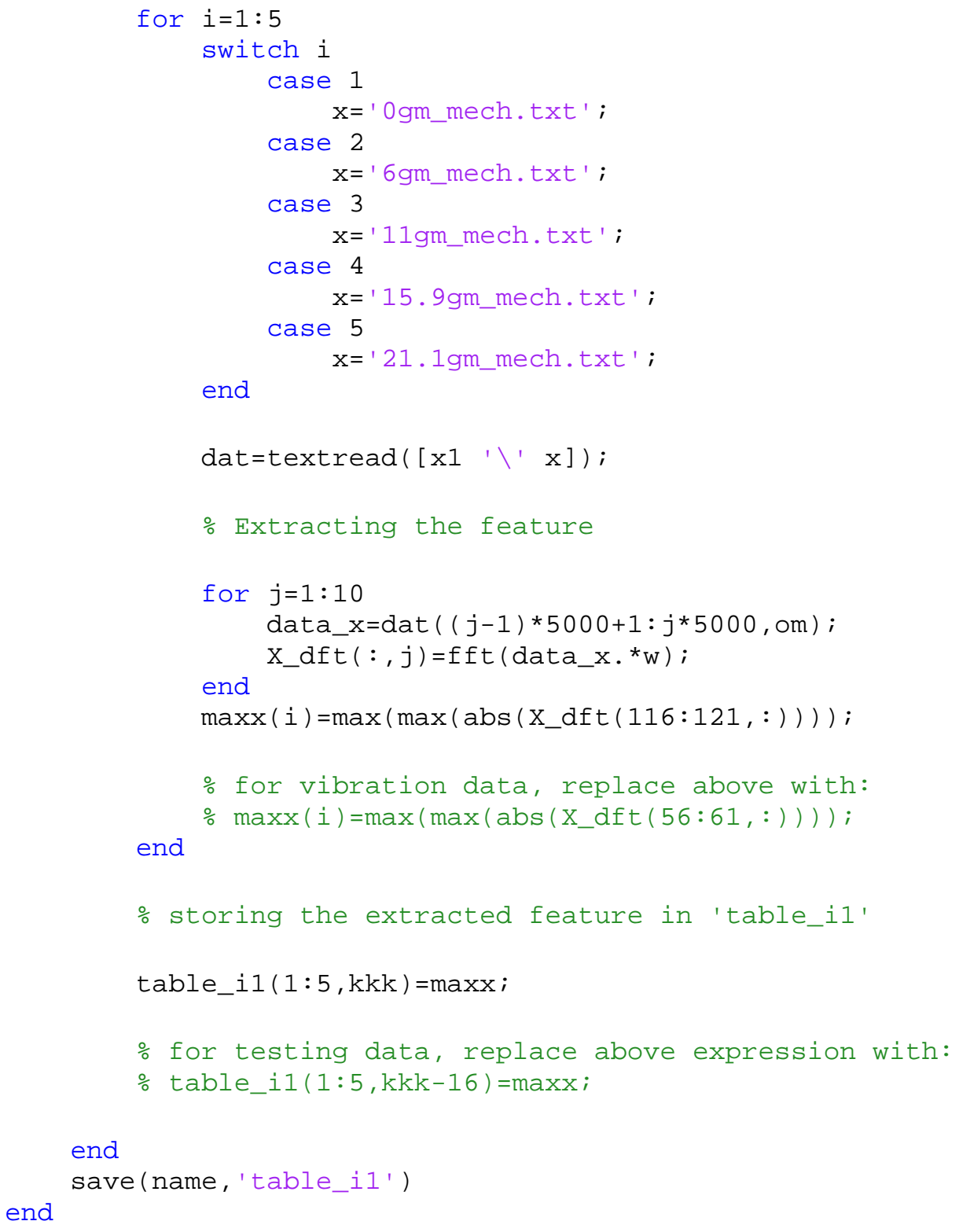




\section{A.2 MATLAB Code for Severity Classification using Dempster Shafer Theory}

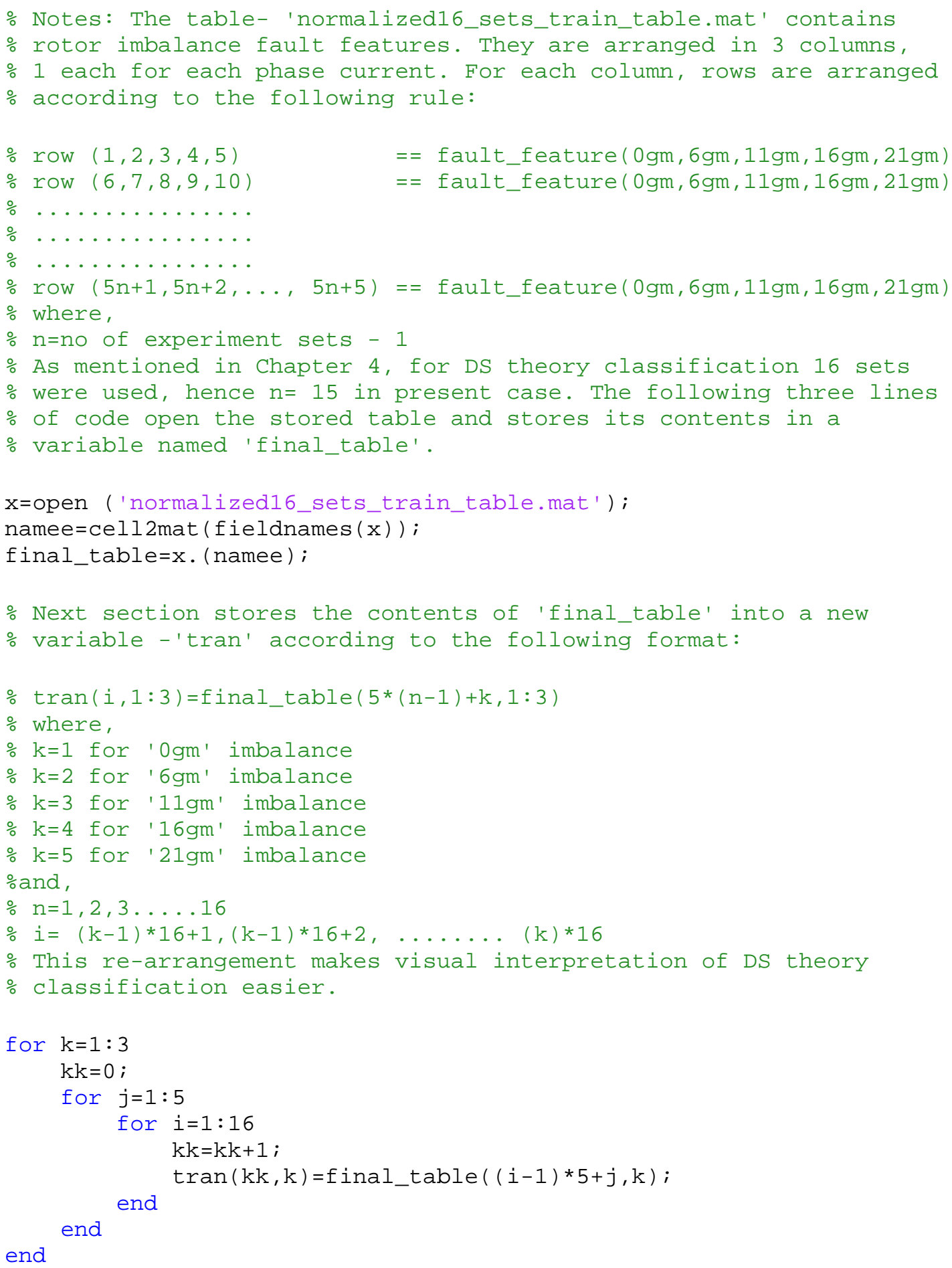




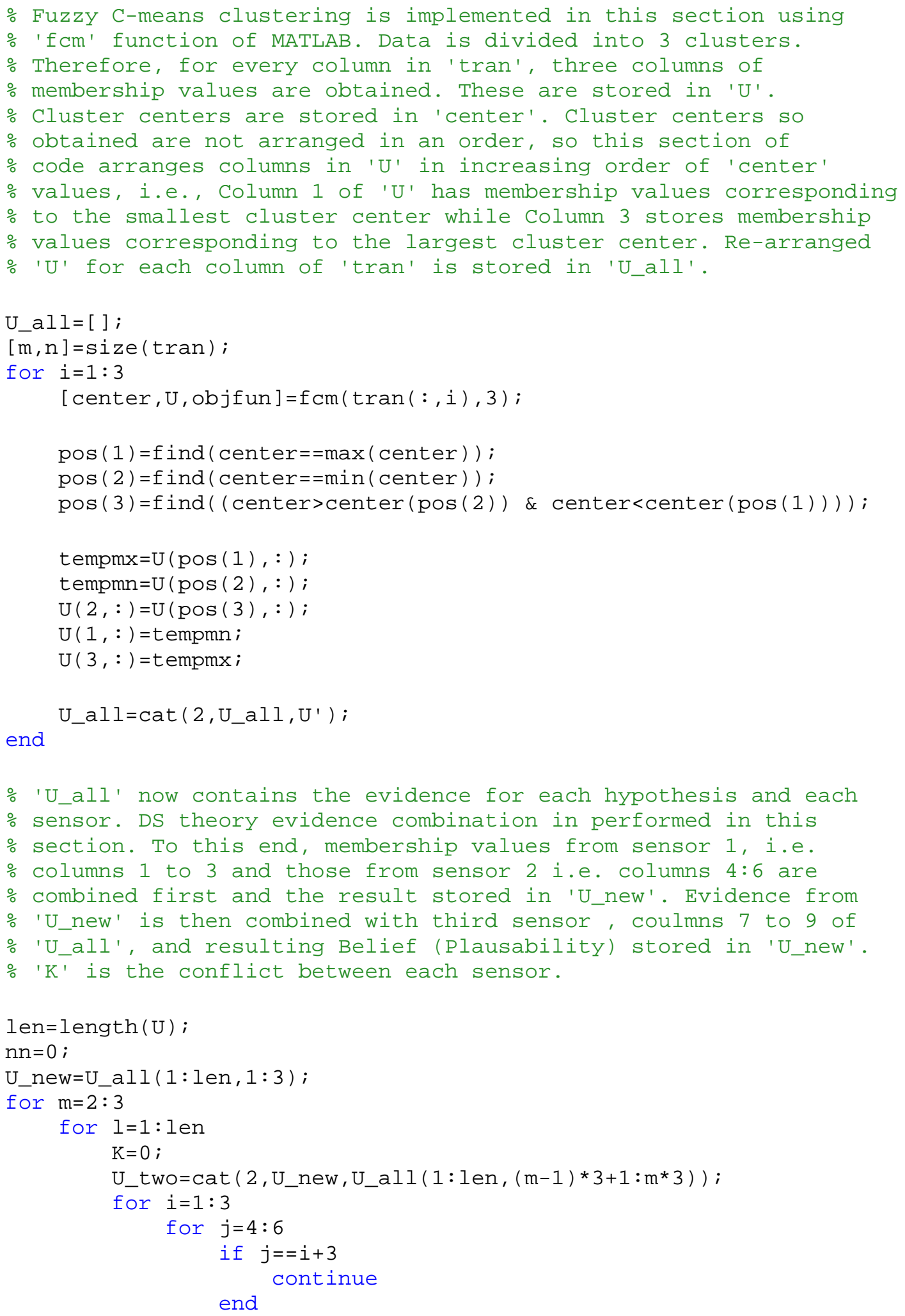




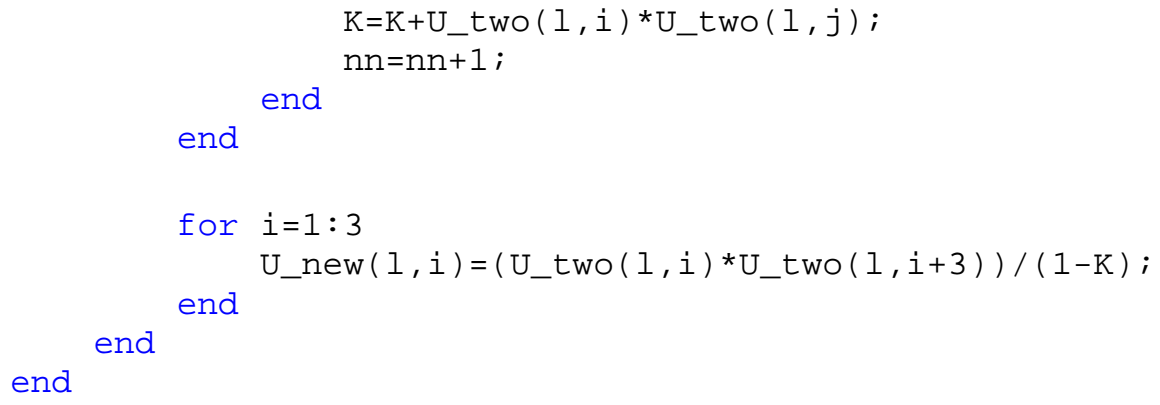




\section{REFERENCES}

[1] G.P. Sullivan, R. Pugh, A.P. Melendez and W.D. Hunt, "Operations and Maintenance Best Practices: A guide to achieving Operational Efficiency", Pacific Northwest National Laboratory, 2004. [Online]. Available:

http://www1.eere.energy.gov/femp/pdfs/omguide_complete.pdf [Accessed: Feb. 20, 2009].

[2] David L. Hall and Sonya A.H. McMullen, "Mathematical Techniques in Multisensor Data Fusion", 2nd ed. Norwood, MA: Artech House, Inc , 2004.].

[3] P. Caselitz and J. Giebhardt, "Advanced maintenance and repair for offshore wind farms using fault prediction techniques". [Online]. Available: http://www.iset.uni-kassel.de/abt/FBE/papers/Berlin2002.pdf. [Accessed: Feb. 11, 2009].

[4] H. Lilholt, et al., "Common Access to wind turbine data for condition monitoring-The IEC 61400-25 family of standards". [Online]. Available:

http://www.risoe.dk/rispubl/art/2006 45 paper.pdf. [Accessed: Mar. 08, 2009].

[5] Z. Hameed, S.H. Ahn and Y.M. Cho, "Practical aspects of a condition monitoring system for a wind turbine with emphasis on its design, system architecture, testing and installation", Renewable Energy, vol. 35, no. 5, pp. 879-894, May 2010. [Online]. Available: www.elsevier.com/locate/renene. [Accessed: Apr. 01, 2010].

[6] Z. Hameed, Y.S. Hong, Y.M. Cho, S.H. Ahn and C.K. Song, "Condition monitoring and fault detection of wind turbines and related algorithms: A review", Renewable and Sustainable Energy Reviews, vol. 13, no. 1, pp. 1-296, Jan. 2009. [Online]. Available: www.elsevier.com/locate/rser. [Accessed: Apr. 01, 2010].

[7] Bi Pengxiang, Xue Jun, Ni Jianli, Zhang Hongyun, Feng Tao and Li Manyuan, "Practice And Strategy For Condition Based Maintenance of Power Supply Equipment", in Transmission and Distribution Conference \& Exhibition: Asia and Pacific, 2005, pp. 1-5.

[8] Palle Christensen and Gregor Giebel, "Availability of Wind Turbines in Remote Places. A statistical and a Real Time View", in European Wind Energy Conference \& Exhibition, 2001. [Online]. Available: http://www.cleverfarm.com. [Accessed: Mar. 21, 2009].

[9] P. Caselitz and J Giebhardt, "Rotor Condition monitoring for improved operational safety of offshore wind energy converters", in The European Academy of Wind Energy Special topic Conference, 2004. [Online]. Available: http://www.cleverfarm.com. [Accessed: Mar. 21, 2009].

[10] Dr. Edwin Becker and Johann Lösl, "Reducing vibration by balancing rotor blades", in english translation of Erneuerbare Energien, Aug. 2009. [Online]. Available: http://www.pruftechnik.com/en/condition-monitoring/support-and-downloads/articles. [Accessed: Dec. 01, 2009]. 
[11] F.L. Lewis, "CBM II - Diagnostics", Automation \& Robotics Research Institute- The University of Texas at Arlington. [Online]. Available:

http://arri.uta.edu/acs/ee5322/lectures/CBM03-II-diagnosis.pdf. [Accessed: Mar. 09, 2009].

[12] T. Bertheau, M. Hoof and T. Laird, "Permanent on-line partial discharge monitoring as strategic concept to condition based diagnosis and maintenance", in Electrical Insulation Conference and Electrical Manufacturing \& Coil Winding Conference, 1999, pp. 201-203.

[13] Ranganath Kothamasu and Samuel H. Huang, "Adaptive Mamdani fuzzy model for condition-based maintenance", Fuzzy Sets and Systems, vol. 158, no. 24, pp. 2715-2733, Dec. 2007. [Online]. Available: www.elsevier.com/locate/fss. [Accessed: Apr. 17, 2009].

[14] G.D. Hadden, P. Bergstrom, G. Vachtsevanos, B.H. Bennett, J. Van Dyke, "Shipboard machinery diagnostics and prognostics/condition based maintenance: a progress report", in Aerospace, 2000, pp. 277-292.

[15] David G. Dorrell, William T. Thomson and Steven Roach, "Analysis of Airgap Flux, Current, and Vibration Signals as a Function of the Combination of Static and Dynamic Airgap Eccentricity in 3-Phase Induction Motors", IEEE Transactions on Industry Applications, vol. 33, no. 1, pp. 24-34, Jan/Feb. 1997.

[16] Don Jarrel, Daniel Sisk and Leonard Bond, "Prognostics and Condition Based Maintenance (CBM)-A Scientific Crystal Ball", Pacific Northwest National Laboratory, 2002. [Online]. Avaialble: http://www.pnl.gov/dsom/diagnostics. [Accessed: Mar. 28, 2009].

[17] Nuclear Power Engineering Section, "Implementation Strategies and Tools for Condition Based maintenance at Nuclear Power Plants", International Atomic Energy Agency, 2007. [Online]. Available: www-pub.iaea.org/MTCD/publications/PDF/te_1551_web.pdf. [Accessed: Apr. 04, 2010].

[18] Sitao Wu and Tommy W. S. Chow, "Induction Machine Fault Detection Using SOM-Based RBF Neural Networks", IEEE Transactions on Industrial Electronics, vol. 51, no. 1, pp. 183-194, Feb. 2004.

[19] Martin Blödt, Marie Chabert, Jérémi Regnier, and Jean Faucher, "Mechanical Load Fault Detection in Induction Motors by Stator Current Time-Frequency Analysis", IEEE Transactions on Industry Applications, vol. 42, no. 6, pp. 1454-1463, November/December 2006.

[20] Bilal Akin, Umut Orguner, Hamid A. Toliyat and Mark Rayner, "PWM Inverter Harmonics Contributions to the Inverter-Fed Induction Machine Bearing Fault Diagnosis", IEEE Transactions On Industrial Electronics, vol. 55, no. 2, pp. 610-619, Feb. 2008.

[21] M. Sahraoui, A. Ghoggal, S.E. Zouzou and M.E. Benbouzid, "Dynamic eccentricity in squirrel cage induction motors - Simulation and analytical study of its spectral signatures on stator currents", Fuzzy Sets and Systems, vol. 16, no. 9, pp. 1503-1513, Oct. 2008. [Online]. Available: www.elsevier.com/locate/simpat. [Accessed: Mar. 2010].

[22] Mohamed El Hachemi Benbouzid,and Gerald B. Kliman,, "What Stator Current ProcessingBased Technique to Use for Induction Motor Rotor Faults Diagnosis?", IEEE Transactions on Energy Conversion, vol. 18, no. 2, pp. 238-244, Jun. 2003. 
[23] Austin H. Bonnett, and George C. Soukup,, "Cause and Analysis of Stator and Rotor Failures in Three-phase Squirrel-Cage Induction Motors", IEEE Transactions on Industry Applications, vol. 28, no. 4, pp. 921-936, July/Aug. 1992.

[24] Randy R. Schoen and Thomas G. Habetler, "Effects of Time-Varying Loads on Rotor Fault Detection in Induction Machines", IEEE Transactions on Industry Applications, vol. 31, no. 4, pp. 921-936, July/Aug. 1995.

[25] Ramzy R. Obaid, and Thomas G. Habetler, "Current-based algorithm for mechanical fault detection in induction motors with arbitrary load conditions", in Industry Applications Conference, 2003, pp. 1347-1351.

[26] Ramzy R. Obaid, Thomas G. Habetler and Rangarajan M. Tallam, "Detecting Load Unbalance and Shaft Misalignment Using Stator Current in Inverter-Driven Induction Motors", in Electric Machines and Drives Conference, Jun. 2003, pp. 1454-1458.

[27] Ramzy R. Obaid, Thomas G. Habetler and David J. Gritter, "A Simplified Technique for Detecting Mechanical Faults using Stator Current in Small Induction Motors", in Industry Applications Conference, Oct. 2000, pp. 479-483.

[28] Subhasis Nandi, Hamid A. Toliyat and Xiaodong Li, "Condition monitoring and Fault Diagnosis of Electrical Motors - A Review", IEEE Transactions on Energy Conversion, vol. 20, no. 4, pp. 719-729, Dec. 2005.

[29] Christian Kral, Thomas G. Habetler and Ronald G. Harley, "Detection of Mechanical Imbalances of Induction Machines Without Spectral Analysis of Time-Domain Signals", IEEE Transactions on Industry Applications, vol. 40, no. 4, pp. 1101-1106, July/Aug. 2004.

[30] W. T. Thomson, "On-Line Current Monitoring to Detect Electrical and Mechanical Faults in Three-Phase Induction Motor Drives", in Life Management of Power Plants, 1994, pp. 6673.

[31] Peter Vas, "Sensorless Vector and Direct Torque Control', New York: Oxford University Press, Inc., 1998.

[32] Bernard Adkins, "The General Theory of Electrical Machines", New York: John Wiley and Sons, Inc., 1959.

[33] Warachart Sae-kok and Pichit Lumyong, "Characteristics Evaluation of 3 Phase Induction Motors Based on an Acceleration Method with Increasing Moment of Inertia Technique", in Diagnostics for Electric Machines, Power Electronics and Drives, 2003, pp. 93-98.

[34] Jyh-Shing Roger Jang, "ANFIS: Adaptive-Network-Based Fuzzy Inference System", IEEE Transactions On Systems, Man, And Cybernetics, vol. 23, no. 3, pp. 665-685, May/June 1993.

[35] S. Ben Chaabane, M. Sayadi, F. Fnaiech and E. Brassart, "Dempster-Shafer Evidence Theory for Image Segmentation: Application in Cells Images", International Journal of Signal Processing, vol. 5, no. 2, pp. 126-132, Spring 2009. [Online]. Available: http://www.waset.org/journals/ijsp/v5.php. 
[36] Kari Sentz and Scott Ferson, "Combination of Evidence in Dempster-Shafer Theory", Sandia National Laboratory, Apr. 2002. [Online]. Avaialble:

www.sandia.gov/epistemic/Reports/SAND2002-0835.pdf. [Accessed: Mar. 01, 2009].

[37] M. Germain, J.M. Boucher and G. B. Benie, "A new mass functions assignment in the Dempster-Shafer theory: the fuzzy statistical approach", in Instrumentation and Measurement Technology, 2008, pp. 825-829.

[38] "Hall Effect Current Sensors L03S***D15 Series", Tamura Corporation. [Online]. Available: www.tamuracorp.com/clientuploads/pdfs/.../L03SXXXD15.pdf.

[39] "Small, Low Power, 3-Axis \pm 3 g i MEMS ${ }^{\circledR}$ Accelerometer", Analog Devices. [Online]. Available: $u w w$.analog.com/static/imported-files/data sheets/ADXL330.pdf.

[40] "SCB-68 68-Pin Shielded Connector Block User Manual”, Mar. 2009, National Instruments. [Online]. Available: http://www.ni.com/pdf/manuals/372551a.pdf.

[41] "Full-Featured E Series Multifunction DAQ 12 or 16-Bit, up to $1.25 \mathrm{MS} / \mathrm{s}$, up to 64 Analog Inputs", National Instruments.[Online]. Available: http://www.ni.com/pdf/products/us/4daqsc199-201 ETC 212-213.pdf.

[42] Mohammed T. Hayajneh, Adel Mahmood Hassan and Fatma Al-Wedyan, "Monitoring defects of ceramic tiles using fuzzy subtractive clustering-based system identification method", Soft Computing - A Fusion of Foundations, Methodologies and Applications, vol. 14, no. 6, pp. 615-626, April 2010.[Online]. Available: http://www.springerlink.com/content/qvwp3445083354h4. 


\section{BIOGRAPHICAL INFORMATION}

Himanshu Jain was born in Dehradun, India in 1986 and completed his high school from St. Gabriel's Academy, Roorkee. He obtained his Bachelor of Technology degree in Electrical Engineering from Govind Ballabh Pant University of Agriculture and Technology, Pantnagar, Uttarakhand, India in 2008 and was awarded Vice-Chancellor's gold medal for being the topper of electrical engineering batch of 2008. His current research is focused on condition monitoring of electric machines. In future, he plans to conduct research on application of power electronics in power system. 